\title{
Perceptions, Attitudes and Behaviour around Climate Change Risks on Livelihood Activities: A Case Study of a Community in Takeo Province, Cambodia
}

By

\section{Ratanakvisal Chean}

A thesis submitted to the Victoria University of Wellington in partial fulfilment of the requirements for the degree of Masters of Development Studies

School of Geography, Environment and Earth Sciences

Victoria University of Wellington 



\begin{abstract}
This thesis investigates the Takeo community's perception of climate change risks and their response strategies. It examines risks occurring in the regions and their impacts on the community. The thesis also explores how the perception of risks frames the community's adaptation and mitigation strategies as well as how those perceptions influence climate change policies. This research draws on a range of risk perception theories. Employing a qualitative approach, this study uses semistructured interviews, document analysis and participant observation as its research methods. Interviews were conducted individually with agricultural practitioners, mothers, community leaders, a local government officer and a government official from the Ministry of Environment.
\end{abstract}

The thesis found that the Takeo's community has a good perception of the issue and its impacts on their community. Droughts are the major concern for the majority of respondents, because these have become more severe and have the most direct impact on farmers' lives, livelihoods and food security. The study reflects the view maintained by past and current theory, that individual perceptions of risks vary, and the perception of risk is influenced by media and peers. This study adds that farmers' direct experience of climate change affects their consideration of such risks as an issue of great personal concern.

Perception of climate change influences the community's responses. Farmers employ a wide range of adaptation strategies such as increasing water storage and improving agricultural techniques. However, adaptation approaches are not enough to provide a long-term solution to the fast changing climate, because the community has limited knowledge of adaptation strategies, resources, and limited support from the government. The community, thus, needs to improve its water management by building more dams and sufficient irrigation that can store enough water for consumption and agriculture in the prolonged dry season. The government should provide more support and services to poor rural communities that rely on agriculture.

Key words: Perception of risk, effects of climate change, community adaptation 


\section{Acknowledgements}

First of all, I would like to express my sincere thanks to my supervisor, Polly Stupples for her guidance and motivational support to complete my research. Polly did not only offer me feedback and guidance, but also encouragement that kept me motivated to conduct my research in the fields while writing and finalising my thesis.

My sincere gratitude also goes to Development Studies programme director, John Overton, as well as professors and staff in Development Studies for their support, effort and knowledge-sharing. Additionally, I would like to thank the governments of Cambodia and New Zealand, particularly the Ministries of Foreign Affairs and Trade who have jointly provided a chance for me to pursue my Master's degree at Victoria University of Wellington. Their funding support was crucial to the completion of this research. I would like also to express my sincere thanks to international support officers, student-learning services and student health clinics that have looked after me since I first arrived in Wellington.

A special word of appreciation goes to the Takeo community and the clerk who provided a very warm welcome and spent time and effort participating in my research. I appreciate the support of the community leaders who provided data and helped me to organise my fieldwork. Without their feedback and participation, this research would not have been possible. I would like to thank my colleagues who have helped me in reaching the community and local government as well as giving me some vocabulary advice so that I could better understand the community. Thanks to Development Studies friends and all Wellingtonians who always encouraged and exchanged ideas with me and proofread my writing.

My last and deep appreciation goes to my parents, sisters and brothers for their physical, emotional and financial supports throughout my journey. Thanks Mom, Dad and siblings who always educated, provided advice, and kept me motivated. I am really delighted to be born in this family because they have sacrificed their time and effort to enable me to undertake this study. Without their inspiration, I would not be able to complete this study. 


\section{Table of Contents}

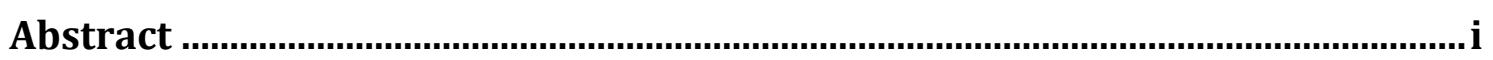

Acknowledgements .........................................................................................ii

List of Figures: ...................................................................................................

List of Tables: ...................................................................................................... vii

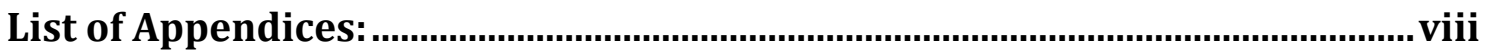

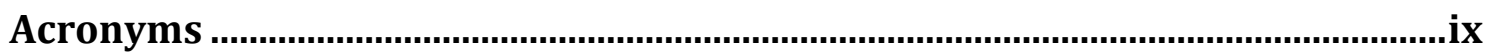

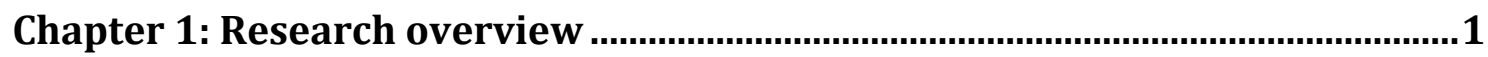

1.1. Introduction.....................................................................................................

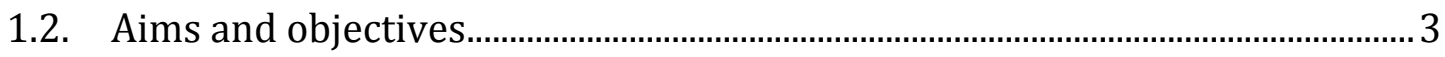

1.3. Research questions..................................................................................................

1.4. Significance of the research .....................................................................................

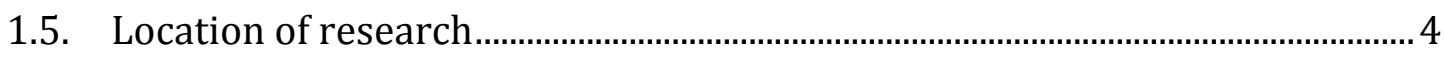

1.6. Thesis outline.............................................................................................................

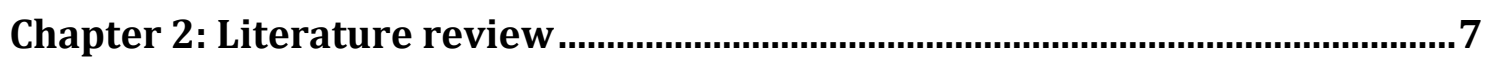

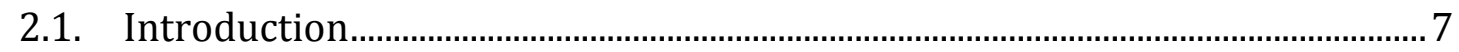

2.2. Climate change and development .........................................................................

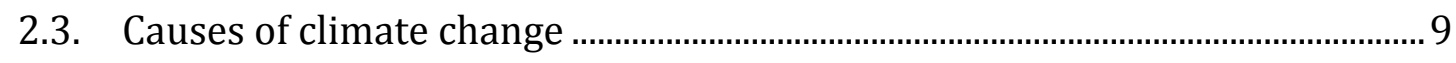

2.4. Impacts of climate change ……………………………………………………….... 11

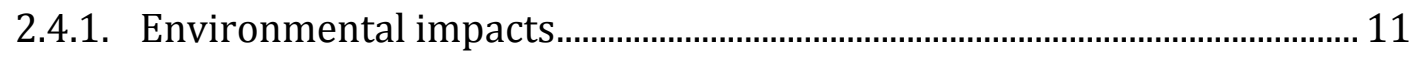

2.4.2. Socio-economic impacts .................................................................................... 12

2.5. Vulnerability to climate change .......................................................................... 13

2.6. Obligations and responses to climate change risks.......................................... 14

2.6.1. Climate change mitigation ........................................................................... 15

2.6.2. Climate change adaptation ............................................................................. 16

2.7. Public awareness of climate change .................................................................... 18

2.8. Perception of climate change risks ........................................................................ 19

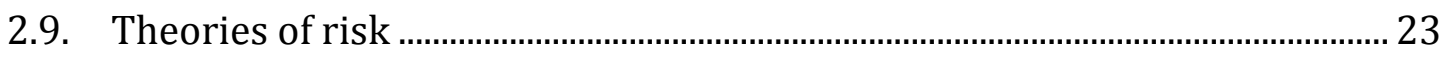

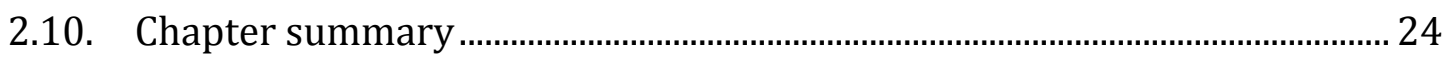

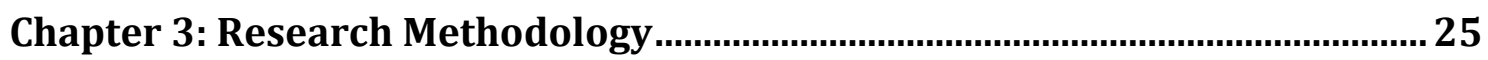

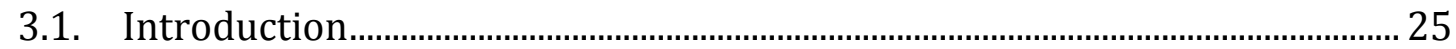




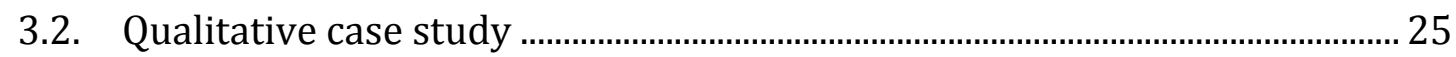

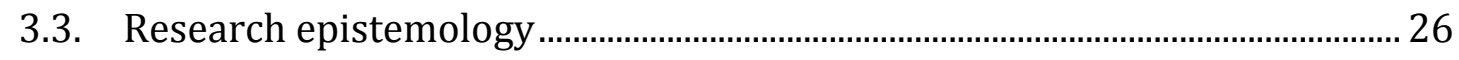

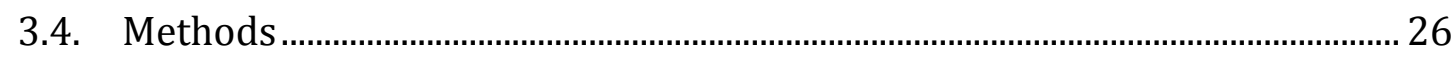

3.4.1. Semi-structured interviews ....................................................................... 27

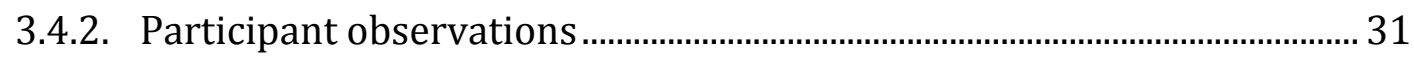

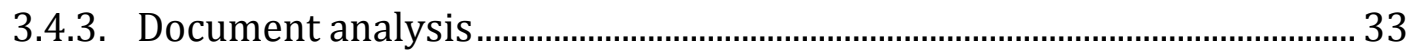

3.5. Data recording procedures, storage and analysis.............................................. 35

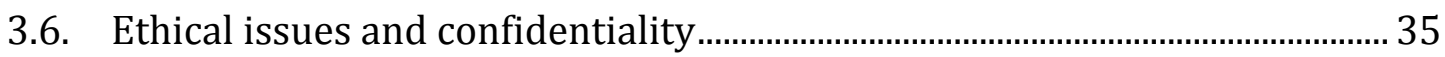

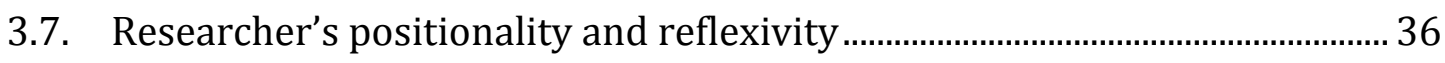

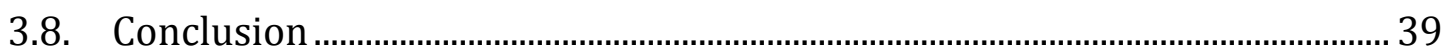

Chapter 4: Climate change in the context of Cambodia ........................................40

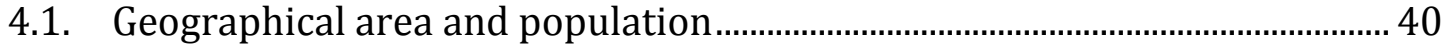

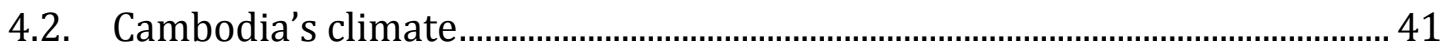

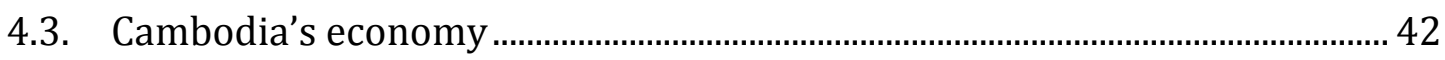

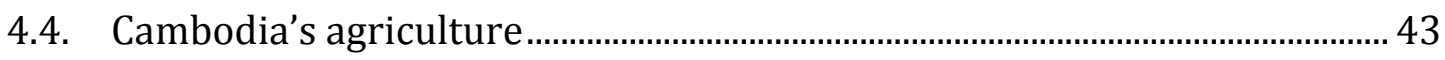

4.5. Climate change in the context of Cambodia........................................................ 45

4.6. Cambodia's climate change policy ……................................................................. 48

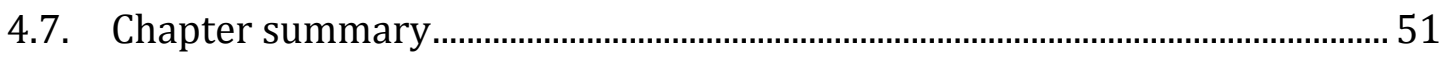

Chapter 5: Perceptions of climate change risks in Takeo...................................52

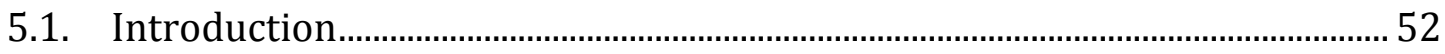

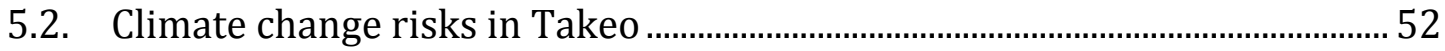

5.3. Perception of the community on causes of climate change ............................. 56

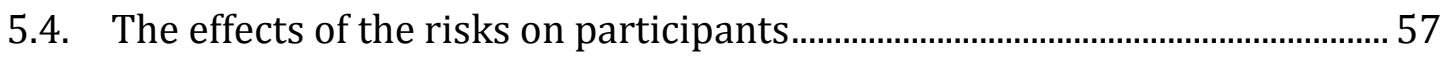

5.4.1. Impacts on the environment and ecological system ................................... 58

5.4.2. Impacts on individuals' and community property.......................................59

5.4.3. Impacts on human health and living ........................................................... 59

5.4.4. Impacts on livelihood and food security of the community ....................... 63

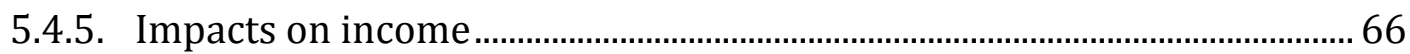

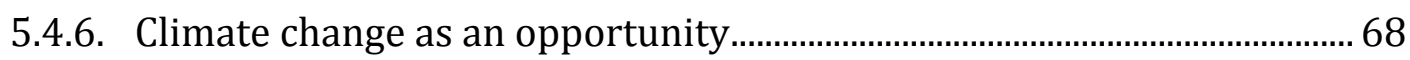

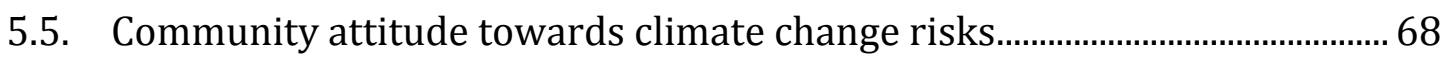

5.6. Community perception about climate change in the future............................. 70

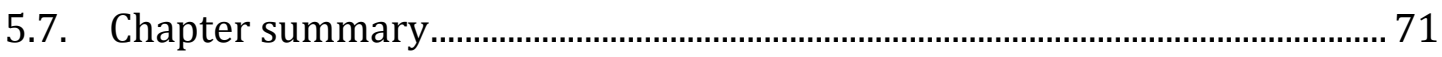

Chapter 6: Community behaviour towards climate change risks...................... 74 


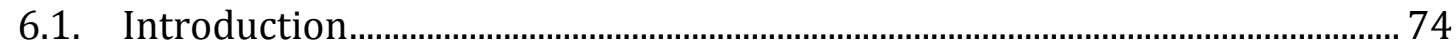

6.2. Role of community in climate change policy ……................................................... 74

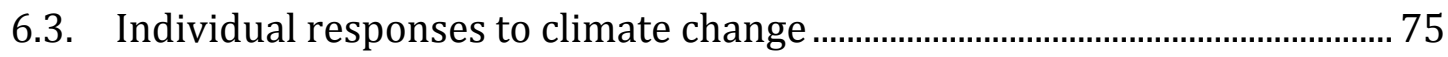

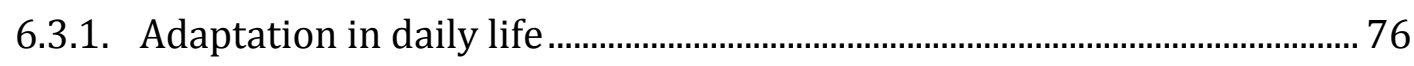

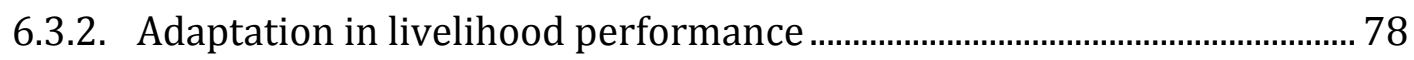

6.4. Community adaptive capability climate change .................................................. 82

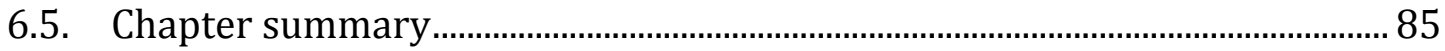

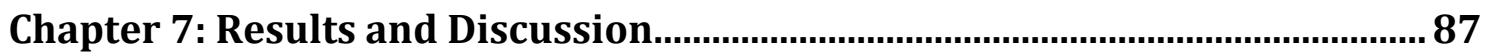

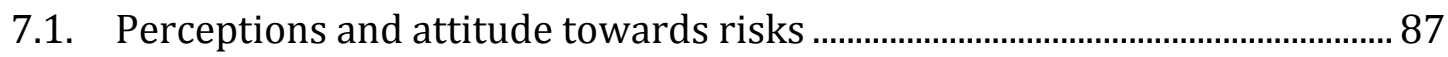

7.2. Influence of risk perception on individual responses ...................................... 90

7.3. Influence of risk perception on climate change policy ……............................. 95

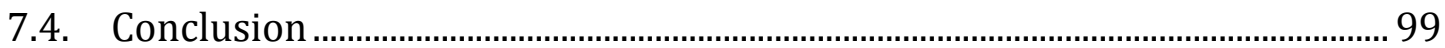

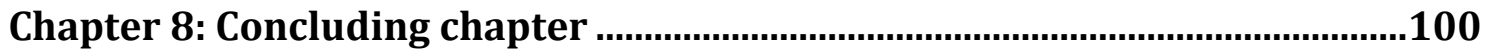

8.1. Summary of research's objective, questions and methodology ....................100

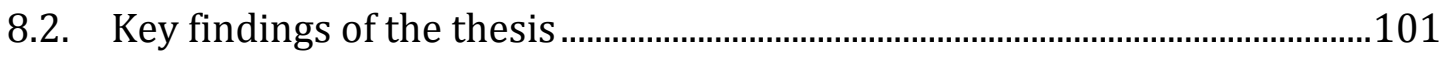

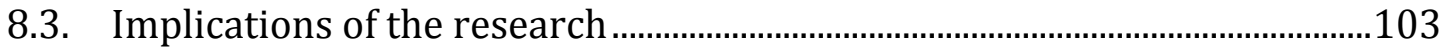

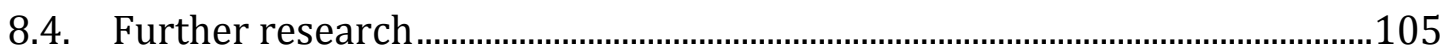

References: .............................................................................................................106

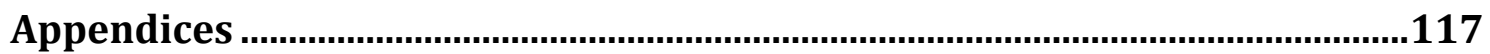




\section{List of Figures:}

Figure 1: Map of Takeo Province, Cambodia....................................................................... 5

Figure 2: Global greenhouse gas emissions by economic sector in 2010 ................... 10

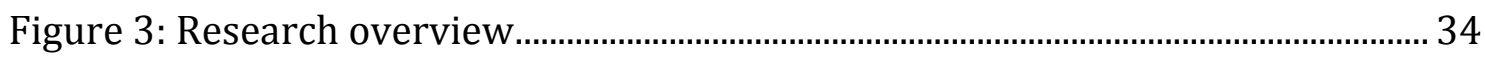

Figure 4: Geographical area of Cambodia ........................................................................... 40

Figure 5: Cambodia paddy production areas from 2011-2015 ……............................ 44

Figure 6: Cambodia paddy yield from 2011-2015 ………................................................. 44

Figure 7: Cambodia rice productivity (calculation from data of Figure 5 \& 6) ......... 45

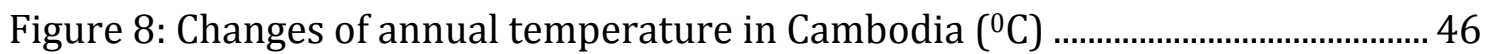

Figure 9: Frequency of storms and their impacts in Cambodia..................................... 55

Figure 10: Frequency of lightning and its impacts on Cambodia................................... 55

Figure 11: Perception of respondents on the causes of climate change ....................... 57

Figure 12: Summary of responses to climate change ........................................................ 86 


\section{List of Tables:}

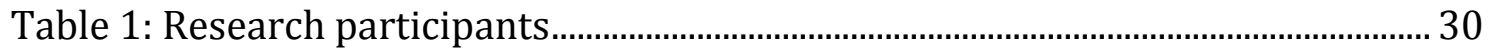

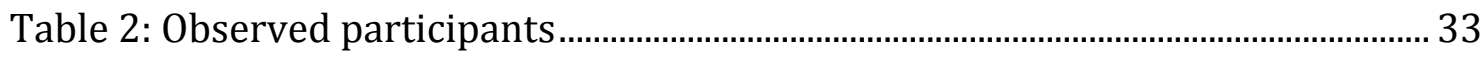

Table 4: Summary of perception of risks and impacts ................................................... 71 


\section{List of Appendices:}

Appendix 1: Ethical approval ....................................................................................117

Appendix 2: Participant information sheet in English ............................................118

Appendix 3: Participant information sheet in Khmer ...............................................120

Appendix 4: Participant consent form in English........................................................123

Appendix 5: Participant consent form in Khmer ........................................................124

Appendix 6: Question guide for agricultural producers ...........................................126

Appendix 7: Question guide for local government and community leaders ......127 


\section{Acronyms}

\begin{tabular}{|c|c|}
\hline $\mathrm{ABC}$ & Australian Broadcasting Corporation \\
\hline $\mathrm{ACF}$ & Action Against Hunger International Organisation \\
\hline ADB & Asian Development Bank \\
\hline $\mathrm{BBC}$ & British Broadcasting Corporation \\
\hline CARDI & Cambodian Agricultural Research and Development Institute \\
\hline CCAP & Climate Change Action Plan \\
\hline CCCSP & Cambodia Climate Change Strategic Plan \\
\hline CDC & Council for the Development of Cambodia \\
\hline CEDAC & Centre for Education and Development in Agriculture in Cambodia \\
\hline CIP & Commune Investment Programme \\
\hline $\mathrm{CO}_{2}$ & Carbon dioxide \\
\hline \multirow[t]{2}{*}{ COP21 } & Conference of the Parties to the United Nations Framework \\
\hline & Convention on Climate Change \\
\hline E.g & For example \\
\hline FAO & Food and Agriculture Organization of the United Nations \\
\hline GDP & Gross Domestic Product \\
\hline Ha & Hectare \\
\hline I.e & That is \\
\hline IPCC & Intergovernmental Panel on Climate Change \\
\hline IRRI & International Rice Research Institute \\
\hline MAFF & Ministry of Agriculture, Forestry and Fishery \\
\hline MoE & Ministry of Environment \\
\hline NAPA & National Adaptation Programme of Action to Climate Change \\
\hline NCDM & National Committee for Disaster Management \\
\hline NGOs & Non-governmental organisations \\
\hline NIS & National Institute of Statistics \\
\hline PPM & Part per million \\
\hline RFA & Radio Free Asia \\
\hline RGC & Royal Government of Cambodia \\
\hline SRI & System of Rice Intensification \\
\hline UN & United Nations \\
\hline UNDP & United Nations Development Programme \\
\hline
\end{tabular}




$\begin{array}{ll}\text { UNEP } & \text { United Nations Environment Programme } \\ \text { UNESCAP } & \text { United Nations Economic and Social Commission for Asia and Pacific } \\ \text { UNFCCC } & \text { United Nations Framework Convention on Climate Change } \\ \text { US dollars } & \text { United States dollars } \\ \text { WHO } & \text { World Health Organisation }\end{array}$




\section{Chapter 1: Research overview}

\subsection{Introduction}

Climate change is increasingly seen as a major issue for human beings and development in both developed and developing countries. The United Nations Framework Convention on Climate Change (UNFCCC) defines climate change as "a change of climate which is attributed directly or indirectly to human activity that alters the composition of the global atmosphere and which is in addition to natural climate variability observed over comparable time periods" (United Nations [UN], 1992, p.3). Climate change is one of the most complex issues that human beings are facing (Morecroft \& Cowan, 2010), and it presents tremendously adverse impacts on many sectors such as the environment, economy, human health and livelihoods (Vicuna, 2007).

There is widespread evidence that climate change is occurring. Changes include sea level and global temperature rise, warming oceans, shrinking ice sheets, declining Arctic sea ice, glacier retreat, extreme weather events, ocean acidification and decreased snow cover. The earth is rapidly getting warmer (Matthew, 2012). Greenhouse gases are increasing, leading to the rise of the earth's average temperature by approximately $0.8^{\circ} \mathrm{C}$ since 1880 (Wheeler \& von Braun, 2013). The world's temperature will continue to rise (Intergovernmental Panel on Climate Change [IPCC], 2014c). Not only has the world's temperature been increasing, but the sea level has also risen by 19 centimetres from 1901 to 2010 (IPCC, 2014c, p.4).

Climate change is occurring globally, but less developed countries will suffer the impacts earliest and greatest. Farmers or rural communities in particular will face major challenges because their income sources mainly derive from agricultural production which is sensitive to global warming and extreme weather events such as flooding and droughts. Cambodia, for example, is ranked as one of the most vulnerable countries to the effects of climate change, because it is located in an already warm climate (Khim \& Phearanich, 2012). Extreme weather events such as floods and droughts are affecting rural farmers, both in their living and income generation. 
Around $80 \%$ of people in Cambodia live in rural areas and depend on the agriculture sector, in particular rice cultivation, for food and income generation. With just a minor change of temperature, crop production yield will reduce and this will affect food security and income generation of farmers in Cambodia (Royal Government of Cambodia [RGC], 2013). In short, climate change is a global threat, but the issue for less wealthy countries such as Cambodia is felt intensely already. Adaptation is, therefore, needed for Cambodia, particularly for the rural community to mitigate the impacts of climate change.

Since farmers are suffering from extreme weather events intensely, it is important to understand how strong the impacts of climate change are on their lives and livelihood, and how they mitigate the risks. Thus this research will examine how a community in Cambodia perceives and adapts to climate change. Slovic (2000) claims that risk perceptions have an influence on both individual's and communal support for mitigation and adaptation measures. Even though there is growing literature on the perception of risk posed by climate change in developing countries such as China and India (Jianjun, Yiwei, Xiaomin, \& Nam, 2015; Udmale, Ichikawa, Manandhar, Ishidaira, \& Kiem, 2014), research in the context of Cambodia is very limited.

Slovic (2000) found that perception of risk is subjective and varies among individuals and within countries. The results from a study of risk perception in a country, therefore, could not be applied in the context of another country, because these countries have different cultural and economic contexts. In light of this, it is essential to conduct studies into risk perception locally. Additionally, some of these studies look at public perceptions rather than the perceptions of a particular community group (e.g. Taylor, Dessai, \& Bruin, 2014). Not many studies on risk perception have been conducted to examine how perception of climate change risk has an influence on adaptation strategies, and how people at grassroots and policy practice level perceive risks and responses. 
Risk perception is a topic where continuing studies need to be undertaken, because an individual's climate change risk perception is not stable, but changes over time based on elements such as the types of extreme weather events occurring, economical situations, the amount of risk information, reports by media and scientists, and worldviews (Hagen, 2013). On the basis of this, it is worth conducting updated research on risk perception over time. For these reasons, it is important to conduct a study to examine how communities in Cambodia perceive and respond to climate change risk, particularly those most at-risk rural agricultural communities.

\subsection{Aims and objectives}

The overall objective of this research is to understand perceptions towards the risks posed by climate change on livelihoods, and the forms of behaviour change and adaptation measures undertaken by a rural community in Takeo province, Cambodia. Thus, the study aims to assess how the Takeo community perceives climate change risks on their livelihood activities and how this has framed their adaptation strategies. This study focuses mainly on adaption rather than mitigation options because Cambodia is a developing country that does not contribute a large amount of greenhouse gases to the atmosphere. In addition, as Cambodia is suffering from the adverse impacts of extreme weather events, it is important to explore adaptation options practised by the rural community. Community perceptions and attitudes may have an influence on the way that this community shapes adaptation strategies. In this thesis, I also investigate the factors that have an influence on participants' understanding of risks.

\subsection{Research questions}

To achieve the aims and overall objective of the study, I will focus on the following sub-questions:

1. How aware are participants of the impacts of climate change on their lives and livelihoods?

2. What specific climate change risks are of most concern to participants in the study area? 
3. What factors are considered important when considering what risks are of the most concern?

4. How have participants' perceptions of climate change risks shaped their adaptation strategies?

5. What potential do these adaptation strategies have to improve community resilience to climate change impacts?

\subsection{Significance of the research}

An in-depth understanding of public perceptions, attitudes and responses to climate change are important to government and development consultants to develop adaptation and mitigation policy (Wei et al., 2014). This research therefore aims to provide academic researchers and policy makers with information about community perceptions of risks and their behaviour that could influence the process of national climate change policy.

This thesis contributes to current literature of impacts of climate change since this research reports the real experiences of a community exposed to natural hazards. The research may also contribute to increased community awareness of climate change, thus improving adaptation strategies and resilience to climate change hazards. Such strategies are crucially important to increasing crop production.

\subsection{Location of research}

The research was conducted in Takeo province. This province is located in the southern part of Cambodia about 87 kilometres from the capital city (Figure 1). According to Mak (2013, p. 22), Takeo borders Vietnam to the south, and with three other provinces of Cambodia to the north (Kampong Speu), east (Kandal), and west (Kampot). 


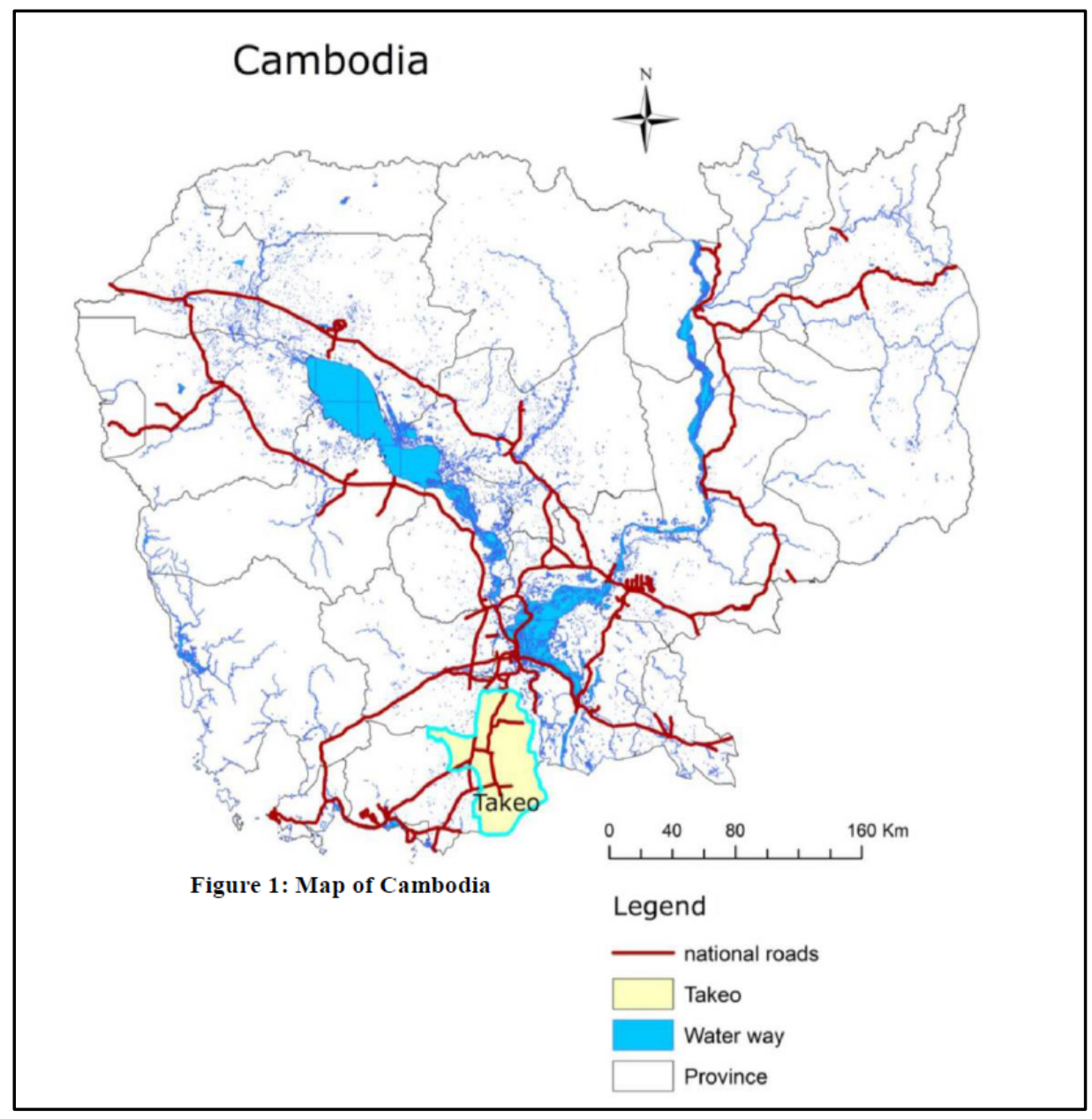

Figure 1: Map of Takeo Province, Cambodia

Source: (Cheng, 2016, p. 5)

The topography of Takeo is diverse, including floodplains, lowland and upland areas. The Bassac river delta plains lie to the east, over a large area of lowland paddy fields, while small areas of lowland and upland mosaic are seen in the western and southern regions (Mak, 2013, p. 22). Takeo has a smaller land area than other provinces of Cambodia but is famous for its rice and cash crop production due to soil conditions and well-developed irrigation systems. In the monsoon climate, Takeo's climate is warm and humid. Annual rainfall in Takeo is between 1200-1400 mm (Mak, 2013, p. 22).

The dry season, on average, does not last longer than four months. In 2008, Takeo had a total population of about 843,931 people, with 409,799 male and 434,132 female (National Institute of Statistics [NIS], 2008). Agriculture is the main source of income for the majority of people in this province. This includes rice farming, 
cash crop production and fisheries. Takeo was chosen for a few reasons. One of the reasons is my personal network with a non-governmental organisation (NGO) in the province, providing easy access for this research ${ }^{1}$. Another reason is that the majority of people in Takeo depend mainly on agriculture for their livelihoods. Importantly, this province is also often visibly affected by climate change such as prolonged droughts and flooding. Takeo is marked as one of Cambodia's most vulnerable provinces to droughts and floods (Ministry of Environment [MoE], 2006).

\subsection{Thesis outline}

This thesis is organised and divided into eight chapters. The first chapter provides an introduction to the research by describing the objective and background of the study. The second chapter reviews literature of climate change and perceptions of risks. The third chapter offers a background of the studied area including geographical area, climate, population, livelihood, and climate change. The fourth chapter explains the methodology and methods that will be used for the research. Ethical issues and positionality will also be presented. The fifth chapter provides findings regarding the perceptions of the Takeo community around climate change risks, while the sixth chapter describes mitigation and adaptation practices. The seventh chapter reveals the discussion of the study. The last chapter concludes the thesis with key findings and suggestions for further research.

\footnotetext{
${ }^{1}$ From 2011 to 2013, I worked as a monitoring and evaluation officer at the Cambodian Centre for Study and Development in Agriculture (CEDAC). CEDAC is an NGO that specialises in organic agriculture, particularly rice production. CEDAC works to improve rural farmers' rice production by providing them with training.
} 


\section{Chapter 2: Literature review}

\subsection{Introduction}

This chapter reviews the published literature of public perception of and responses to climate change. It is divided into four main parts. The first section examines the relationship between climate change and development. The second explores general information to do with climate change such as the causes, negative effects and the most vulnerable groups to the changing environment. The third section discusses mitigation and adaptation responses to adverse impacts of extreme weather events and describes levels of adaptation options. The last section investigates public awareness, knowledge, beliefs and perceptions of climate change risks. In conclusion, theories of risks and some studies of risk perceptions will also be explained.

\subsection{Climate change and development}

Climate change and development are closely interrelated. Climate change is increasingly accepted as a real threat for humans and for development (CorfeeMorlot et al., 2016). Extreme weather events such as droughts, floods and heat waves are occurring and threaten the economy in all countries in the world (Boyd, 2014). Climate change is not only an unpredictable problem (Johan et al., 2009), but is described as the biggest challenge that human beings are facing today (Morecroft \& Cowan, 2010). This does not mean that other issues such as debt, energy, security, food security and ecological damage are not as important as climate change, but climate change has the ability worsen these problems (Morecroft \& Cowan, 2010).

In contrast, development or economic processes are major causes of the changing climate. The 21st century is reported as the warmest century due to the dramatic rise of greenhouse gas concentrations in the atmosphere, resulting from increasing industrial production (Matthew, 2012). Greenhouse gases are "those gaseous constituents of the atmosphere, both natural and anthropogenic, that absorb and re-emit infrared radiation." (UN, 1992, p.7). 
The world's economy is increasing the demand for energy, mainly in China (Olivier, Janssens-Maenhout, Muntean, \& Peters, 2015), leading to the increase of greenhouse gas emissions (Matthew, 2012). Additionally, with the world's population expected to exceed 9 billion in 2050, more food and energy sources to sufficiently feed this number of people are needed. Hence, both energy and agricultural production will need to be extended. This will trigger adverse impacts from a changing environment that will threaten thousands of lives and livelihoods (Lee, 2010). Therefore, development processes are threatened by climate change, which itself is the consequence of development activities.

On the basis of this, an alternative development that is good for both economic growth and sustainable environment is needed as reflected in the UN sustainable development goals. Climate change may have been caused by unsustainable development (Baker, 2006). Sustainable development is perhaps the way to tackle climate change issues. The green economy has, therefore, emerged as a major solution to sustainable development (Lee, 2010, p. 7) with the potential to reduce the impacts of global warming and to solve economic volatility (Lee, 2010; Matthew, 2012).

The green economy was first introduced in 1989 by the London Environmental Economics Centre, but the concept was not widely accepted because it was seen as a challenge to economic growth, as was the case in Korea (Lee, 2010). Business enterprises believed that by shifting to a green economy, their products would not be competitive in the world market because environmental concerns would take priority over manufacturing. The green economy is defined by the United Nations Environment Programme (UNEP) as "one that results in improved human wellbeing and social equity, while significantly reducing environmental risks and ecological scarcities" (cited by Abaza, 2012, p. 5). In this sense, the green economy is an alternative form of production that improves income generation, and presents minimal harm to the environment. A key component of the green economy is low carbon emissions. 
To achieve the green economy or sustainable development, significant effort is required (Lee, 2010). Firstly, vigorous political will and direction and strong policy enforcement are needed. The second requirement is perception and behavioural changes in the acceptance of the green economy concept. This requires some regulation and policy change, such as carbon pricing and taxation as both an incentive and a punishment that could motivate business owners to move towards low carbon business. The most important requirement is advanced technology that will support the goal of the green economy.

As part of this, sustainable infrastructure is recommended as one of the solutions to climate change (Corfee-Morlot et al., 2016). Infrastructure refers broadly to both man-made (energy, transports, buildings and services) and natural (forests, water and landscapes) infrastructure types. Sustainable infrastructure is believed to have the potential to increase economic growth, achieve sustainable development goals (poverty reduction) and reduce the impacts of climate change. In order to move towards sustainable development, changes need to be made in the way people organise cities, generate and use energy, use transportation and services as well as how they manage natural landscapes (Corfee-Morlot et al., 2016, p. 8). In short, as climate change and development are interrelated, new platforms of development are required to maintain economic growth and reduce impacts on the environment.

\subsection{Causes of climate change}

As briefly stated in the previous section, climate change is a consequence of development, in particular the industrial economic sector. Industrial countries are the world's biggest emitters of greenhouse gases, both in the past and at present (Boden, Marland, \& Andres, 2015; Olivier et al., 2015). The industrial sector is the main contributor (about two thirds) to greenhouse gas emissions (Olivier et al., 2015, p. 14). Furthermore, the amount of Carbon dioxide $\left(\mathrm{CO}_{2}\right)$ emitted from burning fossil fuel, producing cement and flaring has increased three times since 1970 (IPCC, 2014c, p.45). Similarly, the emissions of gas from forestry and other land use have also increased by nearly double. 
The burning of fossil fuels releases $\mathrm{CO}_{2}$ into the atmosphere leading to a thicker layer of $\mathrm{CO}_{2}$ that has the potential to trap heat from the sun. As fast-growingeconomic industries still motivate high-carbon infrastructure, with increasing demand for energy and transport, the concentration of greenhouse gas emissions in the atmosphere will double, consequently leading to a much warmer planet.

Another form of development, agriculture, is considered to be one of the major contributors of greenhouse gas emissions. Agricultural activities such as using chemical fertiliser and animal-raising are the major contributors to climate change because both chemical fertilisers and animal manure emit methane, a type of greenhouse gas (Lappé, 2011). For instance, nearly half of New Zealand's greenhouse gas emissions in 2012 were contributed by agriculture (Ministry for the Environment, 2014). In short, industrial and agricultural activities have led to an increase in temperature globally (by more than $1^{\circ} \mathrm{C}$ in 2015), and will continue to increase the global temperature (Blunden \& Arndt, 2016, p. 12).

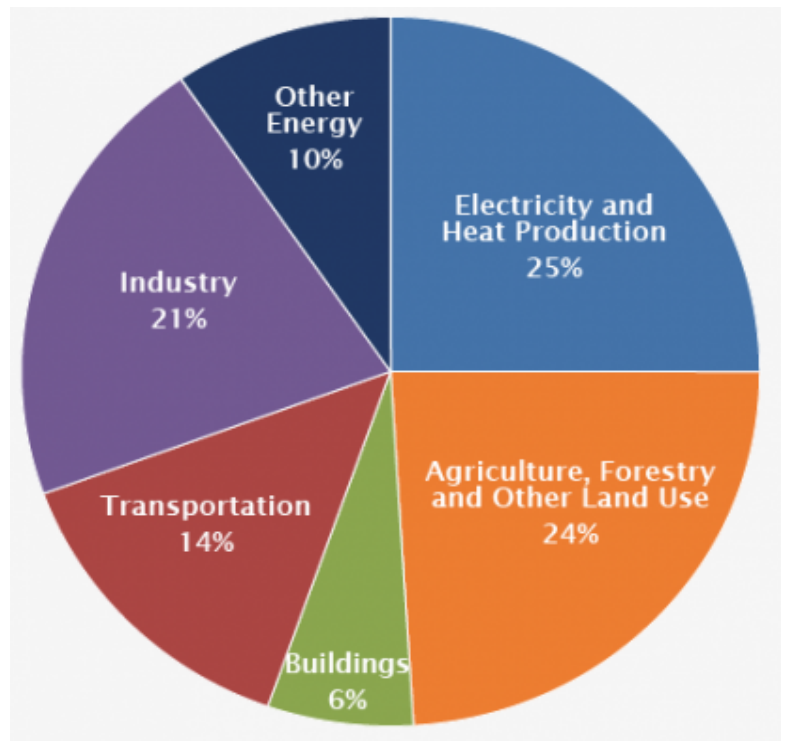

Figure 2: Global greenhouse gas emissions by economic sector in 2010 Source: (IPCC, 2014b, p.44)

Figure 2 indicates the sources of greenhouse gas emissions that are the major cause of global climate change. Emissions of these gases are largely associated with energy consumption (industry, electricity and head production, transportation, building and other energy), accounting for $76 \%$ of total emissions. Using power is the largest contributor to greenhouse gas emissions followed by land use and agriculture. 


\subsection{Impacts of climate change}

Climate change has potentially dire effects on the environment, society and economy. Small changes in the average temperature of the earth can cause floods, droughts, intense rain and frequent and severe heat waves. These extreme weather events bring severe effects on the ecological systems, economic development and human health (Bardsley \& Wiseman, 2012; IPCC, 2007). Human beings - particularly vulnerable groups such as the poor, the young, and the elderly - will be confronted with many problems such as heat waves, extreme climate, malnutrition, food shortage, lost labour productivity, water and vectorborne and non-communicable diseases (Thomas, Sabel, Morton, Hiscock, \& Depledge, 2014). The details of the impacts on environment, society and economy are described in the following parts.

\subsubsection{Environmental impacts}

Environmental impacts of climate change include reduction of water quality, depletion of groundwater, and damage of fish habitat (Udmale et al., 2014). Global warming increases water temperature, reducing oxygen content, promoting algae bloom, and increasing bacteria and fungi (Elshemy, 2013, p. 72). The world's temperature increases lead to drier climates and fresh water depletion (Taylor et al.,2013).

Moreover, changes in $\mathrm{CO}_{2}$ in the ocean and increased ocean surface temperatures are affecting the metabolism and development of marine life and sea plants as well as changing ecological systems in the ocean (Perry, Low, Ellis, \& Reynolds, 2005). With the climate changing faster than the adaptive capacity of organisms, enormous and irreversible damage to coral reef ecosystems is projected to occur. For instance, around 15 to $40 \%$ of species are projected to be extinct when temperature rise exceeds 1 to $2{ }^{\circ} \mathrm{C}$ (Stern Review, 2006, p. 55). 


\subsubsection{Socio-economic impacts}

Climate change is not only affecting the environment but also having adverse impacts on humankind's health, livelihood and economy (Loo, Billa, \& Singh, 2015; Udmale et al., 2014). From 1995 to 2014, more than 15,000 extreme weather events occurred worldwide, killing more than 525,000 people and causing damage to national infrastructures and economies exceeding 2.97 trillion US dollars (Kreft, Eckstein, Dorsch, \& Fischer, 2016). In addition, climate change has caused health problems such as thermal stress, physical injury by flooding and droughts, diarrhoea, respiratory diseases and death caused by heat wave (Haines \& Patz, 2004; Papworth, Maslin, \& Randalls, 2014). Meanwhile, extreme weather events have the potential to worsen existing health problems and the risk of death from malnutrition, vector-borne diseases such as malaria and dengue fever, and heatrelated stress (Collins et al., 2013) .

Extreme weather events are challenging livelihood activities and reducing agricultural production, contributing to economic losses. Flooding, prolonged droughts, and storms, for example, have been damaging and reducing the yields from cereals, horticultural crops and livestock production in many developing countries, leading to losses of income (IPCC, 2007; World Bank, 2009). A study conducted to understand the perception of climate change risks in Yongqiao district of China found that farmers have estimated losing roughly 34\% of grain yields per year due to droughts (Jianjun et al., 2015). They added that droughts threaten their family's food security as they have fewer grain choices for daily consumption. Since $80 \%$ of the rural population in China depend largely on agriculture, this impacts employment prospects as well. Additionally, dry conditions consequently lead to conflicts amongst water users due to the scarcity of water in the area. These combined impacts of climate change on agriculture are widespread and are likely to intensify food insecurity since many farmers lack water for consumption and will not be able to produce crops. The impacts will get worse in the future and exacerbate existing problems such as poverty, food insecurity and economic losses particularly for those in developing countries. 
Finally, the changing climate threatens human life in every sector. The impacts can be seen in damage to ecosystems, destruction of infrastructure, economic losses, and reductions in crop production, leading to difficulty in accessing food and water. These issues have been covered only briefly here, but they indicate the extent of climate change challenges, and demonstrate the interconnectedness of vulnerabilities.

\subsection{Vulnerability to climate change}

Climate change is happening globally but its impacts are not equally shared across regions. The most affected victims of extreme climate events are people from the poorest countries (Harrington et al., 2016; Stern Review, 2006; World Bank, 2009). According to the Global Climate Risk Index 2016, developing countries are generally more susceptible to the impacts of climate change than developed countries (Kreft et al., 2016).

Poor countries are more vulnerable to climate change than wealthy countries because many people live in rural areas that are already warmer and most vulnerable to climate impacts (Harry \& Morad, 2013; Morton, 2007). Furthermore, these countries' economies depend largely on agriculture, which is sensitive to droughts and floods (Leiserowitz, 2007; Ludwig et al., 2007, p. 7). Importantly, developing countries generally have a lower adaptive capacity to the adverse impacts of a changing climate than wealthy countries. They lack human and financial resources, and adequate access to technology to help with adaptation (Harry \& Morad, 2013; Leiserowitz, 2007; Ludwig et al., 2007, p. 7; Morton, 2007).

Smallholder farmers in developing countries are considered to be one of the most vulnerable groups to climate change impacts, particularly droughts (Burnham, 2014; Lappé, 2011; Morton, 2007; Truelove, Carrico, \& Thabrew, 2015) because their families' livelihoods rely heavily on subsistence agriculture (Truelove et al., 2015). Farming production is intensive but not dependent on modern technological equipment and access to the world markets. Additionally, their agricultural land is often situated in marginal environments, which are vulnerable to climate change and land tenure insecurity (Morton, 2007). 
Climate change will exacerbate existing vulnerabilities, and will reduce the ability of smallholder farmers to access water, produce crops and earn income. Furthermore, regional weather patterns such as the monsoon rains are also projected to reduce by $70 \%$ in the late $21^{\text {st }}$ and early $22^{\text {nd }}$ centuries, while the rainy season in Southeast Asian countries is expected to be delayed by up to 15 days, leading to a warmer and wetter climate (Loo et al., 2015). Some areas will be flooded while others will face droughts, damaging crop and livestock productions. Millions of farmers will be forced to migrate temporarily or even permanently, and pushed into hunger.

Alongside this and ocean acidification as well as the world population increase, human beings will also experience shortages of water for consumption and use. Rice production will also be reduced. The International Rice Research Institute proved every $1^{\circ} \mathrm{C}$ increase in the minimum temperature at night in the dry season reduces rice yields by $10 \%$ (cited by RGC, 2013, p.8). Since many farmers in Southeast Asian countries depend on rice production and basic water access, they will suffer difficulties in terms of accessing basic necessities such as water and food.

\subsection{Obligations and responses to climate change risks}

Because the impacts of climate change are massive and can potentially exacerbate existing vulnerabilities, it is important to act with urgency. Responding to climate change risks requires strong commitments from all countries and international cooperation (Fankhauser \& Stern, 2016). However, because developing countries do not have sufficient capacity and finance to cope with climate change as well as developed countries, NGOs and developing countries have initiated a call for climate justice (based on the equality of individuals to address climate change) to identify the responsibilities of developed and developing countries in combating climate change (Mary Robinson Foundation Climate Justice, 2011).

Climate justice states that because wealthy countries are the world's largest emitters of greenhouse gases, they carry a special responsibility. These countries carry obligations to reduce greenhouse gas emissions to a certain level, and to provide support such as financial resources, knowledge and technology transfer 
to improve the capacity of developing countries to mitigate and adapt to the changing climate. Responses to climate change involve two main approaches: mitigation and adaptation. Effective implementation of both mitigation and adaptation are required because no single option is adequate to tackle the adverse impacts of the changing climate (IPCC, 2014c, p.94).

\subsubsection{Climate change mitigation}

Mitigation refers to the reduction of greenhouse gas emissions into the environment which would lessen the severity of climate change impacts (IPCC, 2014c, p.125). Mitigation requires actions at an international level, but particularly for those countries who are the largest emitters of greenhouse gases. The 21st Session of the Conference of the Parties to the United Nations Framework Convention on Climate Change (COP 21) marked a significant advance in global cooperation to reduce the earth's temperature to below $2{ }^{\circ} \mathrm{C}$ (Center for Climate and Energy Solutions, 2015, p. 1). This requires all countries to either decrease activities that release these gases into the atmosphere (such as burning fossil fuels) or to increase the storage space of these gases (for instance, the oceans and forests). Human beings, especially those from developing countries, will face similar disasters that claimed thousands of lives and cost trillions in US dollars from 1995 to 2014 (Section 2.4.2) if they do not take action now (Kreft et al., 2016). Each country must now draft policy to reduce the impacts of climate change.

It is also important to note that individuals need to change their behaviour and lifestyle to reduce greenhouse gas emissions. Addressing climate change requires both governments and individuals to jointly share this responsibility. Government policies, programmes and international treaties are critical for reducing greenhouse gases, thus lessening climate change impacts, but so too are decisions made by billions of individuals every day such as driving cars and turning on the lights (Leiserowitz, 2007; Spence, Poortinga, Butler, \& Pidgeon, 2011). 


\subsubsection{Climate change adaptation}

The second response to climate change is adaptation. Adaptation strategies refer to the adjustment of human beings to a changing climate at present, or to an expected future climate (Cohen, Demeritt, Robinson, \& Rothman, 1998; IPCC, 2014c, p. 118). International and national climate change policies have increasingly focused on adaptation measures during the last decade (Harmer \& Rahman, 2014; Measham et al., 2011b) to maintain the possibility of sustainable development and poverty reduction (Harmeling, Kreft, Rai, \& Vaughan, 2010, p. 2), because mitigation policies were not successful (Khan \& Roberts, 2013).

Human beings have been adapting to climate change for a long time, but due to the virulent impacts of climate-related events, additional adaptation strategies will be needed to limit the adverse effects of projected global warming and variability, irrespective of mitigation efforts (IPCC, 2007). Adaptations are required for many less-developed countries to secure their livelihoods and food security because these countries are suffering destructive socio-economic damage (Wheeler, 2011). Since they have low adaptive capacities and are highly vulnerable to climate change impacts, even under moderate global warming, adaptation is needed to lessen their vulnerabilities which are projected to get worse if no action is taken (Food and Agriculture Organization of the United Nations [FAO], 2012; Truelove et al., 2015).

Adaptive capacity is related to socio-economic development but is not equally shared amongst societies (IPCC, 2007). Different countries and different groups within countries have different ways and resources to cope with the adverse impacts of climate change. Wealthier and better resourced countries have more opportunities to create changes whereas less resourced countries need to invent unique ways to combat the negative effects of climate change. Climate change is starting to be factored into a variety of development plans: how to manage increasingly extreme disasters and their associated risks, how to protect coastlines and deal with sea-level encroachment, how to best manage land and forests, how to deal with and plan for reduced water availability, how to develop resilient crop varieties and how to protect energy and public infrastructure (IPCC, 2014a) . 
Effective solutions to address climate change require strong policy implementation and efforts from both individuals and government at all levels. At an international level, a wide range of adaptation funding systems, such as the Least Developed Countries Fund and the Adaptation Fund, have been developed under the UNFCCC and/or the Kyoto Protocol to reduce the adverse impacts of the changing climate (Measham et al., 2011b). These mechanisms were formulated to provide financial support to developing countries to adapt to climate change impacts by promoting adaptation strategies in development plans and actions (United Nations Framework Convention on Climate Change [UNFCCC], 2013).

At the national level, many governments have established adaptation plans and policies and considered integrating climate change issues into broader development plans (IPCC, 2014c, p.54). Many developing countries have established a national adaptation framework for prioritising their adaptation needs, known as "the National Adaptation Programmes of Action (NAPA)" (Measham et al., 2011a). They have also begun a wide variety of adaptation initiatives such as a commitment to spread information and projections of climate change, the establishment of climate change adaptation protocols, as well as organisational adaptation measures and plans (Measham et al., 2011b). Historically, adaptation policies and plans have often been established from topdown perspectives with limited engagement from people at the grass-root level (Measham et al., 2011b; van Aalst, Cannon, \& Burton, 2008).

Van Aalst et al. (2008) argue that it is important to engage the local community in climate change adaptation plans, particularly to inform bottom-up approaches to climate change adaptation. Many countries, therefore, have rapidly focused on adaptation strategies at the local level recently because people experience the impacts of climate change differently depending on geographical area (Measham et al., 2011b). Geographic variability of climate change impacts requires an approach that analyses vulnerability and adaptation locally or nationally depending on biophysical and social conditions (Measham et al., 2011b). 
Since small communities are often the most vulnerable groups to climate change impacts but the least equipped to address such problems, community-based adaptation is crucial to enhance the resilience of communities and the ecosystems to climate impacts (Mannke, 2011; Reid et al., 2009). To sum up, addressing climate change is an important global priority. Strong policy and efforts from individuals and governments at all levels are needed to effectively tackle the problem. Importantly, an effective solution to climate change requires a shared responsibility amongst the rich and the poor based on their resources.

\subsection{Public awareness of climate change}

Effective climate change reduction requires individuals and governments to work together. As such it is important to understand how and to what extent the public understands climate change as this will have an impact on how they attempt to reduce greenhouse gas emissions and adapt to the changing climate. For example, even though global warming was detected in 1827 by a French scientist, JeanBaptiste Fourier (Leiserowitz, 2007), it was not until 1988, when the world experienced the hottest climate since the middle of the nineteenth century, that people in Europe and Japan started becoming concerned about climate change and showing support for mitigation and adaption (Leiserowitz, 2007). Public opinion of global climate change is therefore vitally important for enacting climate change policy (Burnham, 2014; Wei et al., 2014).

Public awareness of climate change is the foundation of the socio-political context in which policymakers operate, thus influencing political, economic and social action in response to the specific risk (Leiserowitz, 2007). Public opinion of climate change risks and dangers will influence whether the establishment of climate change policies such as treaties, laws and regulation, taxes and subsidies are supported or lobbied against (Burnham, 2014; Wei et al., 2014).

The study of public awareness also needs to take account of who takes climate change as a serious threat because this will explain their efforts in supporting policy solutions. The World Bank (2009) found that although people in less-developed nations do not have as good an understanding and awareness of climate change 
as those in developed countries, they take climate change as a more serious issue. Leiserowitz (2007) also found that people living in wealthy countries were not as concerned with climate change, because they believe that the issue is a geographically distant threat that does not directly harm their family. People in less-developed countries, therefore, expressed stronger support for responsive policy and programmes than those in developed nations (World Bank, 2009).

\subsection{Perception of climate change risks}

Slovic (1987) claimed that policymakers of risk management need to understand how public or lay people perceive and respond to risks, because failure to understand this may result in the ineffectiveness of well-documented policies. Risk perception explains how risky individuals consider a situation to be (Williams \& Noyes, 2007). Slovic (1987) states that public perception of risk is complex. Scientists judge a situation risky based on hazard assessment or risk analysis, whereas how the public considers risks depends on more subjective judgements. People perceive a situation risky based on information they can access from media and due to peer influence (Wachinger, Renn, Begg, \& Kuhlicke, 2013).

Types of risk also affects the way individuals feel concern about risk (Whitmarsh, 2008). When they identify hazards as risks, they make an estimation of how frequent that event happens and how severe and controllable the phenomenon is. Slovic (2000), Lujala, Lein, and Rød (2014) and (Wachinger et al., 2013) found that individuals also perceive risks subjectively based on their personality, knowledge, experience, attitude and gender. Direct experience of climate change, however, has a greater influence than other factors on an individual's concern about the risks associated with climate change (Lujala et al., 2014; Wachinger et al., 2013). People who suffered from climate change hazards, for example, exhibited great concern about the risks of climate change.

Public perception of climate change risks also varies among individuals and between geographical areas (Taylor, Dessai, and Bruine de Bruin, 2014) . Northern citizens of the United Kingdom, for instance, may have experienced hotter summers and warmer winters than those in the south-east, explaining differences 
in perceptions between citizens of the same country towards the changing local climate (Palutikof, Agnew, \& Hoar, 2004). Perception of risk differs from one person to another depending on a wide range of factors, of which geographic location and direct exposure to the impacts of climate change are two. Studies on risk perception, therefore, need to take into consideration local level factors.

A growing literature concludes that risk perception is an important factor that affects the way individuals and societies behave and make decisions in response (Siegrist, Gutscher, \& Earle, 2005, p. 145; Slovic, 2000; Williams \& Noyes, 2007). A study of risk perception in the United Kingdom showed that individuals who were directly affected by floods had less uncertainty about climate change than those who had never been impacted (Spence et al., 2011). The study also showed that those people who had been affected had a higher degree of behavioural change and willingness to reduce carbon emissions through energy consumption in their daily life. This is an example of how risk perception influences behavioural change in response to climate change.

However, several studies have also found that the relationship between risk perception, attitude and responses/ behavioural changes is unclear (Harmer \& Rahman, 2014; Lujala et al., 2014; Whitmarsh, 2008). A comparison study investigating the translation of risk perception of flood and air pollution victims to their responses also found the relationship between perception and behaviour change to be complex (Whitmarsh, 2008). Whitmarsh (2008) found that people who suffered from air pollution were concerned about the problem and more likely to take action in response. However, the victims of floods did not appear to take on any adaptation behaviours. In responding to risks, some people might take actions to mitigate the impacts while others might ignore the risks (Balcom, 2015; Wachinger et al., 2013).

Several studies concluded that information about public perceptions of risk is, therefore, not only important for understanding how individuals respond to risky situations, but also for supporting climate change policy. An in-depth understanding of public perceptions, attitudes and responses towards extreme climate events should underpin the development of state policy (Yu, Wang, Zhang, Wang, \&Wei, 2013). 
Such information is also important for development consultants designing climate change programmes, as well as for grassroots communities participating in adaptation and mitigation programmes (Wei et al., 2014). By being more aware of causes and adverse impacts of environmental changes, people may support the consideration of climate change in policy planning and programmes (Yu et al., 2013).

Since risk perceptions differs between individuals and within regions, the support for adaptation policies should also be conducted differently based on location (Taylor et al., 2014). Geographic variation and direct exposure to climate stresses may result in different responses to climate change adaptation policies. Thus, it is valuable to explore how communities, in a particular place that share particular risk factors, perceive and respond to climate change.

The growing research on farmers' risk perceptions and their response strategies to climate change in the context of developing countries has indicated that farmers in underdeveloped nations perceived risks posed by climate change to a high degree (Bryan, Deressa, Gbetibouo, \& Ringler, 2009; Jianjun et al., 2015; Senaratne \& Scarborough, 2011; Udmale et al., 2014). For instance, farmers in Yongqiao District in China (Jianjun et al., 2015) and Maharashtra state in India (Udmale et al., 2014) were found to notice the severity of extreme weather events, particularly droughts, as the major risk in these areas in terms of their impacts on life and agricultural production. As such, they were practising adaptation options to reduce the effects of droughts.

The study conducted in India by Udmale (2014) separated the preparedness plans and adaptation responses used by Indian farmers to mitigate droughts. To prepare for the droughts, rather than selling harvested grain, the vast majority of farmers stored it for family consumption. Other preparedness measures included storing crop residues for cattle, reducing unnecessary expenses and seeking alternative income sources such as through migration, off-farm income and selling livestock. 
Adaptation measures included changing planting dates, using crop varieties that required little water, collecting and saving water and changing farming and irrigation techniques. The study found that more than $50 \%$ of the farmers changed their crop calendar and used seeds that are tolerant to drought. However, very few farmers used less-water-consuming varieties of crops in responding to drought conditions. Moreover, very few farmers changed the way they irrigated crops such as using a sprinkler. Only a few farmers in the study owned irrigation tools that allowed them to sow crops on time because the monsoon rain pattern had changed. This was because farmers had to consider how to get, use and maintain the technological equipment, in light of their income, farm size and the electricity necessary to operate the tool. These factors explained the reasons behind the low take-up of alternative irrigating systems.

The study conducted in Yongqiao province in China (Jianjun et., 2015) found similar adaptation strategies carried out by farmers. The common options included using crop management techniques (adjusting the crop calendar and using drought tolerant seed varieties), improving land use and management (developing irrigation and water harvesting), diversifying agriculture inputs (mix of crops or livestock production) and increasing off-farm activities. However, Jianjun et al. (2015) found that some farmers also considered temporary and permanent migration as adaptation strategies. The study found that farmers made the decision to use adaptation measures based on their education, experiences, farm size, household income and perceptions towards climate change.

In summary, perception of risk to climate change is complex and differs within individuals and countries of origin, and between geographic regions. Several found that risk perception has an influence on the way individuals respond to and support adaptation and mitigation policies. In light of this, to effectively address the climate change issue, it is important to understand how the public perceives risk. Thus, the following section will examine some studies of risk perception in developing countries. 


\subsection{Theories of risk}

Risk theory is a framework that enable researchers to understand responses to risks (Roeser, Hillerbrand, Sandin, \& Peterson, 2013). The study of risk perception, attitude and behaviour changes is complex, and is largely addressed within the field of psychology, rather than development studies. However, it is useful to consider some of the approaches to theories of risk (Social Amplification Theory and Rational Choice Theory), as they describe a range of influencing factors that are relevant to this research.

Knowledge Theory (KT) states that individuals perceive risks based on their knowledge and information of risks (Wildavsky \& Dake, 1990). People consider a situation or a thing as a risk when they know that it is dangerous. Different people perceive the same risks differently. Some people might consider a risk greater than others.

Social Amplification Theory (SAT) assumes that public risk perception is mainly influenced by factors such as the media and organisational structures (Zaki, 2011). It posits that people could get information of risks from social media, newspapers or television programmes. This will affect their consideration as to whether or not climate change is a real threat to them. Organisational structures also have an influence on the public perception of risks. Entities such as social status, cultural identity, and education all have the potential to frame the way people consider risks (Renn, Burns, Kasperson, Kasperson, \& Slovic, 1992).

Rational Choice Theory (RCT) has had an influence on social science research on human behaviour for many years (Zaki, 2011). RCT examines the way individuals respond to risks based on their perception of risk. The theory states that people respond to risks with a combination of feelings, attitudes and motivation. In other words, individual responses to warnings are different. The theory assumes that people make judgements about a wide range of solutions to risks and choose the solution that is better for them based on their perception (Zaki, 2011, p. 18). Scott (2000) explains that RCT assumes that since individuals cannot achieve everything they want, they will need to make choices depending on the information they have. 


\subsection{Chapter summary}

The chapter reviewed literature regarding climate change and perceptions of risks. The first part explored climate change generally and the relationship between development and risks posed by climate change, as well as related causes and adverse impacts. In addition, the chapter identified farmers in less-developed countries as one of the most vulnerable groups to climate change due to their reliance on subsistence agriculture, and their limited resources for adaptation. The second part of the chapter discussed mitigation and adaptation responses to extreme weather events at both international and local levels. Lastly, the study included the examination of public perception of risks, theories of risks and other relevant studies that investigate individuals' perception of risks and their willingness to take adaptation options in both developed and developing countries. 


\section{Chapter 3: Research Methodology}

\subsection{Introduction}

This chapter examines the methodology and methods that were used to explore the research questions. The study used both primary and secondary data. Primary data on perception of risks posed by climate change was collected through indepth semi-structured interviews and by using participant observation. Secondary data was collected by analysing documents from the government of Cambodia and several NGOs that are working within the climate change field as well as additional online materials and newspapers. Documents collected were both published and unpublished materials including local communal development plans and communal investment programmes.

\subsection{Qualitative case study}

As this research aims at exploring and explaining the perception of local community members around climate change risks and their adaptation strategies, a qualitative methodology was employed. A qualitative approach is effective for research that wants to understand individual or group perceptions, attitudes and experiences, of events, processes and phenomena (Creswell, 2009, p. 4; Glesne, 2006, p. 29). This is because such research allows investigators to understand how people define things, tell their stories and interpret their experiences (StewartWithers, Banks, McGregor, \& Meo-Sewabu, 2014, p. 60). This research in particular aims to offer a framework that elaborates on the situation beyond the statistical data (Vanderstoep, 2009). Qualitative analysis seeks to understand the process of an event rather than its outcomes. Importantly, qualitative methods can offer the backgrounds of individual participants and reveal the narratives of marginalised participants who do not meet the average point of their communities or groups canvassed within a study.

Within the intention to investigate a real-world case about how communities in Cambodia perceived and adapted to climate change risks, this research made a case study of a community in Takeo. Case study research is used in a wide range of 
areas in social science research such as education, psychology, social and political science to provide understandings of individual, community, institutional, social, political and related phenomena to researchers (Yin, 2014, p. 4). Case studies explore a contemporary phenomenon in detail within its here-and-now context, particularly when a shortage of facts indicate where the borderline between the phenomenon and the context might exist (Yin, 2014, p. 16). I conducted a case study in my research because I wanted to understand my research questions in specific contextual conditions (Yin, 2014).

\subsection{Research epistemology}

According to Vanderstoep (2009, p. 165), epistemology is "the study of knowledge". This study employs social constructivism as the central epistemology because this framework seeks to understand the way people live and work based on respondents' views (Creswell, 2009, p. 8). Social constructivism holds that knowledge is constructed through interaction between researchers and participants in sharing, opposing and discussing their ideas or views (Applefield, Huber, \& Moallem, 2001, p. 7). This process has helped inquirers to understand how participants discover the meaning of reality during research interactions. Being a social constructivist, I assumed that individuals seek to understand the meaning of their life and work, and their understanding and interpretation of their experiences and reality of the world are subjective (Creswell, 2014). Thus, this framework was an effective means by which to uncover the main objective of the study: understanding how a community in Cambodia perceives risks and how they amended their farming practices to adapt to climate change.

\subsection{Methods}

Qualitative research methods involve talking to particular groups and institutions about issues as well as the local context of the research area such as geographical, cultural and economic sectors (Stake, 2003). Creswell (2014, p. 185) recommends qualitative researchers use multiple tools such as interviews, participant observations, literature and visual representations to collect data instead of depending on only one data source. This helps inquirers to analyse more 
information and to categorise or group similar and diverse themes. As such, I have utilised three methods including semi-structured interviews, participant observations and texts to understand how people in Takeo province perceive climate change risks and how their perceptions have shaped their adaptation strategies. To analyse the meanings and themes, I evaluated data from observations, interviews and documents (Vanderstoep, 2009, p. 169). The reasons for using these methods are explained below.

\subsubsection{Semi-structured interviews}

Interviewing is the most important tool used to collect data in qualitative studies (Creswell, 2014, p. 185). Qualitative study involves intense and/or prolonged interaction between researchers and the daily activities of individuals, communities, societies and institutions in the studied areas (Punch, 2014, p. 119). Vanderstoep (2009) states that knowledge is not formed unless communication and interaction between the researchers and researched participants happens. The knowledge is not in place but it is held by an individual's perception and interpretation. Thus, interviewing allows researchers to understand others. This tool is an effective means by which to access the way individuals perceive, give meanings and define situations and formations of reality (Creswell, 2014). Thus, interviews enabled me to understand the way the community in Takeo province both understand the risks posed by climate change and construct responses to those risks. Interviewing can take various forms such as face-to-face, individual, and group interviewing. In this research, I employed only one-on-one in-depth interviewing for two reasons. Firstly, I had much more experience with individual interviews than with focus group discussion. Secondly, I wanted to understand how individuals organised their world as well as their thoughts and experiences of climate change risks.

Semi-structured interviews were used in this study because they are appropriate tools for research that seeks to examine individual's experiences, behaviour and perceptions as well as to investigate how and why these people encountered and made sense of reality in such a way (Matthews, 2010, p. 221). Semi-structured interviews are conversations between researchers and researched participants 
that are conducted fairly freely and can vary from one participant to another (Fylan, 2005, p. 65). The inquirers have prepared some questions and ideas about the topic they are going to discuss with the participants, but the questions are not asked in a systematic way. The free-flowing nature of semi-structured interviews enables researchers to understand participants' stories comprehensively through asking for extra information or clarification of answers, as well as obtaining specific stories or cases from some participants that are different from the majority (Bryman, 2008; Fylan, 2005; Punch, 2014, p. 144).

In this research, all interviews were recorded. The interviews were conducted at places suggested by participants (in order to make them more comfortable and secure). Some participants preferred to be interviewed at their houses while others preferred to meet at Saladamnak (a community hall where ceremony or solidarity events happen). The building is similar to the Western concept of a church due to its central location and quiet atmosphere. The interview with the head of local government was conducted in his office as per his suggestion because he considered the process official. Interviews were conducted in Khmer (Cambodian language) using a question guide in Khmer as well.

\subsubsection{Data collection procedure}

In this study, 19 participants comprising of officials from the Ministry of Environment and local government, as well as agricultural community leaders, agricultural practitioners and mothers were interviewed (see Table 1). To obtain access to the participants (farmers and community leaders), I requested permission from the head of local government and community leader. I also held discussions with them in order to gather contextualised information about the community.

This study included a local government officer (commune chief) because he had a lot more information on development activities in the study area than agricultural practitioners. Also, $\mathrm{s} / \mathrm{he}$ is an important key person in planning response strategies as well as implementing these measures in the region. This research also included a government officer at the Ministry of Environment familiar with 
government efforts and policy regarding climate change in Cambodia. Community participants (community leaders and members) were the main research participants given this study's aim to understand how the Takeo community perceives and responds to risks posed by climate change. Since this community is an agricultural community, both community leaders and members are agricultural practitioners (farmers). Even though gender parity was not the central aim of this study, mothers were included because mothers and fathers might have perceived risks differently. This research proceeds on the reflection that mothers might be more concerned about their children than fathers. Similarly, my hypothesis was that fathers might be more concerned about income generation given their typical roles as household heads who earn income to support their families. Thus, including these four groups of participants helped me to unpack the levels of understanding of climate change risks that shape the community's responses. 
Table 1: Research participants

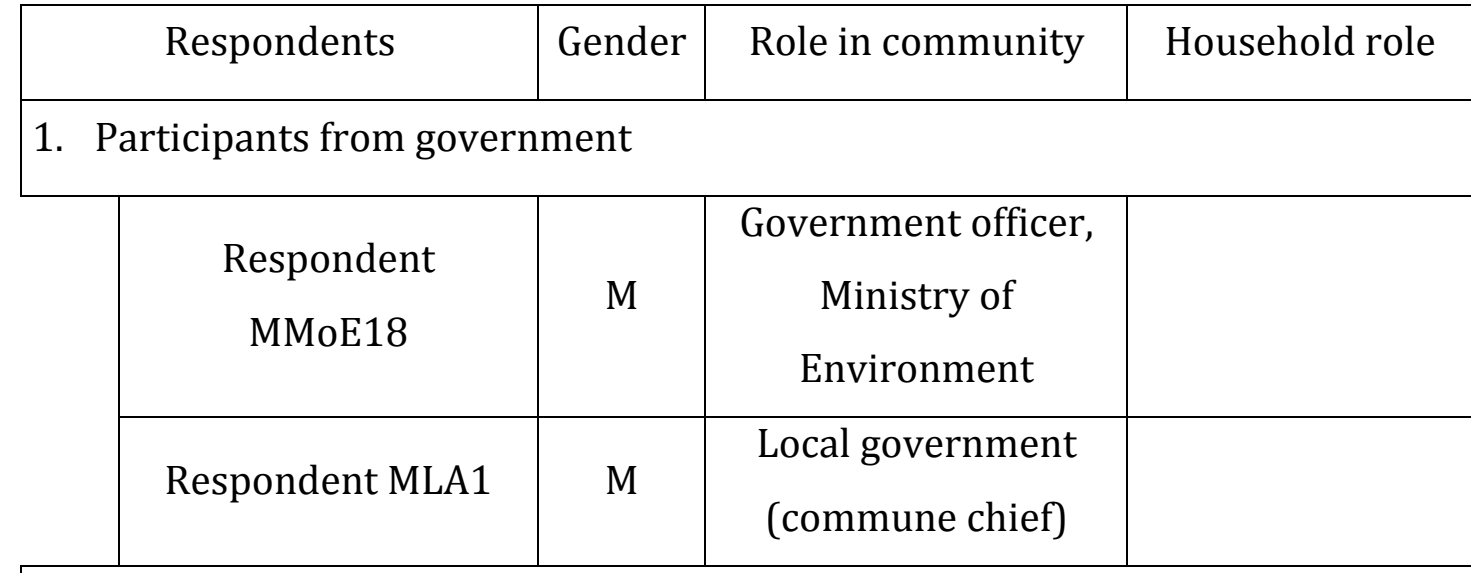

2. Community participants/ agricultural practitioners

\begin{tabular}{|l|c|c|c|}
\hline Respondent MCL2 & M & Community leader & Father \\
\hline Respondent MLAC4 & M & Community leader & Father \\
\hline Respondent MCL6 & M & Community leader & Father \\
\hline Respondent MLAC11 & M & Community leader & Father \\
\hline Respondent MF5 & M & Community member & Father \\
\hline Respondent MF7 & M & Community member & Father \\
\hline Respondent MF9 & M & Community member & Father \\
\hline Respondent MF10 & M & Community member & Father \\
\hline Respondent MF12 & M & Community member & Father \\
\hline Respondent MF14 & M & Community member & Father \\
\hline Respondent MF17 & M & Community member & Father \\
\hline Respondent MF19 & M & Community member & Father \\
\hline Respondent FLAC3 & F & Community leader & Mother \\
\hline Respondent FF8 & F & Community member & Mother \\
\hline Respondent FF13 & F & Community member & Mother \\
\hline Respondent FF15 & F & Community member & Mother \\
\hline Respondent FF16 & F & Community member & Mother \\
\hline
\end{tabular}




\subsubsection{Sampling selection}

Sampling is the recruitment of smaller cases to study from the total population of the study areas/group (Matthews, 2010, p. 153). In this study, I used the snowballing sampling technique due to time constraints on data collection. Snowball recruitment is a research technique in which researchers are introduced to, or recommended to approach, other participants by their informants whom they have already interviewed (Streeton, Cooke, \& Campbell, 2004). Through recommendations from respondents I had already interviewed, I accessed other active participants who were aware of my research topic. This was time-saving as I then avoided having to withdraw potentially unsatisfactory participants after the interviews, since according to Matthews (2010, pp. 225-226), it is better to select participants with prior knowledge of the research topic. There is, however, the possibility of bias within the sample group. I mitigated this by purposively selecting new participants through the recommendations of previous respondents. I approached community members (farmers) recommended by previous members of the community whom I interviewed and I employed the same recruitment technique for mothers and community leaders. To mitigate selection bias, I did not select new farmers from community leaders' recommendations in case they introduced me to farmers who might have had an exclusive connection with them. Also, I selected a participant who is a local water trader because I believed it would be important to include his perspective in the research. I felt that it was significant to understand why he had decided to trade water.

\subsubsection{Participant observations}

Similar to interviewing, participant observation can also be structured or unstructured (Louise Barriball \& While, 1994). In a qualitative study, observation is generally unstructured. Researchers often aim to observe people going about their activities naturally, rather than shaping those activities or intervening in them. In order to record and investigate how farmers have changed agriculture techniques in response to climate change, participant observation was used. Participant observation is one of the methods that enable researchers to understand the way people interact and respond to problems (Miller, 1997). 
Researchers can investigate the way their participants define and interpret the world through spending time with, and staying close to, those people (Punch, 2014). However, this methodology requires rigorous note-taking. Additionally, this is also a challenge for some researchers who may not be a local person, as participant observation requires great effort to understand how participants define things as well as interpret their expressions and ideas.

This research used unstructured observation based on its objective to understand livelihood practices in the Takeo community in the light of the changing climate. Such unstructured observation enabled me to examine how those in the community define their reality through their daily activities. Importantly, this provided a natural way of responding and relating to the study's participants. By utilising this technique, I captured important information that might be missed out by the participants during interviewing. I recorded farmers' agricultural practices in the field. At the end of an observation day with each participant, I asked some questions regarding what I had observed to better understand the outcomes of the observed activities. I have visited five agricultural practitioners for participant observation (see Table 2). All of them were agricultural practitioners. Observations were made based on the approval and availability of participants.

The observations were conducted after the completion of interviews. I spent one morning or afternoon with each participant, visiting their agricultural production. After reaching an agreement with each participant regarding his or her available time, two participants were observed in the morning, and another three in the afternoon. This allowed me to understand the different daily life activities of participants regarding agriculture both in the morning and afternoon. The time variation between separate observations had an unintentional but important effect. With the climate becoming warmer in the afternoons, I gained a better understanding of how the farmers respond to increasing temperatures, an aspect which some of them did not mention in the interviews. Because the climate was getting warming in the afternoon, I got a better understanding of how these farmers responded to the increasing temperature which some of them did not mention in the interviews. 
Observations began with the participants in their households. Subsequently, I requested to visit their planting fields as some participants already grew some crops such as watermelon and pumpkin. As part of observation, I also spent one day walking through the community with a community leader, to gain an in-depth understanding of the situation and geographical area of the region. This activity was critical to gathering relevant the contextualised information, such as where water could be obtained and what agricultural crops had been planted in the region.

Table 2: Observed participants

\begin{tabular}{|l|c|c|}
\hline \multicolumn{1}{|c|}{ Participants } & Male & Female \\
\hline Community leaders & 2 & 2 \\
\hline Community members & 3 & 3 \\
\hline Total & 5 & \\
\hline
\end{tabular}

\subsubsection{Document analysis}

Documents are sources of data that contain a great deal of information for researchers in social science study, both historically and in the present (StewartWithers et al., 2014, p. 64). Document analysis is beneficial for researchers' approach to historical territory and also to their studied literature (Punch, 2014, p. 158). Document analysis does not refer only to written documents, but also to audio and visual evidence such as film, TV programmes and websites (Punch, 2014, p. 158). Documents that can be used in social science research include letters, academic articles, personal notes, biographies, policy documents as well as government and institutional documents. In order to use documentary products in their study, researchers need to consider the credibility of the authors, in addition to the way these articles are constructed and if any agendas are present to avoid bias.

In this research, data has been collected from the government and NGOs. Both published and unpublished data (such as communal investment programmes and communal development plans) have been gathered from the local government of Cambodia. Newspapers and other online materials have also been collected. 
These documents have provided me with a contextualised background of the community. This enabled me to better understand the situation of the study area, including problems that were occurring, as well as projects that have been covered by both government and NGOs. This information was important for my understanding of the influence which outsiders could bring to bear on the way local people perceived risks and adjusted livelihood practices. These documents were collected through online access and through verbal requests to government and NGOs.

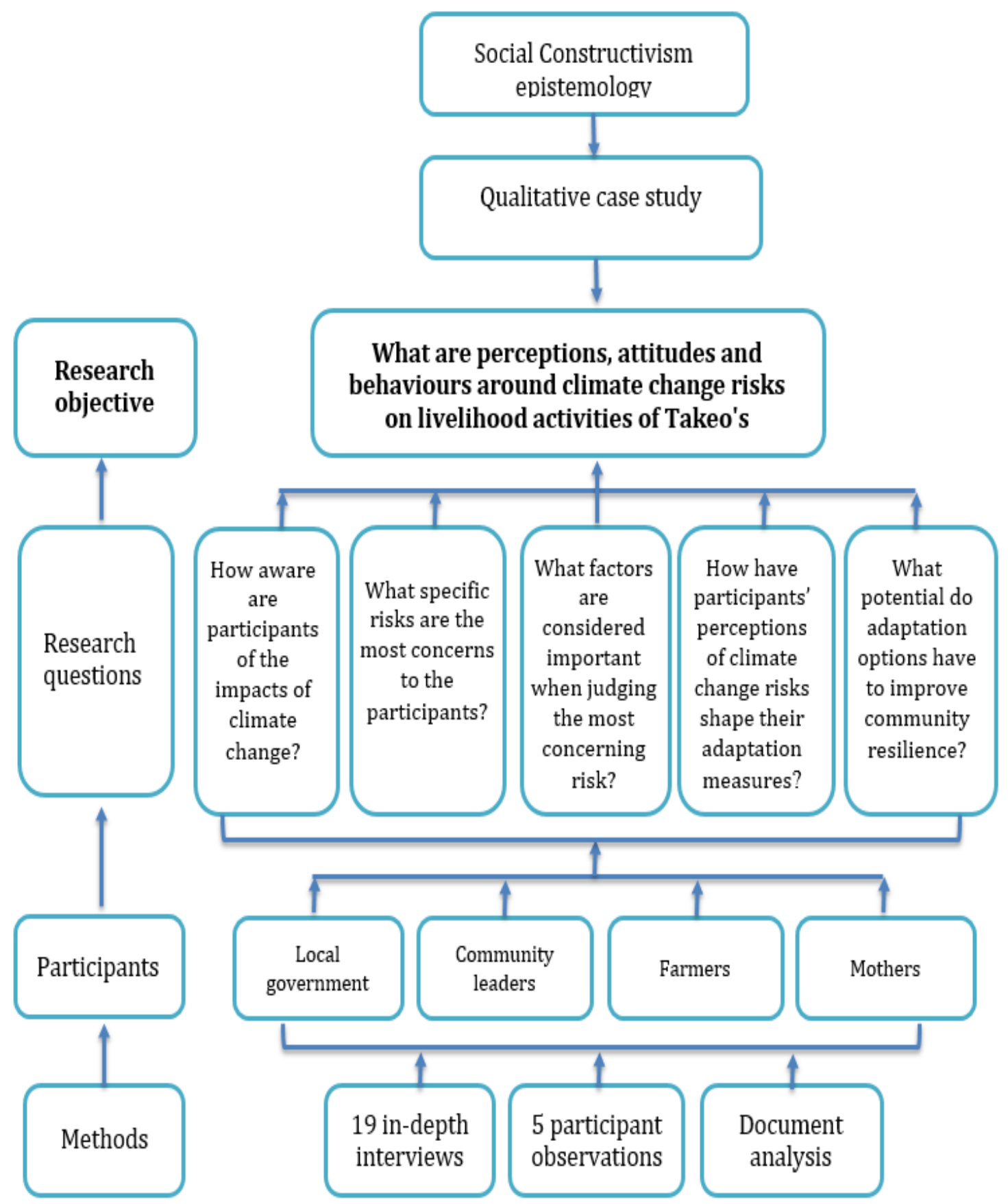

Figure 3: Research overview 


\subsection{Data recording procedures, storage and analysis}

All interviews were audio recorded. Prior to recording, I explained the project's purpose and the process of the recording, and asked for consent. I also noted down some key words and interesting points during the interviews so that I could easily make clarification or ask further questions once participants had finished speaking. The notes were useful for finding quotes or uncovering specific individuals' characteristics. Audio records were stored on a USB flash drive as well as uploaded to a Google drive to avoid loss of information. The USB was protected by a password. All audio files were transcribed into written documents in Khmer language before being translated into English.

Data was analysed using a spreadsheet in Microsoft Excel 2013. Data was coded according to themes and type of responses, and categorised following the format of the question guide:

- Types of climate change risks that the participants had experienced

- What has influenced the participants' awareness of climate change events

- The impacts of these events on the participants' living and income generation

- Degrees of concern about these extreme events

- Respondents' perception and understanding of future climate change impacts

- Respondents' responses to climate change

- Support from government and NGOs

\subsection{Ethical issues and confidentiality}

Ethical considerations to have arisen during the course of this study include the use of audio recording, my positionality, power relations and gender differences between my participants and myself. Many Cambodians, particularly among the elderly and women, are shy. In addition, because Cambodia is still a politically unstable country, recording interviews proves difficult at times. Many resist the idea of being recorded as the recordings may be shared with others such as 
government agencies or political parties who might perceive that the respondents that the respondents were speaking against their own interests. This made it difficult for me to request the recording of interviews. However, after clearly explaining the purpose and the confidentiality of the recordings, in addition to the participant's right to stop the recordings, all participants agreed to be recorded. Even so, some participants were reluctant to speak during recorded interviews.

To ameliorate this situation, I often spent around 15 to 20 minutes with the participants after the recordings were made in order to clarify some of their answers in a more conversational format. Moreover, during the interviews, I often discussed their daily activities to get to know them and make the environment more relaxed. Given Cambodia's history of civil war, many community members from older generations are still afraid of being interviewed and recorded. To address this, I was flexible in terms of the ways that I recorded consent and only those who volunteered were interviewed.

\subsection{Researcher's positionality and reflexivity}

My positionality as both an insider and an outsider in respect of this research had an influence on my work (Chacko, 2004; Sultana, 2007), on the design and process of collecting data, and on the interpretation of outcomes (Arora, 2012; Sultana, 2007). According to Chacko (2004, p. 52) and Maher and Tetreault (1993, p. 118), "Positionality" denotes aspects of identity such as gender, sexuality, age, race, social class, level of education, religion and other attributes that related to positions in society rather than necessary qualities. My positionality as both a local Cambodian and an academic student representing Victoria University as a whole have provided both benefits and challenges to my research.

My positionality as an insider positively influenced my access to the respondents and my understanding of them in cultural terms (Chacko, 2004). As a citizen of Cambodia who is aware of certain hierarchical requirements when preparing to do field research, I was able to access my study's participants easier and faster than a non-Cambodian without such cultural knowledge. Sharing the language of my participants, as well as cultural understating, I was well-placed to interpret the 
specific terms, body language, behaviour and mannerisms of participants, understanding, for example, when a facial expression might signify fear or anxiety. This enabled me to keep participants engaged in conversation, changing my approach if necessary, to navigate around topics in order to reduce any shyness or nervousness.

However, aware that my positionality could influence my interpretation of participants' voices, and thus influence the outcome of my research, I strove to avoid assuming the views of participants. I focused on listening and asking for clarification, and guarded against predicting or speaking for participants. To clarify some points, I have summarised and paraphrased the participants' responses and then asked them whether this is exactly what they meant. I found this was very helpful because sometimes people use different terminology; this approach helped to reduce any misunderstandings.

My positionality as a male researcher was also potentially a challenge to my communication with some female participants. Three out of the five mothers interviewed were shy when being interviewed or communicating with male outsiders. However, this was less of a challenge for me: the age gap between them and I was substantial and hence they treated me as a nephew or brother. Some of them called me nephew. Generally speaking, Cambodian people call each other by hierarchical status in familiar terms, such as brother, nephew, aunt or uncle, rather name, name even when speaking to those outside the family. Finally, it was important to clearly explain to the participants that my research was only related to their perceptions around climate change, which reduced the intensity of the overall process. Despite this, a few of them were still shy.

Another factor affecting my positionality was my previous work in a $\mathrm{NGO}^{2}$ in the community studied, so the participants may have expected my mission to be as a provider rather than a learner. To combat this, I dressed unofficially, and clearly explained the purpose of my study as well as my positioning as a student.

2 From 2011 to 2013, I worked as a monitoring and evaluation officer for the Cambodian Centre for Study and Development in Agriculture (CEDAC). CEDAC is an NGO specialising in organic agriculture, particularly rice production. CEDAC works to improve the rice production of rural farmers by providing them training. 
Even though I am a Cambodian student with a personal network of contacts within the community, my positionality as an outsider to the community and as an educated person influenced to some extent participants' responses. Due to my background as an educated urban dweller, interviewees probably saw me as someone who was knowledgeable and belonging to a higher class. This showed a power gap between the participants and myself. Several participants were reluctant to answer questions relating to general knowledge, claiming that I, as a student, would know more than they did about, for example, the causes of extreme climate events such as prolonged droughts or flooding rain. Some responded to the questions, but clearly believed that I already knew the answer, and that my inquiry was to test a theory, or their level of understanding, rather than driven by a genuine scholarly interest to learn from them.

To counter this, I clearly indicated my position and purpose in conducting this study. I explained that I was doing this research to understand the way they themselves interpret and frame their world. I elaborated that I intended to learn from their experience, and to express their interpretation and understanding of the world to other people, such as scholars, professionals, policymakers and outsiders. In this case, I was a learner and they were the sources of knowledge from whom I wanted to learn. I was not trying to test their level of understanding nor trying to be judgemental about their awareness or their level of education. I also discussed a range of other topics which participants - such as personal lives, rice planting, lifestyles and their kids - since in Cambodian culture, everyone discusses their personal lives and/or daily activities within a general conversation. I did this to reduce the power imbalance between participants and myself, though I feel the power imbalance did remain to an extent in this study.

Besides the challenges, my positionality as an academic scholar representing Victoria University also benefited my research. As the study was approved by the ethical committee of Victoria University of Wellington, and supported with a letter from my supervisor, Polly Stupples, I was able to gain access to participants from the Ministry of Environment more easily. In addition, being an outsider, I was seen as a more independent researcher. I was able to keep interviews going smoothly with neither harm nor involvement in any political influence. 
By coincidence, I arrived in the villages on the date of a scheduled community meeting. This provided me with an opportunity to get to know some community members by having a solidarity lunch together. It was important to chat and have food with local people in a context where there were fewer barriers to communication. This principle is reflected in Sultana's and Chakco's work as they observe, building living and learning relationships with the communities studied offers researchers an opportunity to build a relationship of trust with facilitating the research process (Chacko, 2004; Sultana, 2007).

\subsection{Conclusion}

This chapter explained the methods and methodology that were used to examine the perception and responses of the Takeo community around climate change. The study was driven by a social constructivist epistemology to understand how and why individuals perceive and understand climate change in particular ways. To do this, a qualitative case study approach was used to understand participants' views of how they frame their world, their reflections of climate change impacts, and their adaptation strategies. To collect both primary and secondary data, three methods were employed: semi-structured interviews, participant observation and document analysis. These methods allowed me to understand the context more fully, and analyse the data that emerged in similar and diverse themes. The chapter has also discussed my positionality and reflexivity, as both an insider and outsider, and the benefits and drawbacks of this positionality for the research. 



\section{Chapter 4: Climate change in the context of Cambodia}

This chapter explores climate change impacts for Cambodia and responses towards the issue. To better understand the discussion, some background is included, surveying Cambodia's geography, climate and economy, and the country's experiences of climate change. This information indicates the significance of studying climate change in Cambodia. The chapter firstly examines the geographical area and population of Cambodia followed by a discussion of the country's climate. It then explores the economy and the agriculture sector of the country to understand the livelihood activities of local people. Lastly, the study reviews Cambodia's current climate change policy.

\subsection{Geographical area and population}

Cambodia lies in Southeast Asia and shares international borders with Vietnam to the east, Laos to the north, Thailand to the west; the gulf of Thailand lies to the southwest as shown in Figure 4 (MoE, 2006). Cambodia consists of uplands in the eastern area (an undulating plateau), central lowlands with some hills and rivers, and the Kra Vine alpine region in the southwest (FAO, 2011a, p.1; MoE, 2009a). The country has two main water sources: the Tonle Sap Lake, which covers about $2.2 \%$ of the total land size, and the Mekong river that flows from China.

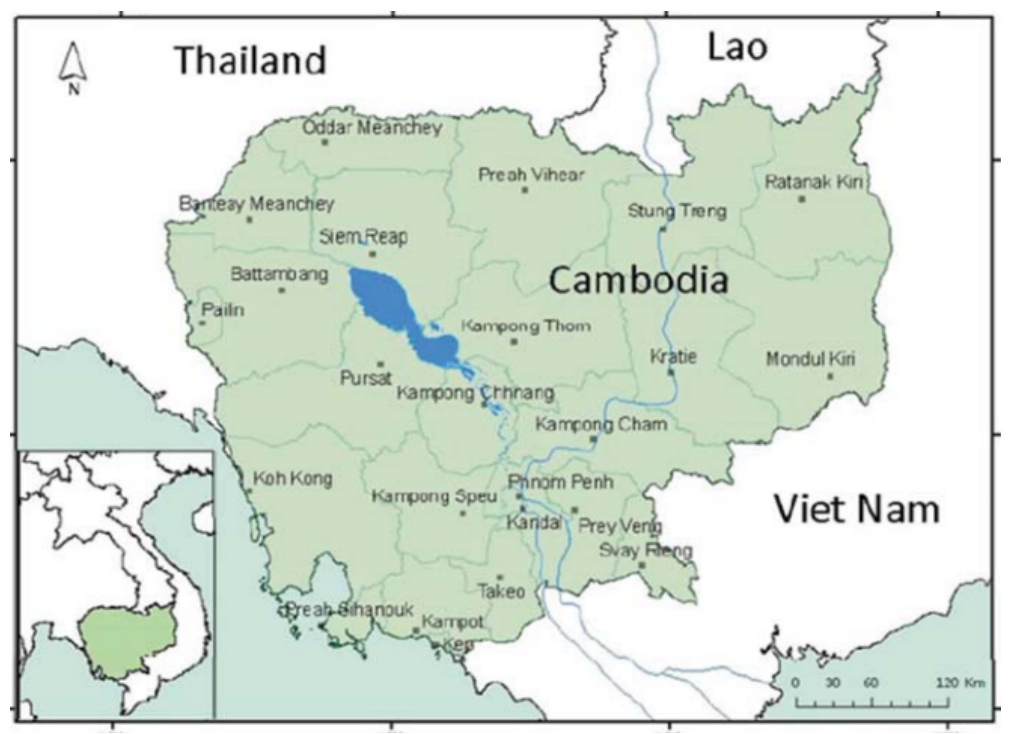

Figure 4: Geographical area of Cambodia

Source: Food and Agriculture Organization of the United Nations (2011b, p. 1) 
With an area of 181,035 square kilometres, Cambodia is a small country. In 2014, Cambodia had a dense population of 15.3 million people (MoE, 2009a; World Bank, 2016). Cambodians have liked to settle in the central plains, and around the Tonle Sap Lake. In 2010, around 52\% of the total population lived in the central part of the country and 30\% around the lake (World Bank, 2011, p. 2). Only 11\% of the total population lived in the highland and mountain regions, while $7 \%$ lived along the coast.

Poverty is a major problem for Cambodia mainly due to a civil war from 19751979 that destroyed infrastructure, schools, hospitals and human resources. In 2015, Cambodia was ranked as the $143^{\text {rd }}$ poorest country in the world (Pasquali, 2015). In 2012, the poverty rate accounted for $17.7 \%$ of the total population (World Health Organisation [WHO], 2016). Although the country has reduced its poverty rate by $50 \%$, approximately 8.1 million Cambodian citizens still lived close to the poverty line in 2009 (WHO, 2016, p.4). The majority of the population live in rural areas and depend on agriculture for their major source of income (Action Against Hunger International Organisation [ACF], 2015; Asian Development Bank [ADB], 2014).

Additionally, Cambodia does not have sufficient electricity. In 2012, 82.8\% of Cambodian people did not have access to electricity (RGC, 2013, p.6). The country depends largely on fossil fuel for electricity production, with $95.2 \%$ of electricity produced from fossil fuel in 2012 (RGC, 2013, p.6). Hydropower, which accounted for $3.3 \%$ of the total electricity produced in 2012 was the largest source of renewable energy. The majority of Cambodian people (more than $80 \%$ ) use fuelwood and charcoal for cooking.

\subsection{Cambodia's climate}

Cambodia is located in a geographical area with a tropical monsoon climate. There are two main seasons for this (Council for Development of Cambodia [CDC], 2012; MoE, 2009a). The dry season occurs from November to April. The rainy season lasts from May to October with rainfall driven by the Southwest Monsoon movement from the Indian Ocean (FAO, 2011a, p.1; World Bank, 2011, p.3). 
Cambodia is warm all year round. The annual average temperature usually measures $28{ }^{\circ} \mathrm{C}$ (Thoeun, 2015). From November to January the weather is cooler. April is the warmest month with a maximum temperature of over $38^{\circ} \mathrm{C}(\mathrm{MoE}$, 2009a, p.6), while January is the coldest month with a minimum temperature of around $17{ }^{\circ} \mathrm{C}$ (Thoeun, 2015). In the rainy season, the Monsoon generally provides $90 \%$ of rainfall throughout the country. The mean annual rainfall varies between 1,200 to 2,000 millimetres (MoE, 2009a, p.5), but this varies drastically within regions as some areas have a mean rainfall of up to 5,000 millimetres (World Bank, 2011 , p. 3). In the central part of the country, average annual rainfall is between 1,200 and 1,900 millimetres. From year to year, rainfall in some areas fluctuates dramatically. For instance, some areas experience no rain for about 15 days between June and July (MoE, 2009a, p.6). Cambodia is a humid country and the humidity varies from 65-70\% between January and February and from 85-90\% from August to September.

\subsection{Cambodia's economy}

Cambodia's economy depends on three major sectors: service, industry and agriculture. Of the total Gross Domestic Product (GDP) in 2015, the service accounted for 41.7\%, industry 29.7\%, and agriculture 28.6\% (Ministry of Agriculture, Forestry and Fishery [MAFF], 2016, p.7). Cambodia's economy has been growing significantly (about 7\% per annum) over the last two decades (World Bank, 2015, p. 1). In 2015, the gross national income (GNI) per capita of Cambodia increased to 1,070 US dollars. The growth is driven largely from the garment and footwear industry, the construction sector and tourism.

In contrast to the achievements in economic development, rural poverty, health and education are still the biggest challenges to Cambodia's wider development. In 2014 , stunting was seen in roughly half a million children aged from zero to five (about 32\%) and around 10\% of children were extremely thin (ACF, 2015, p.12). In addition, many people did not have access to improved water around 35\% and improved sanitation around 52\% (WHO, 2016). 


\subsection{Cambodia's agriculture}

The agricultural sector is one of the major contributors to the country's economy despite low commodity prices. The tropical monsoon climate is beneficial for agricultural activities, particularly rice production (Thomas et al., 2013). The sector was responsible for 28.6\% of Cambodia's GDP in 2015 (MAFF, 2016, p.7) and offered jobs to $45.3 \%$ of the labour population (8 million) in 2014 (MAFF, 2016, p. 7-8) . The vast majority of farmers in Cambodia practise subsistence agriculture with low input and rain-fed farming (FAO, 2011a, p.3). More than $80 \%$ of cultivatable areas still depend on rainwater for irrigation (RGC, 2013, p.5).

The agricultural sector of Cambodia grew by only 5.3\% annually between 2004 and 2012 (Joosu-Palu, 2015). The increase in agricultural production in Cambodia has helped four million people out of poverty over the last decade. Rice is the most important crop in Cambodia. The country has not only produced sufficient rice for the local population, but enough of a surplus to export to other countries (FAO, 2011a). Rice production significantly contributes to national food security and poverty alleviation (Ros, Nang, \& Chhim, 2011). From 2011 to 2015, Cambodia increased its rice growing areas, resulting in increased rice production overall (Figure $5 \& 6$ ). However, paddy yield has decreased slightly over the last two years (Figure 6). Overall rice production increased, but rice yield (ton/hectare) decreased from about 3.2 ton/ha to about 3.08 ton/ha between 2011 and 2015 (Figure 7). This indicates that rice productivity has reduced slightly, and perhaps due to more severe extreme events.

Although Cambodia has produced surplus rice overall, food insecurity is still a major problem for farmers in some rural areas where natural disasters such as droughts and floods occur frequently (FAO, 2011a). In addition, earnings from rice production are defined as low-income. Cambodia does not have a fixed price for rice and the middleman often lowers the price during harvesting season. 


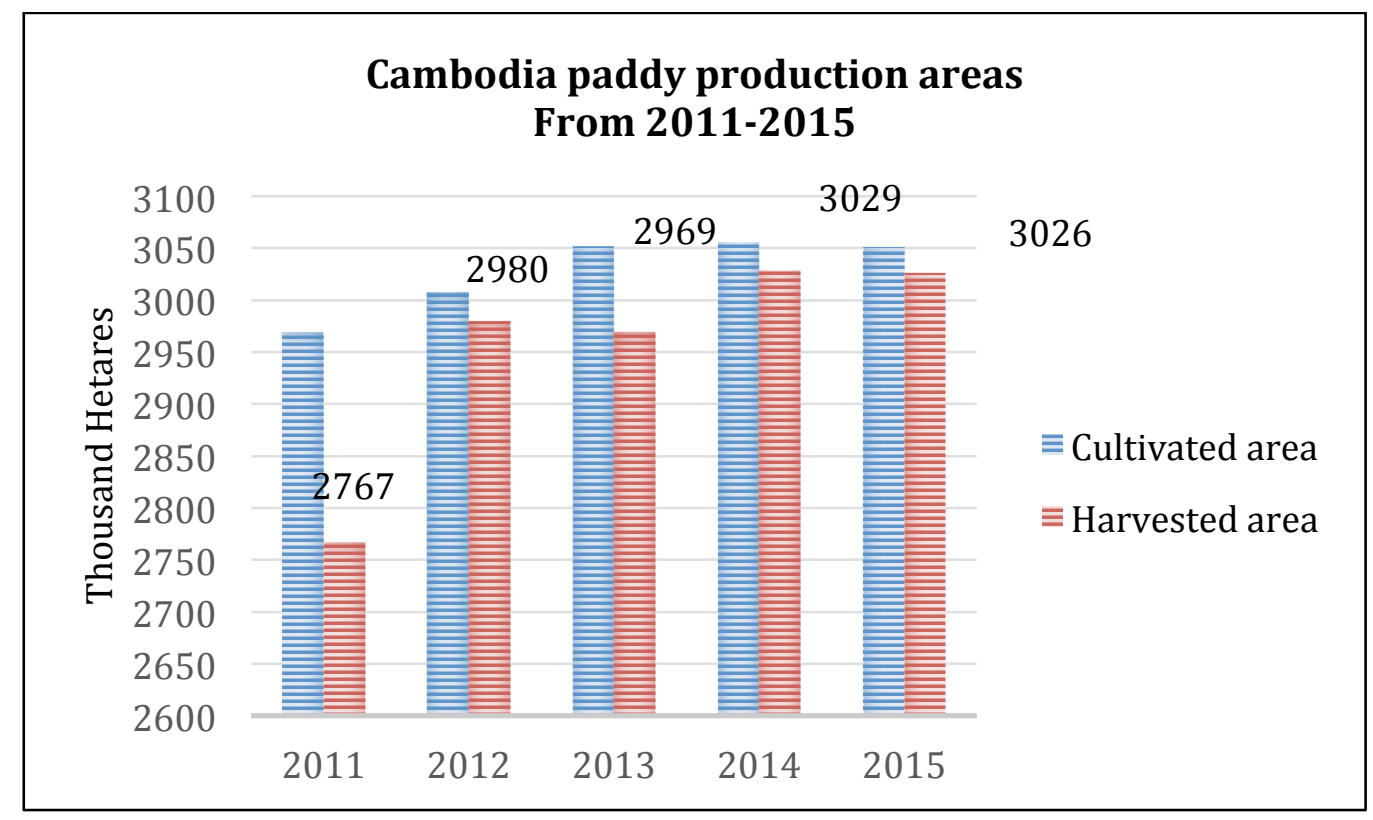

Figure 5: Cambodia paddy production areas from 2011-2015

Source: MAFF (2016, p. 16)

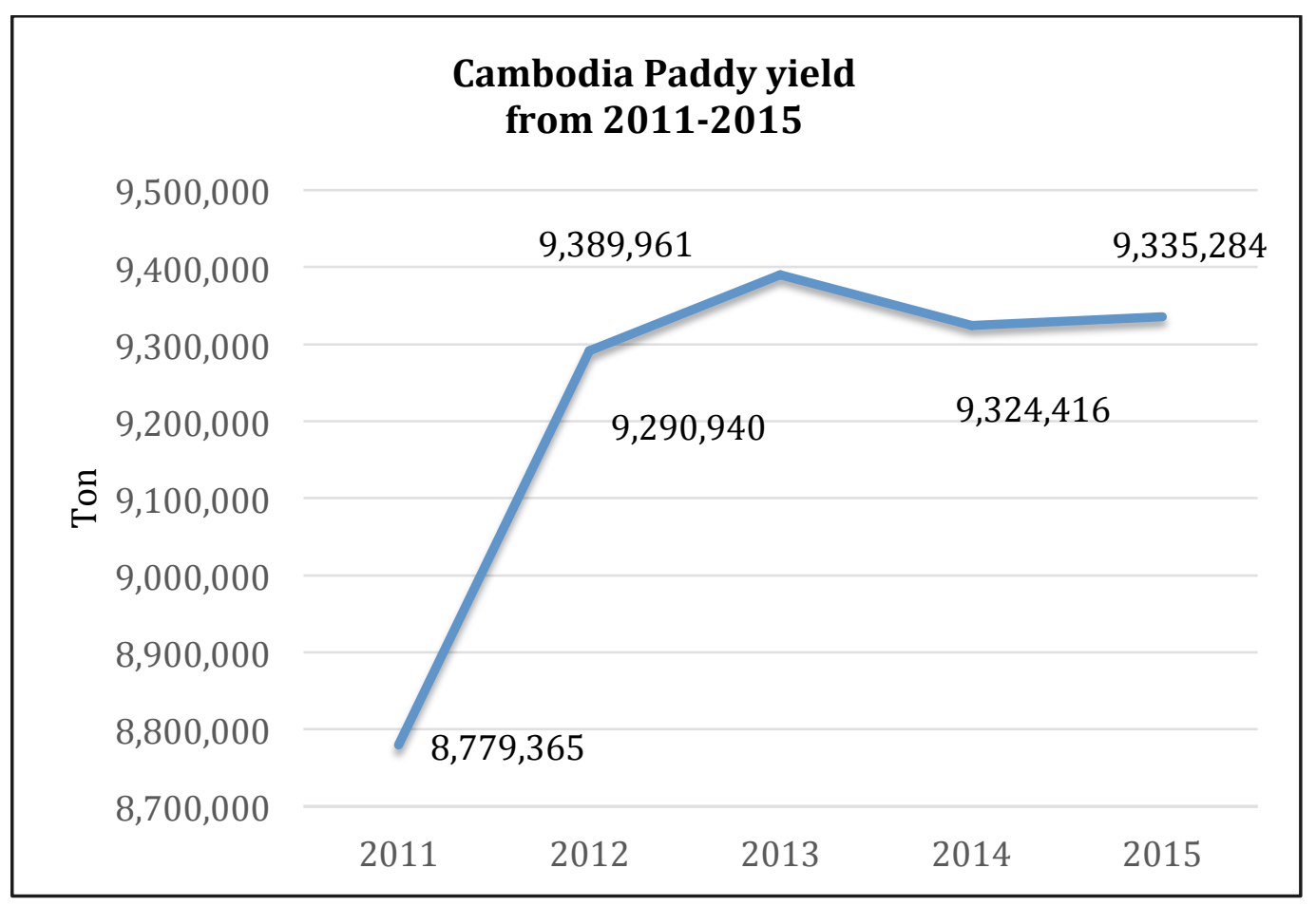

Figure 6: Cambodia paddy yield from 2011-2015

Source: MAFF (2016, p. 16) 


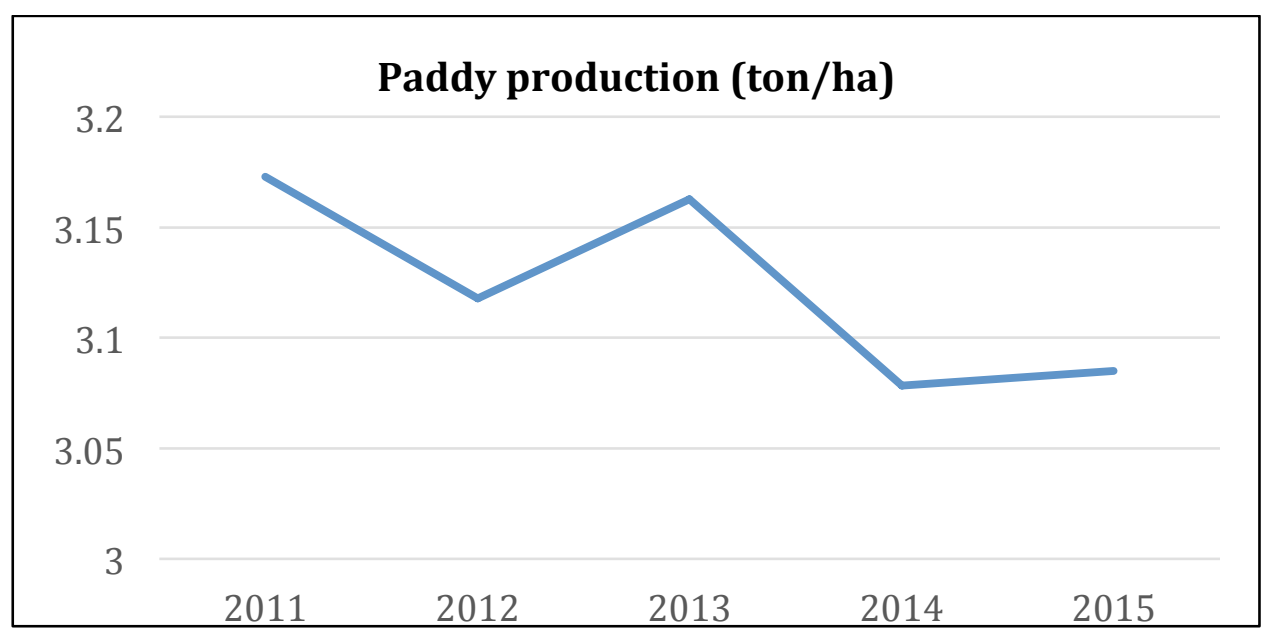

Figure 7: Cambodia rice productivity (calculation from data of Figure 5 \& 6)

\subsection{Climate change in the context of Cambodia}

Cambodia is ranked as one of the most vulnerable countries in the region to the effects of climate change (Khim \& Phearanich, 2012) because of its poor water storage, irrigation systems and infrastructure (ACF, 2015). In addition, more than $80 \%$ of Cambodian people are farmers who live in rural areas with poor adaptive capacity to climate change and limited infrastructure (Khim \& Phearanich, 2012). About $50 \%$ of Cambodia communes are identified as highly vulnerable to climate change (RGC, 2013, p.11).

Cambodia has suffered from climate change-related weather events such as increasing temperature and increased frequency of floods, as well as droughts of higher intensity, lightning, typhoons, seawater intrusion and increased incidences of malaria (NCDM, 2014; Thomas et al., 2013). The country has been getting warmer not only during the days but also at night (World Bank, 2011, p. 4). The annual average temperature in Cambodia has risen by $0.8^{\circ} \mathrm{C}$ since 1960 , rising by $0.18{ }^{\circ} \mathrm{C}$ every decade (RGC, 2013, p.xvi; World Bank, 2011, p.4). Higher temperature increases have been seen in the lowland areas, including Takeo province, than in the upland areas. Cambodia is also expected to get warmer in the future. The average surface temperature throughout Cambodia is projected to climb by 0.7-2.7 ${ }^{0} \mathrm{C}$ by the 2060s (World Bank, 2011, p. 4), depending on the geographical area of each province (RGC, 2013). According to the World Bank data, Cambodia's annual average temperature from 1960 to 2012 increased by nearly $1.5^{\circ} \mathrm{C}$ (Figure 8). 


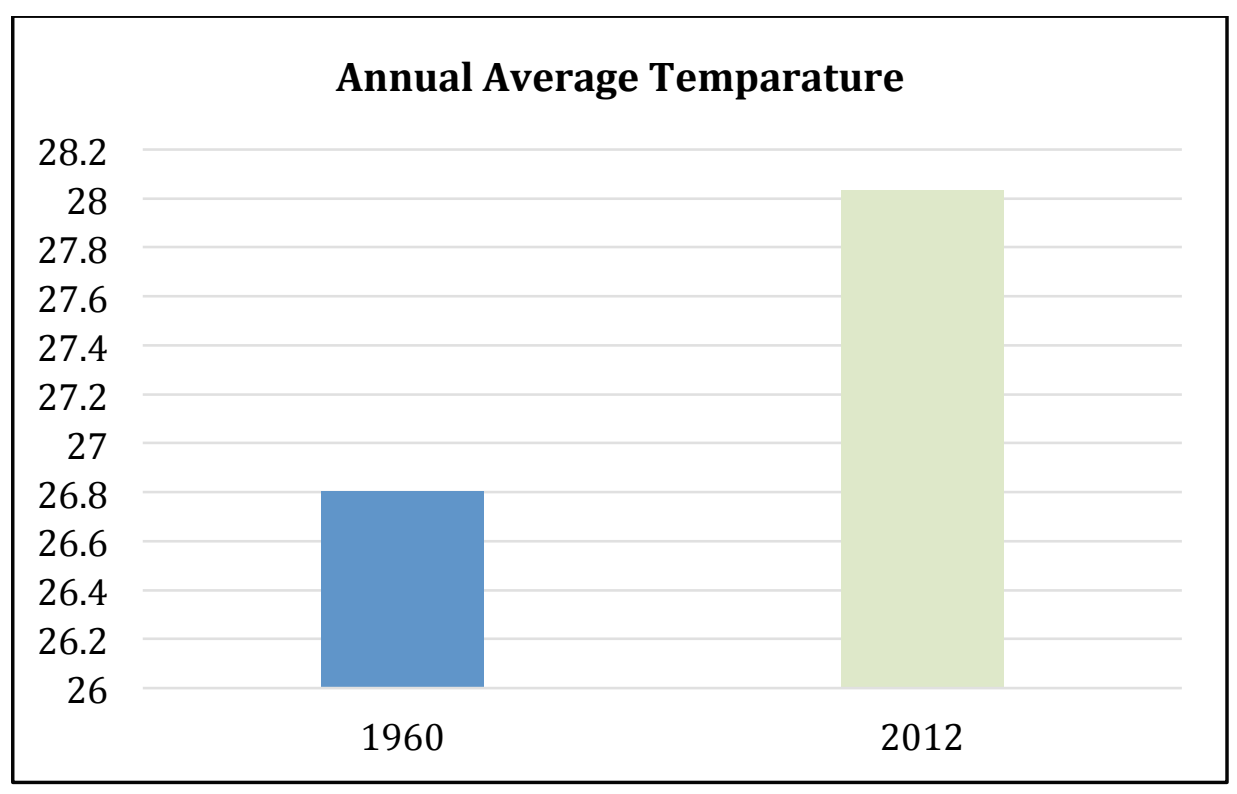

Figure 8: Changes of annual temperature in Cambodia $\left({ }^{\circ} \mathrm{C}\right)$

Data source: Data from the World Bank (n.d)

In addition to a warmer climate, Cambodia's rainfall was also affected by the El Niño cycle. "The El Niño Southern Oscillation cycle is a periodic climatic phenomenon that refers to a warming of the Central and Eastern Pacific, affecting the atmosphere and weather patterns." (United Nations Economic and Social Commission for Asia and the Pacific [UNESCAP], 2015, p.3). The impacts of El Niño vary based on geographical areas and season. El Niño is a complex phenomenon since it can cause droughts in some areas and flooding in others. According to Chan Yutha, spokesman of the Cambodia Ministry of Water Resources and Meteorology, El Niño increased the temperature of the South China Sea and the Western Pacific (Vida, 2015), resulting in prolonged droughts and flooding in Cambodia (ACF, 2015, p.1). The 1997-1998 El Niño, for example, caused severe droughts, resulting in a 250,000-tonne rice shortage for the Cambodian people (Harfenist, 2015).

Cambodia also suffered from the 2015-2016 El Niño which was stronger than the one in 1997-1998 (Harfenist, 2015; Save the Children, 2016; UNESCAP, 2015, p.3). Based on the 2015 satellite data monitoring drought conditions, Cambodians were facing severe water shortages as high water deficits occurred in some parts of Cambodia such as the Takeo and Kampong Speu provinces (ACF, 2015, p.10; Harfenist, 2015). 
The 2015 rainfall was delayed until mid-July, which had negative effects on the country's economy (Save the Children, 2016, p. 4). This delayed and reduced the earlier-planted crops and damaged some of the later rice production in many provinces (ACF, 2015). Fortunately, rainfall conditions improved in the late monsoon season of 2015 resulting in increased crop yield. Amongst the 77,419 hectares of cultivated land affected (UNESCAP, 2015, p.4), approximately 10,000 hectares of paddy fields were completely damaged from the earlier dry weather (ACF, 2015, p.11). The Cambodia Ministry of Water Resources and Meteorology reported that El Niño will continue to delay the 2016 rainy season in Cambodia until late June and some areas of Cambodia would experience severe water shortages (cited by Vida, 2015).

Extreme weather events such as drought, flooding and storms have had devastating effects on Cambodia, causing deaths, and destroying transport and social infrastructure and housing in rural area, as well as severely damaging agricultural production which has led to poverty and food insecurity. Typhoon Ketsana in 2009 impacted around 180,000 households (Leng, 2014, p. 10). The national committee for disaster management in Cambodia (NCDM), for instance, has revealed that the 2011 floods impacted 350,000 households, killed 250 people, and affected more than 400,000 hectares of paddy fields with 267,000 hectares completely destroyed (Leng, 2014, p. 8). Almost 1000 kilometres of roads were also damaged, at a cost of about 630 million US dollars. In addition, according to Radio Free Asia (2014), in 2014 Cambodia faced two climate change hazards at the same time. Provinces along the Mekong and Basac Rivers were flooded while the northern and southern parts of the impoverished country were threatened by droughts. According to the Radio Free Asia (RFA) news, around 396 schools, 154 pagodas, and 32 hospitals were flooded (So, 2015).

Droughts also reduced water availability for rural families and damaged their crops. Droughts have lasted longer in the dry season than they used to (FAO, 2011a, p.7). The 2011 drought occurred in nearly half of the provinces in Cambodia, and affected nearly 4,000 hectares of paddy fields with 53 hectares completely destroyed (Leng, 2014, p. 8). Many water resources dried out, forcing 
people to purchase water for consumption. For example, Sam Chhoy, a farmer in Stoung district of Kampong Thom province in the centre of Cambodia, told RFA that she needed to spend around 6.09 US dollars for a container of water for her family's consumption (So, 2015). This was difficult given that her husband's daily income was only 4.87 US dollars. In addition, Nhim Vanda, Vice Chairman for Cambodia's National Committee for Disaster management said that the delay of rain in Cambodia reduced rice production by as much as $40 \%$ (So, 2015). Since Cambodia depends mainly on agricultural production, a significant decline in crop production could result in more poverty and slower economic growth (Thomas et al., 2013). With only a very small land area covered with full irrigation, it is difficult for Cambodia to increase rice productivity to reach its exporting target of one million tons of milled rice per annum under drought conditions (RGC, 2013, p. 79). In addition to the physical destruction from climate change, the Cambodian economy has been slowed due to the widespread damage. In 2011 extreme weather events cost Cambodia 4.3\% of GDP (RGC, 2013, p.9).

\subsection{Cambodia's climate change policy}

Cambodia's government and NGOs have given a lot of attention to combating climate change because many people have been experiencing devastating economic losses (Toch, 2015). At the international level, Cambodia joined international efforts such as the United Nations Framework Convention in 1995 and signed up to the Kyoto Protocol in 2002 (MoE, 2006). Cambodia submitted its First National Communication to the UNFCCC in 2002. In June 2003, it set up a Climate Change Office (CCCO) to respond to various climate change-related activities including planning and policy formulation, implementation of the UNFCCC, assessment of innovative technologies to adapt to the harmful effects of climate change or to reduce greenhouse gas emissions, and capacity building and awareness raising.

At the national level, the government of Cambodia marked climate change as a cross-cutting issue in the National Strategic Development Plan 2014-2018 (RGC, 2014). Many policies related to climate change have been established to reduce and mitigate the impacts of climate change events on Cambodian households, 
communities and the economy (MoE, 2006). The government believes such policies will also increase the country's capacity to become climate resilient. In 2006, a strategy on climate change adaptation, the National Adaptation Program of Action to Climate Change (NAPA) was appointed to understand the main features of climate risks and the responses of local people (MoE, 2006, p.2).

Recently, the Cambodian government issued the Cambodia Climate Change Strategic Plan, (CCCSP) 2014-2023, updating on the NAPA. The CCCSP 2014-2023 was created to reduce climate change vulnerability and build resilience through improving food, water and energy securities; to protect ecosystem; to promote green development (low-carbon energy and technology); and to promote education and participation of the public in climate change response actions (RGC, 2013, p.3). To operationalise CCCSP, all technical line ministries such as the Ministry of Agriculture, Forestry and Fishery, the Ministry of Environment, and the Ministry of Water Resources and Meteorology have developed climate change strategic plans and actions in their specialised sectors to reduce the impacts of climate change in Cambodia.

For instance, the Ministry of Environment established the Climate Change Action Plan (CCAP) 20016-2018 as a contribution to the implementation of CCCSP (MoE, 2016b). In the agricultural sector, the government has received support from the International Rice Research Institute (IRRI), and the Cambodia Agricultural Research and Development Institute (CARDI) to experiment with better varieties of rice (i.e. with higher yields and greater tolerance to drought) and to introduce modern technologies in agriculture. The government also delivered droughttolerant varieties of rice to farmers as part of its response strategies. In 2015, 2860.02 tons of good rice seeds were produced and delivered to farmers (MAFF, 2016, p.11). The government of Cambodia also established the National Biodigester Programme in 2006 to promote biodigesters in order to reduce greenhouse gas emissions (methane) from animal manure (MAFF,2006). The biodigester is a plant that converts energy from animal manure, and thus reducing the emissions of methane produced by cattle. 
Cambodia also issued the National Policy on Green Growth and the National Strategic Plan on Green Growth 2013-2030 to maintain the stability of economic growth with the protection of natural resources and ecosystems to reduce greenhouse gas emissions and to achieve sustainable development (National Council on Green Growth [NCGG], 2013, p.2). The National Policy on Green Growth aims at improving the access of the Cambodian people to sustainable land use, clean water, food security, renewable energy, information and knowledge, better mobility, and finance and investments (Ministry of Environment, 2009b, p. 8). The government of Cambodia also developed the National Forest Program 2010-2029 to achieve environmental sustainability as part of the Cambodia Millennium Development Goals (Ministry of Agriculture Forestry and Fishery, 2010). The government planned to increase its forest cover and expected to use benefits from forests to improve the livelihoods of local people (Ministry of Agriculture Forestry and Fishery, 2010, p. 2). As the impacts of climate change are severely affecting water availability and the livelihood of rural farmers, the government also set up disaster risk management organisations which provide emergency responses to farmers in Cambodia and help community resilience (Action Against Hunger International Organisation, 2015).

Many projects related to climate-resilient development were implemented with cooperation from NGOs. From 1995 to 2003 for instance, Cambodia implemented 98 projects related to climate change in order to address institutional strengthening, infrastructure development and human resources. Given the agricultural sector is a top priority in development at the national level, the Cambodian government has funded various projects related to climate change adaptation such as land management (improving soil fertility through promoting utilisation of compost in order to increase crop production); multiple cropping (growing different crops year round to increase total production and income); promoting agricultural resilience techniques such as the System for Rice Intensification (SRI)3; and biogas (producing biogas from manure to use as energy for cooking and lighting, and also providing organic fertilisers) (Am, Cuccillato, Nkem, \& Chevillard, 2013).

\footnotetext{
3 System of Rice Intensification (SRI) is a cultivation technique that transplants few young seedlings, but provides high yield due to better crop growth (Lhendup, 2008; Uphoff, 2015). One seedling grows better than many because it absorbs nutrients better.
} 
The climate change projects have improved water resource management, livelihood enhancement and capacity building on climate change in the community (United Nations Development Programme, 2012). For example, the Cambodian Community Based Adaptation Programme rehabilitated small irrigation systems $(48,215$ meters of canal, 862 meters of dam and 22,400 meters of water pipeline installation) that could irrigate more than 10,000 hectares of dry season rice farming, and nearly 30,000 hectares of rainy season rice farming. The programme also rescued more than 5,000 hectares of rice from the long drought that occurred between late May and early August 2012. Such projects created other options to improve the livelihoods of communities through the reduction of financial risk and decreased dependence on having to borrow money from banks or micro-finance institutions that have high interest rates (United Nations Development Programme [UNDP], 2012) .

Despite having many policies to address climate change, climate change still has a severe effects on Cambodia, with its limited capacity to adapt to fast changes in the environment (Seng, 2013). The government of Cambodia has limited financial resources to fund climate change-related activities. There are few climate change researches and training institutions in the country, and climate change data availability and reliability is very limited. Interestingly, the country appears to have a shortage of mechanisms to share information regarding climate change.

\subsection{Chapter summary}

The chapter has discussed climate change and its effects in Cambodia. The chapter has described the geography of the country and the studied area (Takeo province). In addition, it examined the country's climate, economy and agricultural sector to understand the major livelihood activities of local people were. Cambodia's climate change policy was also explored to understand the negative effects of extreme weather events on people and their responses to adverse impacts. Cambodia is a poor, post-war country which has a very low adaptive capacity to climate change. The majority of the population depends mainly on crop production, particularly rice farming for income and food. With climate change becoming more prominent, it will directly affect the lives and livelihoods of Cambodians even more. 


\section{Chapter 5: Perceptions of climate change risks in Takeo}

\subsection{Introduction}

The chapter provides a concrete explanation of participants' experience and interpretation of climate change, consolidating data from interviews, participant observations and document analysis. The chapter seeks to answer the research

questions (1, 2 and 3). This chapter will begin by identifying the risks that have arisen in the studied area from climate change. The causes of extreme weather events will then be identified, and both negative and positive effects of extreme climate events on the Takeo community's living conditions and livelihoods will be explained. After that, the degree of concern participants hold towards climate change risks is explored. Factors that have an influence on community concerns are also examined. Lastly, the perception of the community regarding extreme climate events in the future will be discussed.

\subsection{Climate change risks in Takeo}

Based on the participants' experiences and a review of documents, some major risks have arisen for this region since 1960 (RGC, 2013). These included more frequent and severe storms and lightning, rising temperatures and fluctuations in rainfall patterns that cause prolonged drought and flooding rain. Although these extreme events have occurred since 1960, almost three quarters of the community participants (72.2\%) have only detected such variation during the last five years when there has been a significant shift in temperature and pattern of rainfall. Only $27.8 \%$ said that the weather patterns in their region have been changing over more than 16 years, but the variation was not dramatically obvious until 2012. As Respondent MLAC4 said: "I have observed the changes of temperature and irregular pattern of rainfall since 1986 as I remembered, but at that time it did not vary very quickly and significantly as it is today". The local government officer also made a similar observation. 
All community participants have witnessed the warmer climate although many were not aware of how great the increase was. They felt it was noticeably getting warmer, as Respondent MLAC4 remarked, "I realised it was very hot one day in April 2016 and I talked to my son and other people in the village. I guess the temperature would be around 41 or $42{ }^{\circ} \mathrm{C}$." These observations reflect statistics from the government of Cambodia (RGC, 2013) that temperatures in Cambodia had increased.

Save the Children (2016, p. 4) also reported that weather in Cambodia between December 2015 and May 2016 shifted from hot and humid to hot and dry, and that the temperature reached a maximum of $41{ }^{\circ} \mathrm{C}$ during April and May. The local government officer and all community respondents added that the warmer weather they experienced was not only occurring during the day but also at night time. The government of Cambodia also reported that hotter nights in Cambodia have increased.

Both the local government officer and all community participants noticed that not only had the temperature increased over this period, but the pattern of rainfall had also changed. Some mentioned that the rainy season during the last five years had been delayed each year. They raised the delay of the 2015 and 2016 rainfalls until late May as an example, consistent with the government report about the delay of the 2015 rainfall due to the El Niño effect (MAFF, 2016; Morn \& Igor, 2016). Respondent MLAC4 described the change in that "Generally there is at least some rain earlier in the dry season around March or April.

However, this has recently changed resulting in a prolonged drought in this region." This observation confirms the delay of rain, since Mak (2013, p. 22) points out that, historically, the dry season in Takeo did not last longer than four months on average. Some participants observed that the changes were not only seen in the delayed onset of rain, but also in the amount of rain falling. They commented that the amount of rainfall has fluctuated lately. One participant described a pattern in which there was not any rain for about 2 to 8 weeks, but that the dry was followed with heavy rain every day that caused floods in the area. 
"I remembered that sometimes it is raining lightly and then there is not rain for about a month or two. After that the rain just falls constantly all day long causing flooding rains. Having said that it is not the flood that lasts for a long time as is the case in other provinces of Cambodia where people need to move to higher land. We do have flood from rain water sometimes that damaged dams and the rice fields of farmers" (Respondent FLAC3).

Besides this, all participants noticed that storms and lightning were also happening more frequently and severely in the region. Rain often fell with strong winds and sometimes thunderstorms. Even though none of the respondents had been injured nor had their houses been damaged, they were worried about these possibilities given the virulence and higher frequency of these events. The following quote is an example of one participant's feeling regarding thunderstorms while he was travelling home from work.

"I was travelling from building a client's house. Along the way back home, there was rain with strong wind and loud thunderstorms. I decided to stop somewhere because I was so scared about lightning. I have heard from my neighbours as well as seen in the media about many people were hit by lightning and they had injuries for up to 6 months. Some people were also killed because of that. Thunderstorms lately are very serious and make so much noise" (Respondent MF9).

This reflected the scientific investigation indicating that climate change will increase lightning frequency (Gill, 2014) and thunderstorms (Diffenbaugh, Scherer, \& Trapp, 2013). The National Committee for Disaster Management of Cambodia also reported that in 2015, Cambodia was hit by more severe storms and lightning (Morn \& Igor, 2016). Storm and lightning strikes on Cambodia doubled during the last decade (Figure 9; 10). Amongst the 25 provinces of Cambodia, Takeo had the highest rate of death by lightning, accounting for 107 death from 2006-2016. 


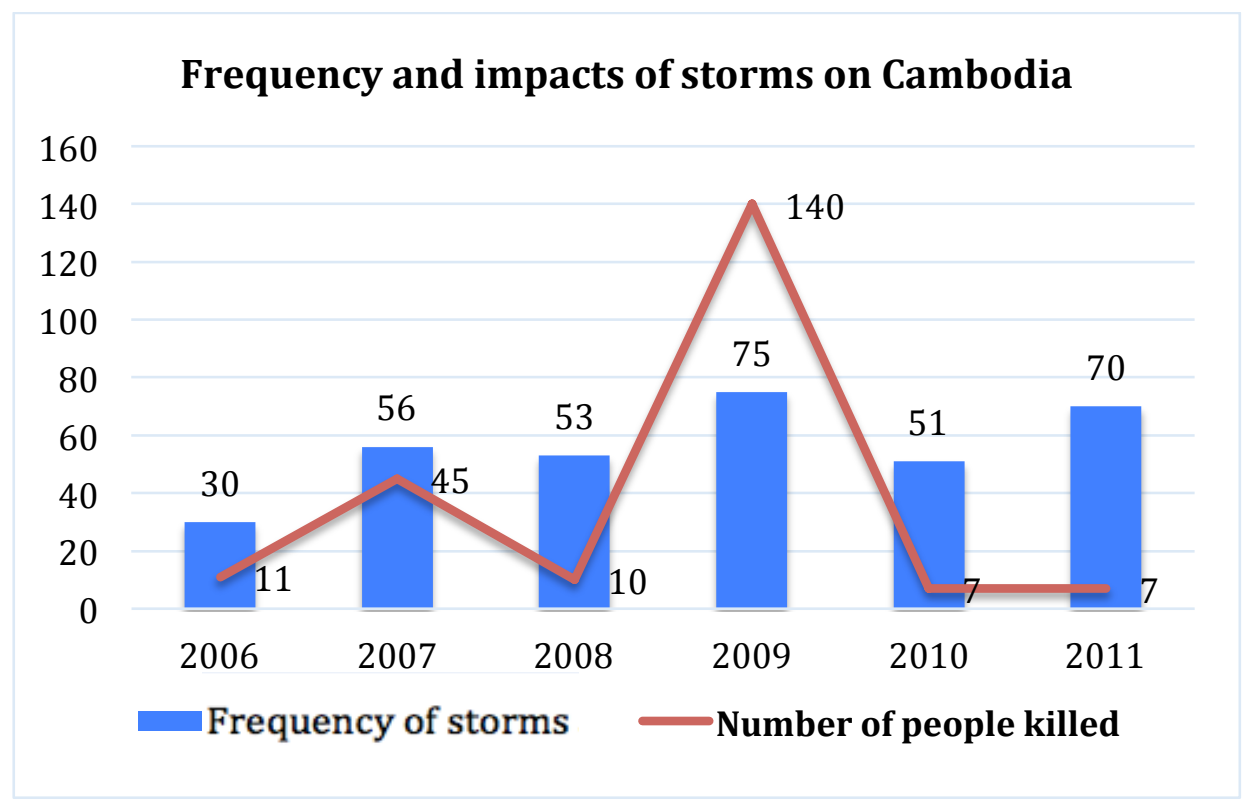

Figure 9: Frequency of storms and their impacts on Cambodia Source: (Leng, 2014, p. 11)

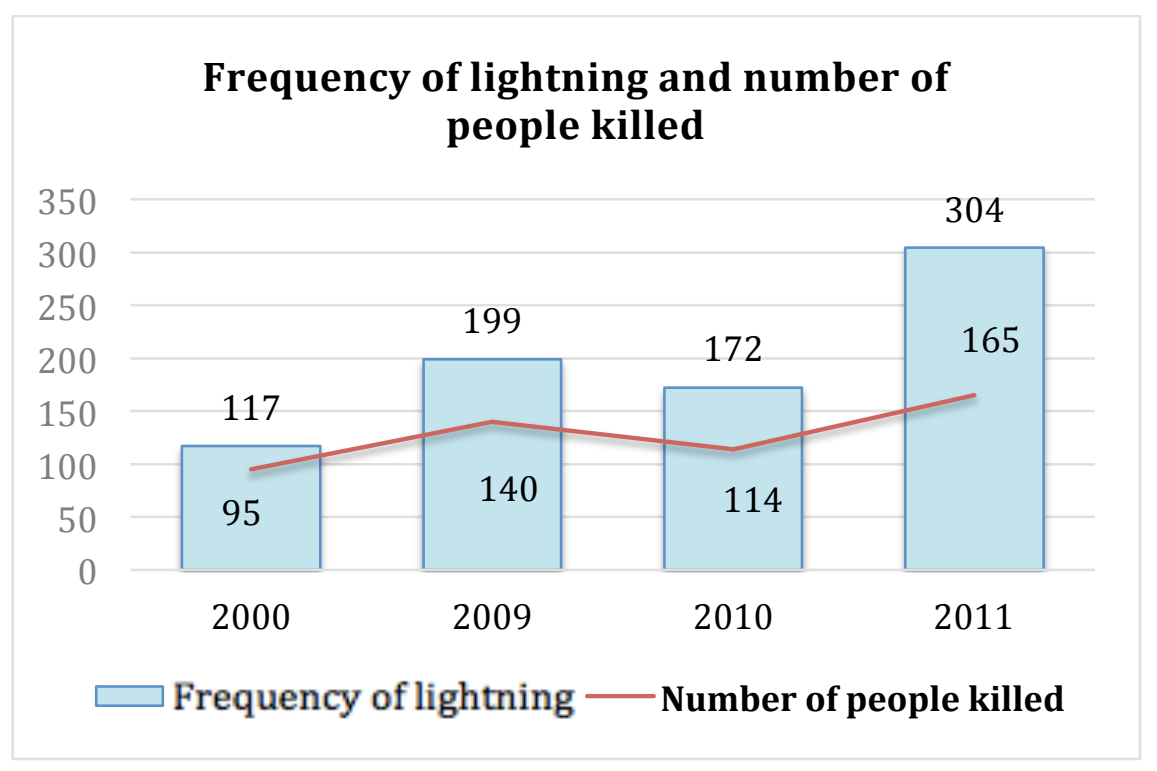

Figure 10: Frequency of lightning and its impacts on Cambodia Source: (Leng, 2014, p. 11)

In short, participants noticed some major risks that appear to be related to climate change. These problems included more frequent and severe storms and lightning, warmer climate and variations in the pattern of rainfall leading to either flooding rains or prolonged droughts. Even though climate change has occurred for some time, not many participants noticed the effects of extreme climate events until recent years when the effects were more obvious and severe. 


\subsection{Perception of the community on causes of climate change}

Even though the community participants all live in the same area, they had different viewpoints on the causes of climate change. Amongst the 17 community participants, $41 \%$ were not aware of the causes of climate change. They explained that they were not well-educated and did not possess scientific knowledge, so they had no idea what was causing this phenomenon. All these respondents were farmers.

Just over half of the respondents (59\%) were aware of what caused climate change. They believed the warmer climate was the consequences of human activities. However, one individual argued that climate change was a natural occurrence not related to human activities; as respondent FLAC3 explained: "The weather is getting hotter. I think it is naturally warm". The others asserted that human activities such as population growth, deforestation, industrial activities, and smoke from vehicles and factories led to increasing levels of greenhouse gas emissions and the depletion of the ozone layer, contributing to climate change.

Nonetheless, one individual who believed that human activities were emitters of greenhouse gas into the atmosphere did not believe that deforestation in Takeo province contributed to the warmer climate. He explained that the trees in his community area were growing a lot more than in the past, so it was other factors not deforestation that caused variation in the climate pattern. In contrast, around $67 \%$ of respondents who believed that climate change was the result of human activities claimed that deforestation and greenhouse gas emissions from vehicles and industrial activities were the primary cause. They were aware of these causes from the media, from other people and from climate change programmes operated by government or NGOs. They understood that forests store $\mathrm{CO}_{2}$, and that this gas is released into the atmosphere once the trees are cut down. In addition, more garment factories were built close to this region. This increased the greenhouse gas emissions from factories and vehicles that transported products in and out. In short, the community participants had different opinions about the causes of climate change, but the majority thought that human activities were the main cause, as shown in Figure 11. 


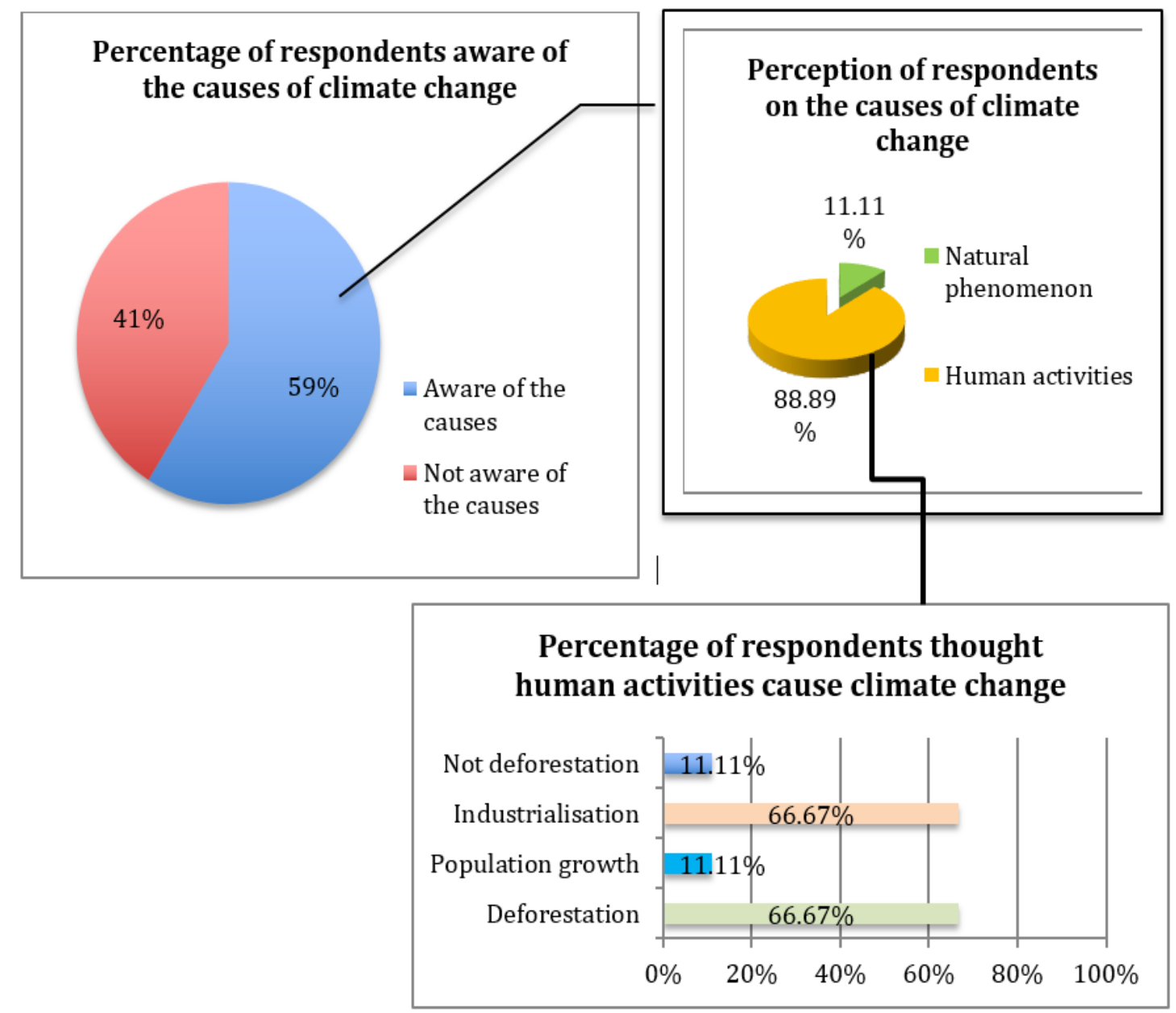

Figure 11: Perception of respondents on the causes of climate change Source: The author, with data of respondents' responses

\subsection{The effects of the risks on participants}

The community indicated that climate change had serious consequences on their families and livelihoods. The issue has not only caused negative effects on individuals but also on the community and on the environment. The impact of climate change on this community as described by community members can be classified into four main categories: (1) impacts on the environment and ecological system, (2) impacts on individuals and community property, (3) impacts on human health and living and (4) impacts on livelihood practices in the community. 


\subsubsection{Impacts on the environment and ecological system}

The review of literature indicates that climate change has negative effects on the environment and ecological systems by damaging fish habitats and reducing water quality and quantity (Elshemy, 2013; Perry et al., 2005; Taylor et al., 2013; Udmale et al., 2014), which the participants of this research agree with. The community members observed a reduction of fish numbers and water depletion in the study area. Some said that there were usually a lot of fish and frogs in the ponds, moving from the ponds or lakes into rice fields and small canals in the rainy season.

However, they noticed that there had not been so many fish or frogs lately. Some attributed this to ponds drying out in the dry season and killing the aquatic life. The loss of aquatic life is understood to be related to not only climate change but also human activity. Some farmers in the community used illegal fishing equipment such as electric catching tools that killed all fish in the ponds. In addition, they caught fish during the reproductive season which depopulates the fish life. Chemical pesticides that had previously been used on crops also killed aquatic life as well as contributed to greenhouse gas emissions during production. Some respondents mentioned that some farmers sprayed chemical pesticides on their rice and that the chemical substances flew into ponds and canals. This had poisoned and killed fish in the area.

Some respondents reported that underground water in the area was accessible only at deeper levels than it used to be due to the hotter climate. This has made the community concerned about whether the underground water will run out. According to Respondent MF10, to drill a well requires drilling up to 35-45 metres, or 50 metres in some areas, while five years ago drilling a well took only about 2530 metres. This was similar for other respondents too as shown in this comment by MCL6: "I had a well drilled in 2014 because it was so difficult to find water for my family to use. The company has drilled up to 36 metres deep to reach the water." In summary, many participants believed that climate change was having negative effects on local ecology and reduced the amount of water both underground and above ground. 


\subsubsection{Impacts on individuals' and community property}

Extreme weather events have not only affected the ecological systems of this community but also caused damage to infrastructure and community property. The local government officer (Respondent MLA1) witnessed flooding in 2013 that damaged a newly-built dam sponsored by the German Embassy in Cambodia. He mentioned that the dam was not only used for irrigating crops, but also as a means of transportation for rice harvests. As the dam was broken, the road that farmers used to transport their rice and rice straw, after harvesting, to their houses was also cut off. This created a difficulty for farmers who then had to take a detour to their rice field that was a lot longer. In addition, the paddy fields that lie along this dam were also damaged and the soil eroded, causing significant damage to the rice yields of farmers in the community. He added that because the damage was massive and required a lot of money to fix, the dam has not been mended yet. Although all research respondents have not suffered property damage from storms, some participants witnessed household damage and some broken trees in the region.

\subsubsection{Impacts on human health and living}

Besides the impacts described above, the warmer climate has also caused health issues, particularly for children, and other living difficulties within this community. Some respondents experienced climate change-related illnesses such as fever, thermal stress, and diarrhoeal and respiratory diseases. Some added that their children often suffered from fevers, colds and diarrhoea because they could not adapt to large and rapid changes in temperature. So (2015) also presented the same case concerning diarrhoea in children. Eight farmers (including three mothers) witnessed their children and grandchildren fall sick from fever, threatening their survival in the warmer weather. Even for those who did not get sick, the warmer climate affected their lifestyle. Many respondents complained that it was hard to sleep at night because it was still hot. As one female farmer said:

"The climate was so hot and this made me very stressful as well as feeling sick due to thermal stress. I could hardly do anything during the day because my house was 
made from coated zinc both roof and wall which was unlined and there was only one floor. Thus, during the day, I was not able to stay in the house, otherwise I could be cooked. Most of the time, I just rested under mango or coconut trees in front of my house" (Respondent FF13).

This reflects the findings concerning the impacts of climate change on health as studied by Haines and Patz (2004), who found that global warming has made people suffer from thermal stress and deaths. For instance, the heat wave in Chicago in 1995 caused more than 700 cases of heat-related deaths. The increase of $\mathrm{CO}_{2}$ will lead to air pollution and also increase the incidence of allergic rhinitis (hay fever). Haines and Patz (2004) added that climate change consequently increases infectious diseases such as dengue fever and malaria.

According the local government officer, climate change has also spread infectious diseases indirectly in Takeo. Respondent MLA1 explained that people in this region contract infectious diseases from using community ponds or wells. In the dry season, some wells and ponds dry out, forcing people to get water from other ponds and wells. Due to crowding and a lack of awareness surrounding sanitation, infection spreads easily. Furthermore, according to one of the community leaders, some children in this area experience meningitis due to high fever. Although this was the case throughout the community, some local government officers suggested that the boiling climate has not caused any deaths in the region yet, unlike in India where many people were killed by heat waves in $2015^{4}$.

In addition, climate change has caused emotional impacts on community members. All respondents were worried about their food, and some feared being killed by extreme events. As crop and livestock production were the major sources of income for families, damage to farming has created economic losses and caused villagers to worry about their livelihoods and feeding their families. The majority of respondents claimed that their production was only enough for household consumption, feeding poultry and to generate some surplus for selling to meet

\footnotetext{
${ }^{4}$ India was hit by heat waves in June, 2015. More than 2000 people were killed by this event while millions were waiting for rainfall. See detail: http://edition.cnn.com/2015/06/01/asia/india-heatwave-deaths/
} 
occasional expenses such as wedding parties, funerals or school fees. They added that if a prolonged drought lasted beyond October villagers would not be able to plant rice for the year.

In such circumstances, some respondents would need to borrow money from moneylenders while others would spend their savings to buy rice from the market for their own consumption and for animal-raising. Worry about sufficient water for consumption was also a related issue for all farmers in the community. One of the local government officers estimated during the interview that the ponds in the pagoda from which local people accessed water would dry out in a month or two. Luckily, some rain fell during that week, though not much.

Climate change was also affecting the respondents' living. The majority faced scarcity of water supplies for washing, cooking and drinking. Some participants noticed that between December and May during the last five years, the weather was so dry that some ponds and wells dried out with greater frequency. This forced the majority to find or buy water from other places for their own consumption and for the feeding of chicken and cattle. It was less challenging for participants to find water for poultry as they used small quantities of water, but cattle needed a lot of water for drinking and cleaning.

About 78\% of respondents have been facing problems finding water for drinking and cooking during the dry seasons over the last three years. "I have 8 water reservoirs that I stored water from last year, but I bought water from a trader one time because rain last week fell. The water cost me 2.5 US dollars" (Respondent MF17). In fact, some had invested in a personal water pump, but these were not be used for drinking and cooking because the water was acidic. "I cannot cook rice with water from the pump because the rice will change colour from white to bluish and the taste is sour as this happened before to my family. Only water from the wells can be used in daily cooking and drinking" (Respondent FLAC3 and MLAC4.)

Some participants were therefore forced to buy water from the local trader, while others transported water by themselves from other places. In short, they wasted time and money getting water. "As my house is not so far from the pagoda, I spent 
around 30 to 50 minutes to transport water from the pond in the pagoda to my house. I have done that a few times, but sometimes I bought from a trader because I was busy" (Respondent MF9).

Despite this, three farmers emphasised that they have not had a problem finding water yet, because their houses were situated close to community wells and ponds, and personal ponds that had not dried out yet. One had 10 water jars to store water for family consumption and a pond (about $4 \mathrm{~m} \times 6 \mathrm{~m} \times 2 \mathrm{~m}$ ) in front of his house to be used for animal and daily cleaning. His house was also situated close to a community pump (about 100 metres away). However, the water in his pond had about 30-50 centimetres left at the time of interview after a light rain two or three days before. The other two farmers (one was the local water trader) also lived close to the pagoda where other farmers were accessing water.

According to some participants, climate change also led to conflicts amongst water users in the community which was the case for Chinese farmers too (Jianjun et al., 2015). Respondent FF15 also described a conflict between water users in the community; "There was a family in this area who have spent money to have mud cleared out of the community pond located in their territory because no one was willing to pay for that. After that they stopped allowing other people to use the pond, since no one contributed to the clearance. This has caused some conflicts with their neighbours, because those families got angry that they were not allowed access anymore."

Extreme weather events such as warmer climate, more frequent and severe storms, and lightning also made some participants anxious and worried. Some respondents were concerned about their property being damaged. In addition, they feared being killed by more frequent and fierce storms and lightning, as mentioned earlier. Several participants complained that they almost could not stand living with this level of warm weather. 


\subsubsection{Impacts on livelihood and food security of the community}

Climate change has also been felt to have many negative effects on the agricultural productivity of the community that might lead to food insecurity. All participants were facing water shortages for agriculture, damaged crop and livestock production, and income losses. The community indicated that the impact on cropping includes delayed planting times, retarded crop growth, sometimes an inability to grow, and a reduction in overall crop yields. Variation of rainfall has had serious impacts on crop farming for this community, as all of their paddy fields were rain-fed. The delay of the onset of rain due to the El Niño effect has been strongly felt during recent times.

All respondents noticed that this phenomenon has delayed growth in crops such as rice, watermelons, pumpkins, cucumbers, green beans, long beans and other vegetables. In addition, some participants were not able to grow early crops, which they normally planted in April. Some explained that normally some rain fell in March and April enabling them to grow early rice. They usually harvested early rice in July or August, before transplanting to the later rice.

However, this routine has shifted due to droughts and some were not able to grow rice or other crops such as watermelon, because no water source was available for irrigation. As Respondent MCL6 described the situation of his late-planting watermelons: “Generally I started harvesting watermelon but this year, I have just started growing it because light rain just fell in May. If you were to research over the last five years, you would see how green this area was."

Besides postponed planting, drought reduced the production yield of fruit trees and other crops. One individual consistently described how climate change caused damage to his fruit plants. He mentioned that the prolonged droughts and the increase in soil temperature have had an influence on the growth of trees around his house. His mango and coconut trees died because he could not afford to irrigate them. According to Respondent MF17, his rice yield would decrease by $20-30 \%$ under moderate prolonged drought conditions, similar to Chinese farmers who lost around 34\% of grain yields (Jianjun et al., 2015). In addition, one participant 
complained about the severe loss of early rice crops over the last three years due to drought.

"During the last three years, I have planted early rice on about 0.2 hectares of paddy field, but I got only around 15 to 20 buckets of paddy (roughly 150-200 kilograms) because there was not any rain. You [Visal] can see how dry this area is now, and there is not any water in the canal at all. Three years ago, I got around 60 buckets of paddy (about 600 kilograms) on this field for early rice production. Thus, this year I did not grow any early rice crop, because of that. Instead I worked as a construction worker, because this was a good earning too" (Respondent MF5).

El Niño, which was a complex phenomenon, causing both droughts and floods, had strong impacts on other crops such as watermelon and pumpkins, causing huge yield losses. Vegetables such as pumpkin and watermelon were easily damaged due to either little or too much rainfall. As one respondent described his planting situation watermelon:

"This year, after a little rain that just wet the soil in May, I planted watermelon in the paddy field, because I thought there would be another rain as usual that would provide enough water for the crop. For a while after that, unfortunately, it dried again which damaged some of it. Luckily, rain fell and the watermelon grew, and now it was flowering and fruiting. I was not sure if it would be harvestable because rain fell often too during the last three days although it was not heavy. Now [while interviewing], the rain was heavy, I hoped it would not be flooded in the watermelon field, otherwise the fruits would be damaged because watermelon required just a little water when it fruited. If this would happen and completely damage the fruits, I wasted the 10-15 US dollars on seeds and fertiliser. This is not to mention my time preparing the soil" (Respondent MF17).

As the Respondents MF5 and MF17 mentioned, they did not only lose income, but wasted time, labour and money on watermelon seeds under drought conditions. They spent around two to three days preparing the soil for planting rice and other vegetables in addition to one to two weeks sowing seeds and transplanting. This was not to mention their time collecting and preparing natural fertiliser. According 
to Respondent MCL6, drought presented big challenges for his family in extending farming production:

“This year, I grew less than 0.1 hectare of spinach because it was too dry to grow in a bigger plot and I do not have enough water to irrigate the plot. To irrigate spinach, I use water from a well that my family also use for everyday life. For this reason, I cannot use all the water from that well to irrigate crops otherwise my family need to find water from other places for daily use."

The respondents faced not only crop damage but also a shortage of feed for their livestock. Some farmers explained that soil became very dry, resulting in not enough grass to feed cattle and chickens. They usually raised chickens in the rice field (only putting them into cages during the night). These poultry ate grass and insects as a source of protein. Several participants noticed that recently there was less grass and fewer insects for chicken-feed due to the drier conditions.

Many respondents added that their cattle had often had insufficient food recently, because of little grass and rice straw. They explained that their rice straw had been reduced because of damage to rice planting. Furthermore, rice straw was produced less because their rice planting technique had changed from transplanting to sowing. The change in technique was because they had been forced to focus on other jobs to earn extra income (discussed more in Section 6.2.2). Respondent MCL6 reported his difficult situation in finding feed for cattle:

"The weather was so hot and the rice field was dried out, so that it was so difficult to harvest grass for cattle because grass hardly grew. Even when the rain fell in late May, some farmers planted casual crops such as pumpkin and watermelon while others were ploughing soil, preparing for early rice production. This consequently got rid of grass that I was usually able to harvest for my cattle. It was very difficult to find feed for cattle. Usually, rice straw costs nothing, but now six or seven cubic metres of it costs around 40 US dollars, which feeds a cow for only about 1.5 to 2 months. Interestingly, if you did not have any networks, you would not get any, because other farmers who produced surplus rice straw sold it among their own networks only." 
Some farmers also emphasised the outbreak of diseases and heat-related deaths among poultry. Some noticed that chicken and ducks often died during April when the temperature reaches $40{ }^{\circ} \mathrm{C}$. On the other hand, some indicated that their poultry died after the first rain during the dry season. Even though cattle have not suffered from heat-related stress, these animals have sometimes been killed by thunderstorms. According to Respondents MCL6 and MF10, in June 2016, three cattle were killed by lightning strike. The owner of the cattle sold the carcasses for 175 US dollars each, where they could be sold live for around 800 to 1,000 US dollars 5 .

All these impacts on rice, watermelon, and livestock (chicken and cow) production have reduced farmers' food security. The loss of fish due to global warming, discussed in Section 5.4.1, has affected the availability of protein sources and the food preferences of rural farmers in Cambodia. Although not all respondents raised fish for income, they conserved the wild fish to have migrated from the canal to their rice fields and personal ponds during the rainy season. Such fish offered a protein source for their family, in both wet and dry seasons, before the ponds dried out. Fish is an important source of protein that contributes to Cambodia's food security (Food and Agriculture Organization of the United Nations, 2014; Vilain, Baran, Gallego, \& Samadee, 2016). Of Cambodians' total protein intake, $37 \%$ comes from fish (Vilain et al., 2016, p. 27), while fish is also the most important protein source (80\%) for Cambodia's livestock production (Royal Government of Cambodia, 2013, p. 6).

\subsubsection{Impacts on income}

Since weather events have delayed and damaged the production of crops such as early rice and watermelon, as well as affected livestock farming, participants have lost income from these sources (as mentioned by Respondent MF5 and MF17). Respondent MF7 narrated the economic loss thus: “Over the last three years, my early rice crop was damaged and I did not harvest any at all. Usually, I get around 1,000 kilograms of paddy that I can sell at about 0.3 US dollars per kilogram"

\footnotetext{
${ }^{5}$ Andrew "Cosi", an Australian running a cow charity in Cambodia, told ABC News that he bought a cow in Cambodia for 700 US dollars (Australian Broadcasting Corporation, 2015).
} 
(Respondent MF7). In these three years, then, Respondent MF7 had lost roughly 900 US dollars of income from early rice planting. Income was also lost from cattle deaths in thunderstorms and from heat-related poultry deaths.

In spite of this, participants noticed that their later rice production during the last five years has provided slightly higher yields than previously, consistent with government data indicating that total paddy production in Cambodia has increased during the last five years (MAFF, 2016, p. 16). One respondent reported that his 2015 rice yield was about 10 baskets (150 kilograms) higher than in 2014. Some participants assumed that the increase of rice production was the result of improved agricultural techniques, such as increasing the use of natural fertiliser and compost, and deferring planting until after the July-August drought. Some projection models also indicate that within the temperature increase of $2-3{ }^{\circ} \mathrm{C}$, yields of some cereals, particularly wheat and rice, will increase; but they will decrease with 3-4 ${ }^{0} \mathrm{C}$ (Stern Review, 2006, p. 67).

Respondent FF8, who ran a grocery shop in the community in addition to rice planting, complained about very slow business. She indicated that once crops were damaged, people did not spend money on snacks as much as they used to, because they kept it for main food. She added that because their early rice was damaged, some people owed her for cooking ingredients and intended to pay later after harvesting the later rice. Additional impacts on income generation included participants having to spend money buying products that they had previously produced, such as animal feed. Some respondents spent money on rice straw and commercial feed for cattle and poultry due to a lack of available free feed. Moreover, since flooding rains had caused damage to vegetable gardens, they needed to buy vegetables from the market instead of being self-sufficient.

Some participants also commented on how warming temperatures affected their performance in non-agricultural jobs. Three participants who worked as construction workers (Respondent MF9; MCL6; MF5) in addition to farming complained about the boiling climate during the day; they were not able to continue work through the middle of the day. Respondent MF9 said: "It was so hot during the day, and I was not able to continue building houses for clients from 11.30 am to 
$2.00 \mathrm{pm}$ because the heat made me so sweaty and itchy all over my face and body. Importantly, the heat was so strong that it made me dizzy and unable to work."

In short, respondents witnessed a range of negative impacts from climate change. The impacts were on the environment, community property, their health, their living and their livelihoods, and particularly caused agricultural losses. Extreme weather events have affected the growth and reproduction of fish, reduced water availability, damaged crop production and infrastructure, and importantly reduced the income of farmers.

\subsubsection{Climate change as an opportunity}

Even though climate change has had many negative effects on the livelihood of those in the community, it has also benefited some farmers. For instance, Respondent MF14, who was the water trader (and also a farmer) earning some extra income from delivering water to other people in the community. He made more than 10 US dollars a day from this business. However, he needed to share a small part of his income with the monks as a contribution towards rehabilitating the ponds in the pagoda from which he transports the water. He used to be a motor-taxi driver and the income from delivering water was better than his previous occupation.

Respondent MCL6 also benefited from factors associated with climate change. As many people did not grow crops during the dry season, he sold some of the spinach and other crops that he grew at home. Community members bought from his garden every day. This has saved him time from taking his products to sell in the market. This means that climate change has also provided opportunity for some people to earn extra income in addition to their agriculture practices.

\subsection{Community attitude towards climate change risks}

All participants stated that they were very concerned about all climate change risks occurring in their community for several reasons. One reason was that these problems were causing many negative impacts on their health, living and income generation. In addition, these extreme events made them fearful and anxious. Another reason was that climate change seemed uncontrollable. Some respondents 
explained that climate change was happening globally and they were not capable of dealing with the issue. Although they have adapted to some degree, the damage was still intense and caused losses of income for them.

Since men and women shared responsibility in household and agricultural practices, both male and female respondents, as fathers and mothers, were most concerned about their household income and food supply. Although all were also concerned about their children's health, mothers exhibited stronger worries about their children's health and food than fathers: $40 \%$ of mothers stated they were very concerned about food and their children's studies as well as health and survival in a hotter climate, while around $16 \%$ of father participants expressed great concern for their children. As one male participant said: "I am strongly concerned about my grandchildren's health rather than my own life, because know that children (under five years old) are less able to cope with the fast changing climate compared with youth and mature persons like me."

When deciding which risk was of the most concern, each participant gave different responses. Although lightning strikes were not considered the most likely events to affect community members, all participants exhibited great fear of them all the same. One respondent said that he was most concerned about the increasing temperature because he was scared after seeing many people in India killed by heat waves in 2015 .

"I am very concerned about global warming because I saw in the television programme that many Indian people were killed by a heat wave in 2015. This made me so shocked and scared. I cannot imagine how horribly painful and difficult for those people who were killed by this heat wave. I really do not want to this happen to me or my family" (Respondent MF12).

Two participants (one female) also stressed that they were most concerned about storms because they had seen on the television, and heard through other media, that storms were becoming violent, damaging houses and causing death. The female respondent said she was afraid that a storm would hit and destroy her newly-built house which she had saved money for years to build. 
Among all the climate change effects occurring in the community, prolonged drought was the most concerning issue, as ranked by $82 \%$ of respondents, because it had direct and major consequences on their living and income generation. Droughts occurred more frequently and lasted longer, even drying out ponds, forcing people to find water from other places. This consequently damaged crop production and affected animal-raising, the major sources of income and food for these families. Thus, many were frightened that they would starve as a result of the impacts. To sum up, farmers are more concerned about effects that risk serious damage to their food security and income on a daily basis. However, some also considered risk of effects which are severe and instant such as lightning.

\subsection{Community perception about climate change in the future}

Because most participants have only noticed climate change in the last five years, I continued to question them about how they perceived the risks of such changes in the next five to ten years. Around $80 \%$ of respondents said they did not know whether the risks were getting worse or better. They explained that they did not know whether the earth's average temperature would increase or decrease in the future because they had no means by which to monitor or predict. In addition, they believed that only scientists can predict or understand the trends associated with these risks. This clearly indicates that most respondents are not aware of climate science globally and did not have access to information about the trends or implications of climate change in the future. Awareness was based on their own experience, and some information from the local news, media and other people, rather than academic research.

The rest of the participants (20\%) believed that the risks of climate change would continue to be triggered because human action cannot be stopped. One participant explained that the industrial revolution would not be slowed down. Industrial countries would not stop producing technological products, as this boosts their economic growth. Similarly, human beings whose lives depend on technology would never give up their lifestyles. On account of this, one respondent was sure that the impacts of climate change would get worse and worse. Having said that, he 
felt that if there was any solution or pressure from powerful organisations to stop these activities, global warming would be reduced. However, he thought that this was highly unlikely. In brief, very few respondents in Takeo were aware of climate change scenarios in the next five or ten years. The majority indicated uncertainty about future climate change.

\subsection{Chapter summary}

This chapter detailed how the community in Takeo province perceived and described climate change risks. A summary of the findings can be found in Table 4. Respondents have witnessed several extreme climate events in the area, for example increasing temperatures, prolonged drought and flooding rains. Although the participants live within the same community and area, their views on climate change are different.

Not many have noticed these extreme events until the significant variation during the last five years. The majority of participants, who were aware of extreme weather events in Takeo, believed that climate change issues were caused by human activities such as deforestation and greenhouse gas emissions from industrialised factories and vehicles.

Table 3: Summary of perception of risks and impacts 


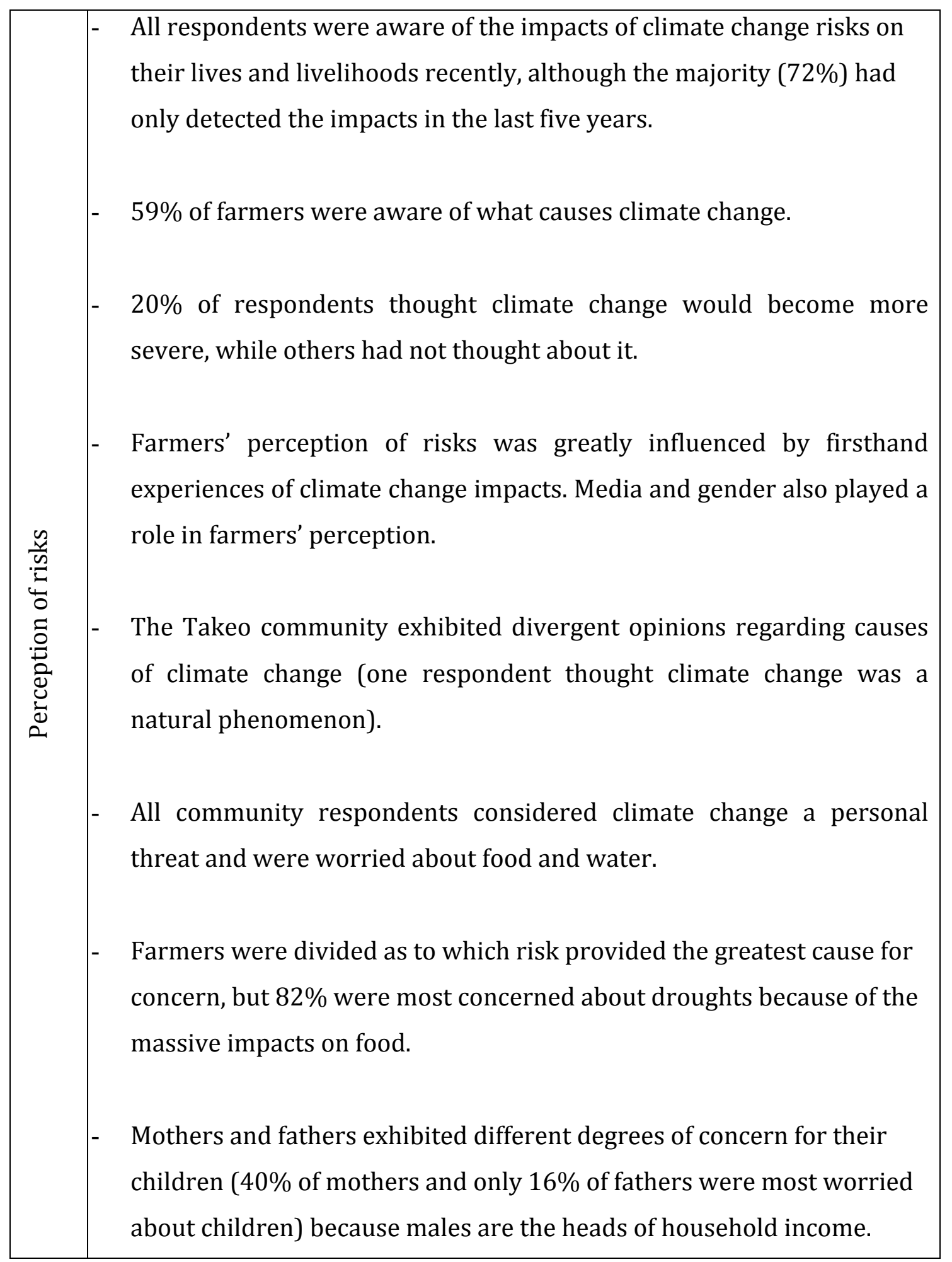




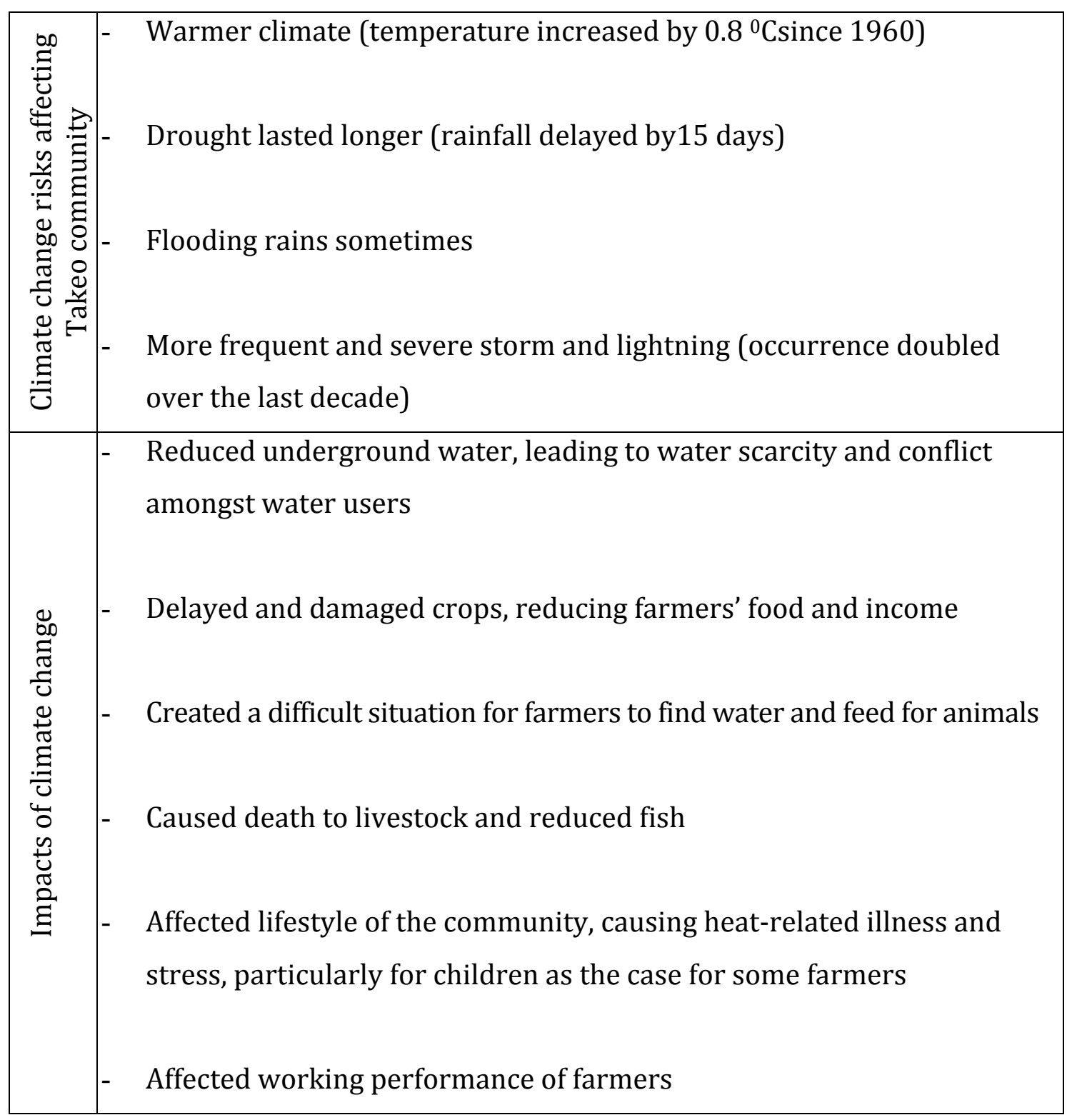

Climate change events have impacted the community intensely. Prolonged drought and late rainfall have caused difficulties in finding water for consumption and agriculture. Consequently, community participants have lost income from farming and spend a lot more money to buy vegetables, spending money and time on agriculture when it was damaged by weather events. Extreme weather events have also generated much concern for the studied community. The study indicated that mothers exhibited more concern for children's wellbeing than fathers. The majority of respondents indicated that their greatest concern lay with prolonged drought above any other risks because such events caused direct damage to livelihood practices. However, fear and exposure to information around climate change risks also influenced the way people perceived which risks were of most concern. 


\section{Chapter 6: Community behaviour towards climate change risks}

\subsection{Introduction}

This chapter explains community behaviour towards risks through summarising the responses of the community in Takeo to the climate change that has been perceived. The previous chapter showed that the Takeo community has suffered a great deal from climate change, particularly from prolonged droughts, but that they have limited awareness around this issue. This chapter, therefore, looks at behaviour changes in the community, in terms of responding to the risks posed by these extreme events. The chapter answers questions 4 and 5 of the research. The chapter is structured based on two main themes. The first part describes the responses to climate change of individuals and the community. The second theme moves towards policy implementation and the behaviour of this community in dealing with climate change. This investigation will help evaluate the challenges that this community has faced in adapting to and mitigating climate change impacts.

\subsection{Role of community in climate change policy}

Community leaders have assisted local government in motivating community members mitigate and adapt to climate change. One community leader (Respondent MLAC4) pointed out that local government was planning to grow 10,000 trees in the school area of the community, so that children can have a cooler place to rest and study. Furthermore, they have motivated farmers to protect forests and trees in the community. The community also motivated its members to reduce using chemical fertiliser and pesticides to reduce greenhouse gas emissions.

Additionally, the Takeo community assisted local government in disseminating information about extreme weather events and adaptation strategies to the farmers. Several respondents noted that local government and community committees had been recently disseminating information about the changing environment such as droughts and storms. They reminded respondents to conserve water and collect rainwater as well as to share water with each other. Importantly, they have asked people to take more care of children, the most 
susceptible group to the increasing temperatures. The government has also provided emergency responses to the shortages of water in the area. Respondent MF12 reported that in 2016, because the drought conditions were so strong, the government prepared ten trucks to transport water from other areas to the people living here. In fact, these trucks had already delivered some water to schools in the community, also suffering from insufficient water. However, farmers in this community had not received this service at the time of interviews because they were able to find water in the nearby ponds or wells (Respondent MLAC4).

In the agricultural sector, the local government reported that they have also sought funding support from the national government, NGOs and other aid agencies to build dams, canals, community ponds and wells. For instance, in 2012, three community ponds and one dam were built with sponsorship from the German Embassy in Cambodia (Respondent MLA1). In addition, technical agricultural training had been provided to the community through cooperation with NGOs such as the Centre for Education and Development in Agriculture in Cambodia (CEDAC) and the Ministry of Agriculture, Forestry and Fishery (Respondent MLA1). These organisations have provided training about rice transplanting techniques that use fewer rice seeds and are more suitable for prolonged drought. They have also promoted ecological agriculture techniques to the community by teaching them how to make compost and carry out better animal husbandry.

\subsection{Individual responses to climate change}

The previous chapter identified several risks posed by climate change in Takeo such as increasing temperature, fluctuation of rainfall patterns, prolonged drought, flooding rains, storms and lightning. Aware of the direct impacts which extreme events are having on their community, all the respondents have tried a variety of adaptation strategies to improve their climate-resilience. Even though the participants have different levels of understanding about climate change, their responses are similar. Respondents have discussed and shared information and responses with each other. In addition, they tended to follow those farmers who demonstrated better adaptation responses. 
Community participants not only adapted to climate change but also contributed to the reduction of greenhouse gas emissions. Mitigation measures include using biodigesters and organic fertiliser that reduces carbon emissions compared to chemical fertilisers. According to one community leader (Respondent MLAC4), roughly $8 \%$ of people in this community had a biodigester and used the energy from converting animal manure for cooking and lighting Adaptation strategies practised by individual farmers were categorised into two groups, adaptation for daily life and adaptation in agricultural production.

\subsubsection{Adaptation in daily life}

The adaptation strategies used by individuals included mitigating heat-related stress and protecting themselves from storms and lightning. Participants protected themselves from lightning strike by avoiding going out in the rain and instead staying in their houses or somewhere safe during thunderstorms. One participant said he was so scared on one occasion, that he stopped his motorbike and stayed under a cottage, or at another farmer's house.

One respondent (Respondent MF10) also reminded his sons and daughters not to play in the rain or collect rainwater even though some of his water jars were empty. This was because thunderstorms and lightning were considered so severe that they could cause death. In addition, several participants mentioned switching off electronic devices such as televisions and telephones when there was rain. Some participants also cut back the trees around their houses to avoid damage from storms and thunderstorms.

As the temperature in this area had reached over $40{ }^{\circ} \mathrm{C}$, all participants had developed several techniques to live in this heat. During the day, some participants described taking more showers to cool down; those who did not have enough water used a wet towel. In addition, some mentioned resting or finding cooler places during the day such as under a tree or on the ground floor of the house to avoid being cooked on the top floor where temperatures were too hot. The majority of farmers also indicated using fans to cool down. Several participants 
stressed that it was very hot, not only during the day, but also at night; these families would use fans overnight without which they could not sleep. Even though these techniques did not make significant improvements, they were helpful to some degree and practical. Besides these simple measures, many did not have any strategy to deal with extreme heat; many could not afford to restructure their houses to make them cooler or to purchase a cooling machine such as an air conditioner or hydro fan.

Addressing water shortages, participants increased water storage and reservoirs. All community participants had increased water jars (Image 3) to store rainwater for drinking and cooking. According to one local authority, each household now owned at least five water jars while they had only had one or two in the past. One participant witnessed that his family had increased up to nine water jars. Several participants had invested in drilling a well or digging a pond as an adaptation strategy during prolonged drought. Two respondents drilled a well in 2014 for pumping water for daily use such as cleaning and showering, as well as for irrigating crops (in home gardens) because they often did not have enough water during the dry season. A couple of participants had a pond dug in the last two years. Two participants cleaned mud out of their ponds every one or two years, enabling the ponds to store more water.

In addition, all respondents tried to save and use water more effectively. Participants claimed that they had tried to use as little water as possible. Some commented that instead of cooling down by taking a shower, they cooled their bodies with wet towels. All participants had also separated cooking water from water for other uses. They identified collected rainwater for cooking and drinking only, believing that rainwater was safer than either acid water from wells or unclean water from ponds where they raised fish and allowed ducks to get in.

Some participants pointed out that had also requested water from neighbours and nearby ponds as response strategies. Buying and transporting water from other water sources was another strategy that many respondents had used to ensure they had water for consumption. The respondent who was the trader of water from the pagoda said that he had been operating this business since 2014 by 
realising the potential benefit of this. He said the demand for water was high, because many people did not have enough water from February to May or June.

\subsubsection{Adaptation in livelihood performance}

Detecting economic losses from the devastating impacts of climate change, the Takeo community had developed several adaptation strategies to maintaining food security and income generation through improving production yields and increasing off-farm income. Adaptation strategies in on-farm activities included improving agricultural production techniques, adjusting planting dates and using drought-tolerant seeds.

All participants have changed rice planting techniques from traditional methods to SRI because they believed SRI provided higher yields and used less water than traditional methods. SRI was introduced by the government and NGOs under the climate change programme discussed in Section 4.6. Traditionally, rice seeds were sown in nurseries for about 45-70 days. Seedlings were then transplanted from nurseries to rice fields in a bunch of seedlings (about four or five seedlings for each transplanting time).

During the last 10 years, the community had shifted to SRI practices in their rice farming. With SRI techniques, rice seeds may be sown in nurseries for about 15-30 days before being transplanted to rice fields. Moreover, rice seedlings are transplanted one by one (though some used two seedlings each transplanting time). SRI requires less and less rice seed but provides a much higher yield compared to the traditional practice ${ }^{6}$. Traditional techniques provide around 2 tons of paddies per hectare whereas SRI provides at least 3 tons. Importantly, the alternative techniques also save farmers time in planting rice (both sowing and transplanting).

\footnotetext{
${ }^{6}$ System of Rice Intensification (SRI) is a cultivation technique that transplants few young seedlings, but provides high yield due to better crop growth (Lhendup, 2008; Uphoff, 2015). One seedling grows better than many because it absorbs nutrients better.
} 
Likewise, all community participants have adjusted their planting schedules based on forecast and actual rainfall, rather than planting rice based on their calendar, as they used to do. They have improved access to mass media such as television and radio, or they may ask others with access to weather forecasts, such as local authorities and other farmers in the community.

Weather forecasts are important for respondents as they prepare for crop planting. At the time of writing (2016), all had outlined their scheduled rice planting based on the weather forecast. For instance, in June 2016, the majority pointed out that they had not started their later rice farming having heard from the national weather forecast that there would be a short drought in July and August. Thus, they planned to sow their rice seeds in seedbeds in early or mid-August so they could transplant the seedlings in September when rain was due to fall.

Another adaptation technique used for crop planting was to begin farming rice in the paddy fields closest to water sources. One respondent pointed out that he would start producing rice in the fields that were closer to ponds or canals than other fields. If a drought occurred after rain he would be able to drain the remaining water from those water sources to irrigate the crops for a short while. Moreover, some participants had also grown vegetables such as pumpkin, watermelon and beans on rice fields which were close to their houses and ponds or wells. This was for a similar reason: it is easier for them to grow on this field than on ground further away from a water source.

To reduce the risk of crop damage, all community participants in the region used varieties which consumed less water and provided higher yields such as IR66 and Sen Pidor, varieties that were introduced by the government and NGOs. IR66 and Sen Pidor are early maturity varieties which take only about 105 to 120 days from growing until harvest (Cambodian Agricultural Research and Development Institute [CARDI], 2002b, p.1; 2005, p.1). The respondents usually grew IR66 and Sen Pidor as early rice before growing medium or late maturity rice (between April and July). These varieties took less time to grow and required only a small amount of water, with less susceptibility to drought than other types. 
Recently, due to drought conditions lasting longer, respondents had shifted from late maturity varieties that take longer than 150 days (from growing to harvesting), to medium maturity varieties such as Pka Romdoul that take about 120 to 150 days from growing until harvest. These varieties are medium sensitive to photoperiod flower which means that they only flower after mid-October (CARDI, 2002a, p. 1; 2005, p. 1). However, they still grew late maturity rice in some paddy fields because these varieties grew better in heavy rainfall and flower after mid-November (sensitive to photoperiod flower) ${ }^{7}$. In case of heavy rain in October or November, these varieties would still provide a good yield.

Using natural instead of synthetic fertiliser was another technique that the respondents had been carrying out in rice planting. Although they were not aware that chemical fertilisers emit greenhouse gases, all of the respondents believed that the organic fertiliser was better for crops and soil and more economical than synthetic ones. They added that compost or animal manure was also free because they raised cattle themselves for ploughing rice fields.

The benefits of natural fertiliser included that in case of drought, natural fertiliser did not burn the seedlings like chemical fertilisers did. Nutrients in animal manure, or slurry from biodigester plants, stayed longer in the soil than chemical fertiliser. If droughts occurred after they applied natural fertiliser to the paddy field, the nutrient remained in the soil to feed the seedlings. Each respondent had reduced fertiliser use by 50-100 kilograms per hectare of rice land. One respondent had gone completely organic.

"I have done chemical-free agriculture for about six years already by replacing synthetic fertiliser with compost, natural fertiliser and slurry from my biodigester. I had this biodigester constructed in 2014 because it is hard to find wood for cooking. Importantly wood is more expensive than it was. I have realised that slurry is better quality than fresh animal manure because animal manure is limited in its use, as it will burn the crop if I use synthetic fertiliser too much. Unlike

\footnotetext{
${ }^{7}$ For a hectare of paddy field, different varieties of rice require different levels of water in the field.

- $\quad$ Early maturity varieties require $262 \mathrm{~mm}$ of water from growth to harvest

- $\quad$ Medium maturity varieties need $332 \mathrm{~mm}$ of water from growth to harvest

- $\quad$ Late maturity varieties need $407 \mathrm{~mm}$ of water from growth to harvest
}

(Men, 2007, p. 26) 
animal manure, slurry will not burn the crop; also it does not smell awful. The gas from animal manure is converted to energy so that I do not need to find or buy wood for cooking” (Respondent MCL2).

Additionally, all respondents grew other crops in the dry season (before early rice production) to cover the rice fields. This reduced soil degradation and helped provide extra income. They understood the benefits of covering soil with other crops from the climate change programmes run by the government and NGOs. Instead of keeping the soil unplanted, all grew crops such as mung beans, long beans, pumpkins, watermelons, cucumbers, corn, eggplants and other vegetables on the rice fields.

Some also rotated bean crops with corn or other vegetables. They grew beans and corn instead of planting early rice in some paddy fields to get extra income or to use in animal husbandry if the drought lasted longer. "I grew beans in one of my paddy fields this year. If the weather is not too dry, I will harvest the yield for selling and the residuals for feeding cattle. If it is too dry to get any yield, I will harvest the beans for feeding cattle, so that I do not waste money and time getting grass for cattle" (Respondent MCL2). Doing this not only generates extra income but also reduces soil erosion and improves soil quality for later rice planting.

As climate change impacts were severely damaging, reducing crops, the majority of respondents could not depend on rice production as their only income. For this reason, off-farm income was seen as an alternative source that many had used to increase their livelihoods. Besides growing crops and feeding poultry and cattle, the participants or their family members considered doing other jobs such as garment production and construction work. Thanks to garment factories built close to the community, many were employed by this industry nowadays. Each worker earned the minimum salary of 140 US dollars a month. This amount of money enabled them to buy food and water for consumption. For instance, Respondent MF10 indicated that his wife and daughter had been working for the garment industry and earned around 280 to 380 US dollars a month. With this salary, plus his salary as a local government officer, his family would survive without agricultural work. They were considering resting from planting rice 
because drought conditions seemed to last longer. Likewise, in addition to agricultural farming, three participants had been working as construction workers to earn additional income for their families. As the work was not paid per hour, they worked as contractors on a fixed price basis.

The Takeo community also collectively save and lend money within their community. This was introduced and coordinated by the government and NGOs under climate change programmes. The money earns interest and reduces borrowing from microfinance organisations, stopping cash flowing out of the community. The community had a social budget for providing mutual help to people in the community in case of an emergency.

In summary, individuals have made a variety of efforts to adapt to and mitigate climate change impacts. Farmers also contributed to reductions of greenhouse gas emissions through using biodigesters and decreasing the amount of chemical fertiliser in planting rice and other crops. Regarding adaptation, participants increased their adaptability to increased temperatures through resting under trees or cleaning their bodies with wet towels. As droughts are the highest concern for the community, they have focused on improving their access to water by collecting rainwater, improving ponds and wells, and accessing water from nearby ponds. In addition, they have improved cropping techniques by rotating crops and transplanting younger and fewer seedlings of rice. The community was also diversifying its livelihood strategies from simply growing crops, to gaining income from off-farm jobs such as garment work.

\subsection{Community adaptive capability climate change}

As climate change is occurring globally and causing many problems for many people, particularly those living in developing countries, dealing with the issue is critically important. Even so, responding to the problem requires a lot of effort. Although the community studied here has carried out some measures to cope with climate change, several challenges existed, including limited support from the government, low income, lack of cooperation within the community, and the great impacts of climate change itself. This made it difficult for the community to mitigate the impacts. 
One of the challenges for this community in responding to climate change impacts is the limited budget of both local government and the community to improve community capacity to become more resilient to climate change impacts. Addressing a prolonged drought requires the community to construct dams and irrigation systems that can supply water for crop production both in the dry and rainy seasons. However, the development of irrigation systems and reservoirs requires time and resources (human and capital) and this is not affordable for Cambodia (Khmertimes, 2015).

A government officer at the Ministry of Environment (Respondent MMoE18) observed: "The Cambodian Government has strongly focused on addressing climate change problems but, due to limited budgets and the high cost of projects, they were rarely implemented. Cambodia is still a developing country and the government struggles to afford to build adequate infrastructure". Yet it was also very difficult for the community to build such infrastructure on their own to secure their rice production. Respondent FLAC3 estimated that improving a community pond would cost around 4,000 to 5,000 US dollars, which was not affordable for the community.

Another challenge to improving the community's adaptive capacity to extreme weather events is the requirement of unaffordable technology and equipment such as air-conditioners and fans. Farmers in this area were considered poor, as they earned less than 1,158 US dollars a year (World Bank, 2015). On account of this, it was not easy for them to purchase 200 to 300 US dollars of equipment. Such equipment contributes to greenhouse gas emissions, and importantly requires sufficient electricity to run. And yet $82.8 \%$ of Cambodians did not have access to electricity in 2012 (RGC, 2013, p. 6). Electricity is also often cut off during the day due to insufficient supply versus high demand. Moreover, although the government would refund 150 US dollars as an incentive for farmers in the area to construct biodigesters, not many farmers have able to build such plants. Since even the smallest biodigesters ( 2 cubic meters) cost about 450 US dollars, farmers need to pay 300 US dollars by themselves. Moreover, this sized plant can provide only one or two hours of gas for cooking and lighting which is not sufficient for a big family. 
Besides the limited budget of the community to purchase such technology, an inability to produce varieties of tolerant crops is another challenge farmers faced in mitigating the impacts of climate change. To grow crops in a changing climate requires scientists or agronomists to produce crop varieties that are resistant to drought conditions. As Cambodia does not possess advanced technology to develop these varieties itself, this does not seem to be achievable. Even though farmers grew varieties such as IR66 and Pka Romdoul which use less water, these varieties were not tolerant to drought conditions, and can survive only 7-10 days in flooding condition (Chan, 2011, p. 16)

Although some farmers commented that local government has disseminated information about average temperature and climate change events, they had not been told how to deal with the problems. In addition, the local government officer indicated that some community members were not interested in information that was disseminated and did not even attend the village general meetings that discussed climate change. One male and two female farmers said that the government had disseminated climate change information to them, but they were not interested.

Lack of cooperation and responsibility also presented a challenge for this community to respond to extreme climate events. According to one participant who lived close to one of the community ponds, some people in this area did not show good cooperation. Some of them did not show high responsibility for communal resources. Respondent FF15 gave one case:

"The pond situated in the east of my house is the community pond. Around 8 to 10 families have used this pond. It was very shallow because no one has led or proposed to local government to clear the mud out of this pond for many years, so it always dries out in late February or early March. I was not able to pay for that" (Respondent FF15).

Since this pond did not belong to her, her family did not seem to show commitment or willingness to clear the mud out of the ponds when they had free time. She also 
expressed feelings of uncertainty to do so herself because she said it should be the responsibility of the community not hers alone.

\subsection{Chapter summary}

This chapter described response strategies to climate change practised by the Takeo community. The study found that farmers have been practising a variety of mitigation and adaptation approaches both at individual and community level. At the community level, local government has improved irrigation systems such as dams and canals. The government has also cooperated with the community and some NGOs to promote and disseminate information around climate change impacts, adaptation and mitigation to farmers. Many projects related to climate change have been raised in the communal plans and given priority. This chapter has also described the influence of community perception of risks on climate change policy efforts. However, not many projects related to climate change were implemented due to limited budget of the government.

To reduce greenhouse gas emissions, some farmers have used biodigesters and reduced the amount of chemical fertiliser and pesticide used in crop production. Adapting to a hot climate, participants have used fans, taken showers and rested under the trees. In agricultural production, farmers used some adaptation measures such as SRI techniques, rotating crops and planting drought tolerant varieties of rice. They have also improved water access and storage through increasing water jars.

Moreover, they increased their incomes from off-farm activities such as construction work and garment work at the industrial factory. Although the community has been responding to climate change, some challenges have emerged which have created further difficulties as the community struggles to mitigate the impacts. Limited budget from the government and the community to build improved irrigation systems and the unaffordability of advanced technology such as hydro fans were seen as one of the challenges. Moreover, farmers did not seem to exhibit a strong commitment or responsibility to addressing climate change 
personally. Adaptation in the agricultural sector by individuals was challenged by an inability to produce a variety of crops that are tolerant to droughts.

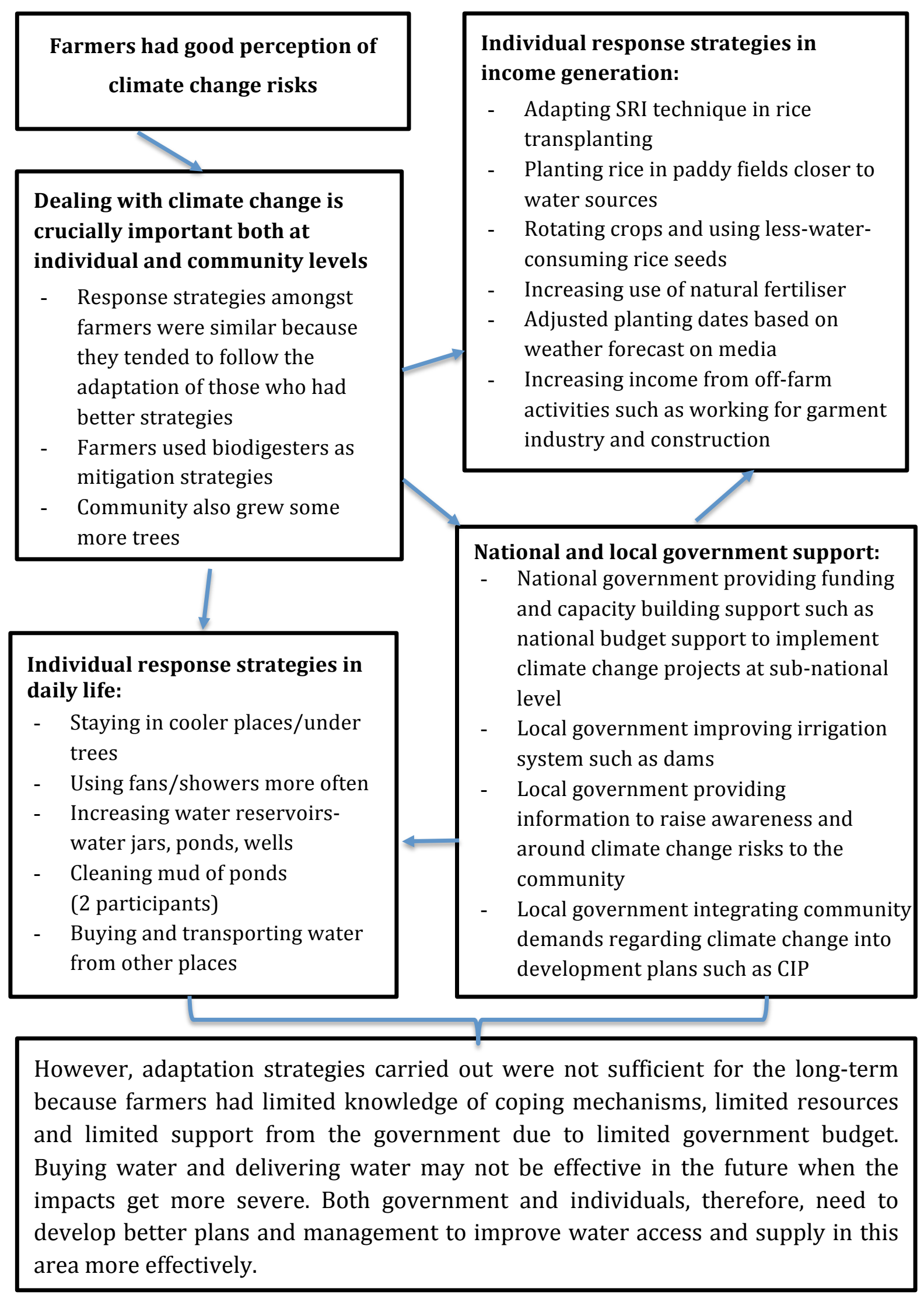

Figure 12: Summary of responses to climate change 



\section{Chapter 7: Results and Discussion}

This chapter firstly discuss the perception of risks posed by climate change amongst farmers in Takeo in relation to the previous literature. It will also examine how individuals perceived the same risks differently and why they considered risks in a specific and different way from each other. The second part of this chapter will discuss how the perceptions of risks in the community shaped their adaptation strategies. Finally the chapter explores how perceptions of risks have an impact on behaviour response, and potentially on the adaptation and mitigation policy of the country.

\subsection{Perceptions and attitude towards risks}

The results of this study suggest that Takeo's community had a good perception of climate change although they had limited understanding of the complexities of the issue. Furthermore, even though the community shared a similar cultural background and language, perceptions of risks varied within the community. Individual perceptions of risks were influenced by factors including personal experience, access to information, gender, and involvement of participants in development programmes provided by government and NGOs. Personal observations and experiences appeared to be the main factor in determining farmers' perception of risks and their judgement of which risk was the most concerning.

The Takeo community had little technical or scientific knowledge of climate change. Although climate change is increasingly regarded as the biggest challenge to development in every country around the world, nearly half the farmers in this study were not aware of the causes of climate change. Importantly, the majority were not aware that the impacts of global climate change will worsen unless urgent actions is carried out to reduce greenhouse gas concentration in the atmosphere in order to keep temperature rise to below $2{ }^{\circ} \mathrm{C}$. Thus, the Takeo community had little understanding of the global scale of climate change, nor did they have access to much information or literature around climate change such as academic articles, policy, public debates and discussions. 
In spite of their limited awareness of climate change globally, the community had a good perception of extreme weather events. Farmers were well aware of the impacts and severity of extreme events, such as prolonged droughts and floods, on their lives and livelihoods, mostly from personal experience and partially from information received through media, peers and local government. Some farmers had personally observed changes in environmental patterns in Takeo over the last 30 years. Farmers in the community were able to judge climate change by comparing the recent climate in the area to that of the previous five or ten years through observation and experience. All respondents believed that environmental conditions had changed dramatically over the last half-decade and caused many negative impacts. Prolonged droughts were ranked as the most severe risk posed by climate change because these occurred frequently and caused the most direct and greatest damage to farmers' agricultural productivity, particularly to rice planting.

The results of this research therefore reinforce the findings of previous studies which explored the perception of climate change risks amongst farmers in Ethiopia, South Africa, Norway, China and India (Bryan et al., 2009; Jianjun et al., 2015; Lujala et al., 2014; Senaratne \& Scarborough, 2011; Thomas, Twyman, Osbahr, \& Hewitson, 2007; Udmale et al., 2014). These studies indicated that most respondents perceived the changes of weather patterns to a high extent. In addition, farmers in China and India believed that climate change was real because they had experienced the severity of extreme climate events such as droughts (Jianjun et al., 2015; Udmale et al., 2014), and observed directly the adverse impacts these had on their agriculture production, particularly cash crops. It is clear that direct experience and observation significantly raises the awareness of small-scale farmers about the risks of climate change.

Previous studies indicate that media such as the Internet, television and newspapers are the major sources from which the public obtains information about climate change (Akompab et al., 2012; Wei et al., 2014), and that media has an influence on public perceptions of climate change (Antilla, 2010; Brulle, Carmichael, \& Jenkins, 2012; Leiserowitz, 2005). Social Amplification Theory states that an individual's consideration of risks is influenced by media and organisational structure. This study also found that the Takeo community obtained information 
about increasing temperatures, droughts and lightning from radio and television programmes. Such information influenced the way the local community judged which risk was the most severe; as this study found, $17 \%$ of respondents judged lighting and heat waves (covered by the media) as their highest concern. Farmers also gained some knowledge from NGOs and from government information sharing.

However, the results also indicated that perception of the risks posed by climate change were not uniform throughout the community, but varied from one farmer to another, even though they lived within the same geographical area and shared cultural backgrounds. Levels of engagement in development activities, as well as gender and the ability to access information pertaining to environmental patterns all influenced individuals' perception of climate change, thus suggesting that Knowledge Theory (which argues that people perceive risks based on their knowledge and access to information) is also relevant in understanding differing perceptions.

While the vast majority of respondents in Takeo who were aware of the causes of climate change believed that the issue was the result of human activities, one individual argued that it was a natural phenomenon. The arguments of respondents differed based on differences in personal opinion, observation and knowledge of the issue. In addition, levels of engagement in development programmes influenced farmers' awareness of climate change. Even though all participants had a similar educational background (with high school being the highest), community leaders who had more opportunities to engage in development and climate change training programmes were more aware of changes in environmental patterns than others in the community. The way that individuals perceived, and were concerned about, risks also varied according to gender. The result of this study showed that mothers were more concerned about children's food and study than fathers when discussing their concerns about climate change.

The study additionally found that the Takeo community considered climate change risks at the personal rather than the societal level. Farmers believed that climate change was threatening them personally because extreme weather events, 
especially prolonged droughts, were occurring in the area and had direct consequences on their standard of living and income generation, particularly on their agricultural productivity (the major source of income). This finding contradicts research undertaken by researchers in the industrialised world (Hagen, 2013; Ockwell, Whitmarsh, \& O'Neill, 2009) where respondents believed that climate change was happening but that it did not affect their lives or their families yet, and hence they did not consider risks posed by extreme weather as a personal threat. One of these studies, by Hagen (2013), was undertaken by using an online survey and we might infer a certain level of wealth among respondents who have access to that technology.

It is highly likely that because the Takeo community's major source of income has been affected by extreme weather events, they considered the risks to be personal. In contrast, it is possible that the respondents in the previous researches had income sources from sectors that were not directly affected by climate change. The findings of this rese arch, therefore, reflect the suggestion made by Leiserowitz (2007), that people in developing countries consider climate change as a direct threat more than those in the developed world because they were suffering more directly and greatly from extreme weather events, coupled with a low adaptive capacity to respond. This research, therefore, argues that the consequences of climate change may be felt as a direct impact on personal income, and thereby influence individual perceptions and levels of concern over the risks associated with climate change impacts.

\subsection{Influence of risk perception on individual responses}

This research aimed at understanding how perceptions of risks posed by climate change framed the Takeo community's responses, and thus explored adaptation and mitigation strategies. The finding reflects previous literature (Siegrist et al., 2005, p. 145; Slovic, 2000; Williams \& Noyes, 2007) with the point that the perception of climate change risk has influenced the Takeo community's adaptation and mitigation responses. However, this study argued that due to limited awareness of response strategies, adaptation measures practised by 
farmers were not adequate for long-term responses. Their perception of risks also had an influence on government climate change policy.

Having noticed that climate change was a real crisis causing negative impacts on their lives and economy, the Takeo community has changed their response behaviour by implementing a variety of adaptation and mitigation strategies to mitigate climate change impacts on their lives and agricultural production. These strategies included harvesting rainwater, using fans and resting under the shade to avoid heat. Perceiving climate change as one of the biggest challenges for generating income, farmers in Takeo were adopting similar alternative farming practices to farmers in Maharashtra state, India (Udmale et al., 2014) and in Ethiopia (Sørhaug, 2011). Adaptation strategies included adjusting cropping dates, harvesting water and saving water, changing planting techniques, using hybrid crop seeds and seeking alternative incomes (from off-farm, money lenders or microfinance institutions). Both Sorhaug (2011) and Udmale et al. (2014) indicate that some farmers considered temporary or permanent migration as one of their adaptation strategies. This was not the case of farmers in Takeo, because they found alternative income by working in construction enterprises as well as in the garment factories, which had recently moved closer to the Takeo area from Phnom Penh.

The respondents had different perceptions of, and concern about, risks, but they shared similar adaptation strategies. This was partly because the community had shared information about climate change with each other, and most had followed the example shown by community leaders who had better adaptation strategies. For instance, those who had two or three water jars recently increased their water reservoirs to five or six. This finding contradicts that of Jianjun et al. (2015), who found that farmers in China made decisions to adapt to climate change differently based on their degree of education, planting experience, land size, income and perception of risks. Those within the Takeo community had different perceptions about climate change but only slight differences in education, farm size and income. Such small differences may account for their similar adaptation responses. A larger study investigating adaptation strategies across more sectors of society in Cambodia would be needed to assess the impact of education, income and farm size on adaptation approaches 
Although all respondents shared similar adaptation strategies, they exhibited different degrees of responding behaviour. Amongst the 17 agricultural practitioners, nine seemed to show stronger commitment and intention to adapt to climate change such as cleaning mud from ponds to store more water, digging ponds and wells. They explained that since the impacts were intensely felt on their main sources of income, they needed to take action with their own initiative rather than just waiting for support. They were able to do this because they usually had free time before rice planting. Others seemed to wait for support from government and NGOs rather than engaging directly in their own adaptation measures.

Three farmers who had community ponds situated in their house areas, for instance, were waiting for government or NGOs to clean mud out of the ponds instead of initiating this themselves. They explained they were not able to clean the ponds themselves as they lacked the funds to have it done. Also the ponds did not belong to only their family. Even though those farmers were direct beneficiaries of the ponds, they considered cleaning the ponds as the responsibility of the community and government. Instead of spending time calling for this action, they spent money and time obtaining water from somewhere else. This research, thus contributes to the Rational Choice Theory that individuals' perception of risks plays an important role in their decision to choose response strategies. RCT holds that the public responds to risks differently based on their feeling and motivation.

However, despite having a variety of adaptations, alternative agricultural practices carried out by farmers were not enough to provide long-term solutions to climate vulnerabilities, because farmers had limited resources and knowledge of coping mechanisms and limited support from the government. The community was running out of ground water as some ponds and wells were running dry.

Although the community has increased water jars to collect rainwater, they were able to use water harvested from rain only for cooking and drinking; it was not plentiful enough for other uses such as showering and feeding animals. Thus, they were forced find and buy water from somewhere else. Buying water was not an effective solution to cope with extreme drought for the Takeo community, because farmers earned less than one or two US dollars a day, not enough to buy a bucket 
of water, which cost about two and a half US dollars each (ACF, 2015). Delivering water from other areas to farmers in Takeo, as an emergency response mechanism undertaken by the government, is also not sustainable when droughts become more severe, drying out water in areas close to the community.

Furthermore, the community itself did not have an effective way of managing water over the long-term. The community has a just-improved collective pond which was half full of water (observation on 10 June, 2016), and some farmers have personal ponds that were estimated to supply water for cooking and drinking until early or mid-April. However, some people took baths with shampoo and soap in those ponds while some farmers washed clothes and cleaned animals such as cattle in the same ponds. In the personal ponds, farmers also raised fish (not commercial fish, but fish that had migrated from canals during the rainy season). These activities dirtied the water, so it was not used for cooking and drinking. Since the community did not have any effective regulation to manage such big ponds efficiently, they instead saw buying water from water traders as a solution. In addition, individuals did not seem to exhibit sufficient responsibility to improve access to water for their own consumption, although the impacts on their families were getting stronger. This was because the community did not have a good awareness of adaptation strategies. It is therefore important to raise awareness to improve farmers' understanding of the solutions required to reduce the impacts of extreme events.

In response to this challenge, the leader of this community was thinking about improving the management of water. He mentioned that he was going to discuss this weakness with the community and ban farmers from using the community pond any way they wished, and to keep it only for water consumption. However, he complained about the difficulty in educating farmers to use water more efficiently because some tended to be selfish and did not care much about others, as in the case of washing clothes in the pond. Even though this was a challenge, he was going to improve the management of water, since he saw the potential of the pond to provide sufficient water for around 20 to 30 families in this area during the dry season. 
Adaptation in agriculture was also not sufficient. Although farmers were using adopted rice varieties that required a small amount of water, they could not control the water level that was critical for better yield. Higher or lower amounts of water were bad for growth and yielding of rice. Moreover, farmers depended mainly on cattle for agriculture. The use of technology in planting in this community was very low because farmers have small farms that do not lie as a plot. This explained the difficulty in using technology in rice planting in addition to the unaffordability of purchasing the equipment. The results of this study confirmed the previous literature that found that the farmers in India and China were practising a wide range of adaptation and mitigation measures, but that these measures were insufficient (Jianjun et al., 2015; Udmale et al., 2014). In India, just more than half the farmers in Maharashtra State had changed their planting date and the variety of crops grown to those tolerant to droughts, while uptake of technological equipment such as sprinklers for irrigation was low.

Furthermore, individuals perceived risks at the personal level but did not see solutions as an individual responsibility. They seemed to expect support from the government or NGOs in Cambodia, and from outsiders such as developed countries and scientists, to deal with climate change, rather than exhibiting their own commitment. When asked about their perception of risks posed by climate change in the next five to ten years, the majority of respondents replied that they did not know anything about the future trend of these extreme weather events. When discussing their adaptation strategies or plans to address future risks, they did not suggest any further solutions or adaptations. They responded that the only thing they could do was to have some more water jars to collect rainwater. They believed people in developed nations had experienced climate change earlier and had a better understanding and knowledge of climate change than they did, and that responses to climate change were the responsibility of the government and outsiders. This reflects the finding of Whitmarsh (2008) who found that the attitude of the public who had experienced climate change directly were no different from those who had not suffered the impacts. 
One reason for this may be that they had limited knowledge and understanding of climate change, few resources and low income. It probably seems beyond their capacity to deal with climate change, as it is a global issue that requires global scale actions. Farmers in Takeo were practising subsistence agriculture, while the income from rice and livestock production is only enough for a year's consumption, with a little surplus for education. The community is also located in a remote area where accessibility to media is limited (electricity is insufficient), and support from the government is insufficient. While these factors demonstrate the vulnerability of the community to climate change, they also indicate limits to the kinds of mitigation and adaptation strategies that the community can adapt.

\subsection{Influence of risk perception on climate change policy}

Previous studies argue that public perceptions and awareness of risks posed by climate change also have an influence on adaptation and mitigation policy development (Burnham, 2014; Jianjun et al., 2015; Leiserowitz, 2007; Lujala et al., 2014; Udmale et al., 2014; Wei et al., 2014; Yu et al., 2013). This research agrees. Information about individuals' perceptions and awareness of risks was important to inform policymakers. In addition, once individuals believed climate change was real, they would be willing to change their behaviours and support mitigation policy. These ideas are reflected in my findings. The Takeo community considered climate change as a great personal concern, and all respondents strongly affirmed that this issue should be given priority in development plans. The participants believed that improving irrigation systems and preserving natural forests were the best ways to combat climate change problems. Through these measures, they could have sufficient water for family consumption and agricultural production.

The local government officer also strongly agreed that dealing with climate change was very important. However, his perception of what to do first was slightly different from the community respondents. He pointed out that the first solution to climate change was to provide people with awareness and education about extreme climate events. He perceived that farmers in the community had limited awareness of climate change; therefore knowledge of the issue was important if farmers were to be made aware of risks and solution. As a result, they would start 
thinking about possible actions in response to extreme climate events and how to live and work in the changing climate.

Such understanding has influenced the mainstreaming of climate change adaptation and mitigation projects in the Commune Investment Programmes (CIP) and Commune Development Plans (CDP) of local government. Every year, local government gathers the needs of community from farmer's responses to make CIP plan. Recently, the community raised their needs regarding climate change events, demanding the construction of dams and ponds (Respondent MLA1). Many projects related to climate change had therefore been proposed and prioritised in CIP 2014 (Cheang Taung Commune, 2014; 2016). These projects included the construction of dams, community ponds and biodigester plants as well as providing training and awareness campaigns around climate change risks and agricultural techniques to enable community members to survive in the changing climate.

The influence of perception of risks on the planning process was not only seen at the local government level, but also at the national level (MoE, 2016a). Cambodia had a development vision to become a green and climate-resilient country and the government had marked the importance of responding to climate change (RGC, 2013). Adaptation and mitigation options were prioritised in policy at both the national and local government levels. In addition, the government had recently mainstreamed climate change into its development plan (MoE, 2016a) and budgeting at the sub-national level (UNDP, 2014). The government of Cambodia decided to move climate change planning and budgeting from the national to the local level after $50 \%$ of communes in Cambodia were identified as being most vulnerable to the impacts of climate change (UNDP, 2014).

The National Committee for Management of Sub-national Democratic Development (NCDD), the government organisation responsible for climate change action, was preparing guidelines for implementing climate change adaptation projects at the sub-national level with the support from the United Nations Development Programme (UNDP) in Cambodia. From 2009 to 2011, the Cambodian government spent an average of around $15.8 \%$ of its national budget on projects related to climate change (RGC, 2013, p. 25). A number of government-supported projects 
related to climate change were proposed in the Commune Investment Programme (CIP) and prioritised. According to the 2016 CIP, projects included the construction of dams, community ponds and biodigester plants as well as providing training and awareness campaigns around climate change risks and agricultural techniques to enable the community members to survive in the changing climate.

However, despite responses to climate change receiving growing support in planning processes, this research shows that actions remained limited. Only 5-6\% of state expenditure (which was very low) were spent on climate change projects at local government level (RGC, 2013, p. 25). In addition, despite having plans to combat climate change issues, few projects had been carried out. From the 2014 CIP, only a few projects related to climate change have been implemented due to the limited budget of the local government. These included training on rice production techniques and well-drilling. In addition, the government of Cambodia mainly alerted and advised farmers to conserve water in response to shortages of water, but had no plan to develop more reservoirs or irrigation systems at a national level (ACF, 2015, p. 12). Local news reported similarly that while an important solution to climate change is to improve irrigation systems, this requires time and resources (human and finance) not affordable by Cambodia (Khmertimes, 2015).

In addition, while one of the government officers at the Ministry of Environment explained that the government has shown a commitment by developing policy to combat climate change issue in Cambodia, policy implementation has been slow because Cambodia is prioritising economic development and employment:

"To construct garment factories or buildings in Cambodia, the companies need to have environmental impact assessments (EIAs), and businesses must follow the guidelines of the assessments. Having said that, as Cambodia wants to attract more investors, especially from China, to do business, the EIA's could not apply very strict rules or punishments. Moreover, a lot more garment factories have been built and land concessions have been approved. The companies have cleared land to build apartments for renting and warehouses or to grow crops. This has increased greenhouse gas emissions but Cambodia needs the economic development and employment opportunities for local people." (Respondent MMoE18). 
This demonstrates one of the overriding conflicts for developing countries in promoting migration policies - that is, the need to, at the same time, promote economic growth and often through industrialisation. While the idea of the Green Economy aims to address this challenge, whether it is possible to realise this seems questionable at present in Cambodia.

There was also evidence indicating that Cambodia's government failed to protect forest cover and reduce greenhouse gas emissions. Although the government set the policy to increase forest conservation areas, the forest cover in Cambodia has decreased significantly during the last 15 years from $66.65 \%$ in 2000 to $47.68 \%$ in 2014 (Open Development Cambodia, 2016; Sopheak, 2017). The amount of carbon emissions in Cambodia also increased from 8.84 in 2001 to 43.6 million tonnes in 2014 (Global Forest Watch Climate, 2014). This finding is consistent with the literature mentioning that climate change is the biggest challenge but economic growth has received greater investment (Lee, 2010; Matthew, 2012). This suggests that greater motivation is needed to support the concept of a green economy in the development plans of the government.

This research found that some farmers saw technology as the cause of climate change but not the solution. The respondents who believed that the impacts of climate change would be exacerbated in the next five to ten years, indicated that human lifestyles were not likely to change. People would continue to depend on technology such as cars and mobile phones for living. Thus, while technology will continue to make life more comfortable, production processes will continue to contribute to greenhouse gas emissions. Indeed, farmers in this study saw technology as the cause of the problem but not the solution to it. They seemed unaware of innovations to reduce greenhouse gas emissions such as renewable energy (solar panels and wind turbines). Perhaps this is because advanced technology is only slowly becoming more present in Cambodia and that technology is not yet available to small-scale farmers. Furthermore, communication of climate change information by media and government and NGOs may not mention such possibilities. 


\subsection{Conclusion}

This chapter has discussed the findings of the study in relation to previous research. Similar to previous studies, this study found that Takeo's community has a fairly good perception of the risks posed by climate change and they believed the issue is severe and leading to adverse impacts on their lives and livelihoods. However, farmers in Takeo also had different viewpoints and concerns on the extreme weather events. Adding to the points that previous studies had mentioned about media as the main source of climate change information, this study found that direct personal observation also played a significant role in risk perception amongst farmers in the community, and that gender was a contributing factor in framing risks.

The chapter also discussed the relationship between community perceptions of risks and their adaptation strategies and policy responses to climate change. Similar to previous studies, Takeo's community was found to be using different adaptation strategies to cope with living in the changing climate. Despite their efforts, their adaptation measures are not sufficient due to their limited knowledge of adaptation strategies and insufficient resources. In addition, limited support from the government due to insufficient funds for climate change projects also limits responses, and the continued drive for economic growth through industrialisation creates a contradictory environment. Although the respondents perceived risks as personal, they did not seem to consider the solution as personal. Instead they were expecting the government and outsiders to deal with the issue. It is important that policymakers are informed to provide further training and support to these people, who remain some of the most vulnerable to the impact of climate change. 



\section{Chapter 8: Concluding chapter}

This chapter provides a summary of the thesis covering the research objectives, questions, methodology, participants, key findings and recommendations for further study. The chapter is divided into two main sections. The first part summarises the research process and the second part focuses on the implications of the thesis leading to suggestions for further research.

\subsection{Summary of research's objective, questions and methodology}

The thesis was conducted to understand the perceptions of the Takeo community around risks and their adaptation options to climate change. To understand the main objective of the research, I explored five main questions:

1. How aware are participants of the impacts of climate change on their lives and livelihoods?

2. What specific climate change risks are of the most concern to participants in the study area?

3. What factors are considered important when considering what risks are of the most concern?

4. How have participants' perceptions of climate change risks shaped their adaptation strategies?

5. What potential do these adaptation strategies have to improve community resilience to climate change impacts?

To answer these questions, I used qualitative methods. From a social constructivist perspective, I employed three main methods: in-depth interview, participant observation and document analysis. These tools were used because of their benefits in helping to understand the situation of participants, and to make sense of and draw conclusions from the data.

I approached and interviewed 19 participants (five females/mothers) individually. Five of them (three females) were visited for a half-day observation. Amongst the 19 participants, one of them (one male) is the government officer at the Ministry of 
Environment, one of them (one male) is local government officer, and 17 of them (five female) are farmers. Amongst the 17 farmers, five of them (one female) are community leaders, while the others are community members.

\subsection{Key findings of the thesis}

The first question of this research sought to understand farmers' understanding and perceptions of risks posed by climate change. This research focused on farmers' awareness of the severity and impacts of extreme weather events experienced in Takeo province, Cambodia. The study found that farmers in Takeo had little knowledge and understanding of climate change and adaptation strategies, but they had good perception of risks and adverse impacts of extreme weather events on their life, health, food and economic activities. Respondents witnessed that extreme weather events had caused some health-related issues such as heat-related stress, anxiety and concern, and had affected the agricultural production of the community. These events not only damaged crop and livestock production, but also reduced their grain yield and caused death to cattle and chickens. Farmers in Takeo were aware of the changes of the environmental patterns mainly from personal observation and experiences. They were also informed about the changing of weather patterns by media, government officials and NGO staff.

I found that participants considered climate change as a great personal threat, because of their first-hand experience and impacts to their major income. The participants were highly concerned about climate change impacts because they detected extreme weather events such as severe and more frequent storms, thunderstorms, lightning, floods and prolonged droughts. Farmers in Takeo explained different reasons supporting their judgement of which risk was their greatest concern. Even though none of the participants experienced any damage from these threats, they were concerned about storms, thunderstorms and the warmer climate (heat waves). The majority of farmers considered prolonged droughts as the most concerning threat. Others chose storms, thunderstorms and heat waves as the most concerning risks, because of media coverage of these events. Farmers had seen the massive damage of these events on other farmers' 
lives and properties, both in Cambodia and other countries. Such messages made them fearful and anxious about having similar experiences. They were afraid that they would be killed, or their houses would be destroyed and they would have nowhere to live. Those who judged droughts as the most concerning risk explained that this type of risk was occurring more frequently and with more severity, and having direct impacts on their livelihood. Droughts have lasted longer recently and caused postponed planting dates and even prevented farmers from planting early rice. Some farmers did not plant early rice while others did but got less grain yield than usual due to a lack of water. This has reduced farmers' food and income from selling early rice. Thus, farmers were continually concerned about food for their family consumption, and income for dealing with other expenses such as school fees for their children.

The community's risk perception impacted individual behaviour in responding to climate change as well as climate change policy. The community was found to be practising both mitigation and adaption measures. To mitigate climate change at the commune level, government and respondents had planted more trees and used biodigesters to convert energy from animal manure. The conversion process reduced the emissions of methane from animal manure to the atmosphere. In responding to climate change, the government of Cambodia had also provided training and awareness campaigns to improve the awareness and understanding of local people about climate change. Regarding adaptation options, the government also improved irrigation systems, building dams and canals to improve water sources for agricultural production in the area. Moreover, many projects related to climate change were integrated into development plans.

At an individual level, adapting to the increasing temperature, farmers have stayed in cool places such as under trees or at the ground floor of their houses during mid-day which was the hottest time. In addition, the respondents have used fans to cool down. In responding to storms and lighting strikes, participants stay in safe places such as houses and avoid travelling or using electronic devices during rain. In agricultural practices, farmers have used alternative farming options such as adjusting their planting dates based on weather forecasts rather than their traditional habits, and changing agricultural techniques such as applying SRI 
(transplanting one or two rice seedlings) that use less water and take shorter planting and growing times than traditional planting. Furthermore, farmers started planting rice in the paddy fields close to water sources the earliest so that they could irrigate crops. Farmers also increased the amount of natural fertiliser used and reduced synthetic fertiliser. Because prolonged droughts were the most common and serious issue in this area, farmers had used drought-tolerant varieties of crops and improved water management by collecting rainwater and acquiring or buying water from other areas. As climate change has reduced the productivity of Takeo's community leading to losses of income, the respondents had sought alternative income from off-farm activities such as working for garment factories.

Considering the strength of the adverse impacts of droughts and increasing temperature, the adaptation and mitigation approaches carried out by farmers were neither sufficient nor effective as long-term strategies to improve the community's resilience in living in the changing environment. Although farmers' use of less-water-requirement crops, this variety of crops was not sufficiently drought resistant that they could be grown in more severe drought. Importantly, the community did not have an effective mechanism for managing water for consumption and irrigating crops. They were forced to buy and transport water from elsewhere. The community did not have water reservoirs or irrigation systems that could provide sufficient water for their consumption, or any surplus for rice or cash crop planting. In short they were not able to control water. The current strategies - for farmers to buy water, and government to deliver water from other areas - will not be effective in the long-term. Such vulnerabilities would increase if prolonged droughts begin to last longer. Farmers could not afford to rehabilitate ponds and canals in the area, and the limited budget from the government made it hard to have enough water for planting the crops which are the major source of income of farmers in this area.

\subsection{Implications of the research}

The study demonstrated that the rural poor in Cambodia remain highly vulnerable to the impacts of climate change. The adverse impacts of extreme weather events on the community in Cambodia were clearly apparent and were getting more 
severe, but the community's adaptive capacity to these events was low. Although the negative effects were localised, they were felt intensely by farmers in Takeo. Farmers did not only face difficulty in their lifestyle, but also faced destruction in income generation. Climate change did not only delay rice production, but also reduced its yield. Livestock such as poultry was also killed. Climate change is, therefore, contributing to water inaccessibility, food insecurity and triggering poverty in this area. This therefore requires urgent action from both government and the community to improve the community resilience to climate change. The Takeo community should improve the way it manages water reservoirs and agricultural practices, so that they can store enough water for consumption and agriculture even if there is prolonged drought.

Similarly, the government should improve its support and budget to climate change programmes at the sub-national level. Government should provide more agricultural support services to help farmers adjust their farming techniques. It could increase the construction of infrastructure such as dams and irrigation systems at the national level, such that infrastructure can store and provide sufficient water to rural families. Since the government has noticed that budget expenditure on climate change projects at the local level was low, this should be increased. With the limited human and financial resources of the local community, budget supports from the government on irrigation improvement is critical. In addition, dissemination of climate change adaptation and mitigation strategies should be taken into consideration, because farmers in the area had very limited awareness and understanding of how to adapt to the changing climate. Coordination support and effort between national and local government is also important to equip this community with adaptation knowledge to become more resilient.

The government of Cambodia should also exhibit stronger efforts to combat climate change. Since Cambodia has a responsibility in climate justice to reduce greenhouse gas emissions and increase the adaptive capacity of local people, the government should enforce law and policy to achieve this goal. Forest protection law should be enforced since the government has also failed to protect forest cover. Since farmers are also suffering from the more severe impacts of climate 
change with little water sources and adaptation knowledge, farmers need to be better equipped with adaptive capacity for long-term preparedness.

\subsection{Further research}

This study has provided an understanding of how the agricultural community in Takeo province, Cambodia, perceived risks posed by climate change and how their perception of risk shaped mitigation and adaptation responses The study indicated that even though farmers in the community had good perception of risk, their adaptation was low. In light of this, further research on the effectiveness of communication of climate change information and climate change policy in Cambodia to improve the resilience of rural farmers should be conducted.

In addition, this study has focused on only one community in the mainland area of Cambodia, so further research that compares more than one region (provinces) would be valuable. This is because climate vulnerability differs from one place to another and this might have an influence on the way people perceive risks. For instance, the study has focused on the area where droughts are the most risky threat while, for other areas in Cambodia, flooding maybe the most threatening risk. If this is the case, the government, or development agencies, should consider implementation of adaptation based on location rather than practising a national plan throughout the country. 


\section{References:}

Abaza, H. (2012). Green Economy in Action: Articles and excerpts that illustrate green economy and sustainable development efforts. Retrieved from http://www.un.org/waterforlifedecade/pdf/green_economy_in_action_eng. pdf

Action Against Hunger International Organisation. (2015). 2015/2016 El Niño in Asia - An Actor Analysis. Retrieved from http://un.or.id/elnino/images/download/ACFIN_El-Nino-in-Asia_201512.pdf

Akompab, D. A., Peng, B., Susan, W., Janet, G., Iain, A. W., \& Martha, A. (2012). Awareness of and Attitudes towards Heat Waves within the Context of Climate Change among a Cohort of Residents in Adelaide, Australia. Awareness of and Attitudes towards Heat Waves within the Context of Climate Change among a Cohort of Residents in Adelaide, Australia, 10(1), 1-17. doi:10.3390/ijerph10010001

Am, P., Cuccillato, E., Nkem, J., \& Chevillard, J. (2013). Mainstreaming climate change resilience into development planning in Cambodia. Retrieved from London:

Antilla, L. (2010). Self-censorship and science: a geographical review of media coverage of climate tipping points. Public Understanding of Science, 19(2), 240-256. doi:10.1177/0963662508094099

Applefield, J. M., Huber, R., \& Moallem, M. (2001). Constructivism in Theory and Practice: Toward a Better Understanding. High School Journal, 84(2), 35-53.

Arora, P. (2012). 'Your kool-aid is not my kool-aid': ideologies on microfinance within an INGO culture. Development in Practice, 22(7), 1006-1018. doi:10.1080/09614524.2012.696583

Asian Development Bank. (2014). Cambodia Country Poverty Analysis 2014. Retrieved from https://www.adb.org/sites/default/files/institutionaldocument/151706/cambodia-country-poverty-analysis-2014.pdf

Australian Broadcasting Corporation. (2015). Rising out of poverty: Cambodian cash cows [Press release]. Retrieved from http://www.abc.net.au/news/2015-03-13/cows-for-cambodia-charitypoverty/6314030

Baker, S. (2006). Sustainable development. London [u.a.]: Routledge.

Balcom, N. (2015). Communicating Risk: how people respond to coastal storm warnings. Wrack Lines: A Connecticut Sea Grant Publication, 15(2), 4-8.

Bardsley, D. K., \& Wiseman, N. D. (2012). Climate change vulnerability and social development for remote indigenous communities of South Australia. Global Environmental Change, 22(3), 713-723. doi:http://dx.doi.org/10.1016/j.gloenvcha.2012.04.003

Blunden, J., \& Arndt, D. S. (2016). State of the Climate in 2015.(p. S241-S275). Bulletin of the American Meteorological Society, 97(8), S241.

Boden, T. A., Marland, G., \& Andres, R. J. (2015). National CO2 Emissions from FossilFuel Burning, Cement Manufacture, and Gas Flaring: 1751-2011. Retrieved from 
Boyd, E. (2014). Climate change and development. In V. Desai, R. B. Potter, \& C. Ebooks (Eds.), The companion to development studies / edited by Vandana Desai and Robert B. Potter (Third edition.. ed.): Abingdon, Oxon : Routledge.

Brulle, R., Carmichael, J., \& Jenkins, J. (2012). Shifting public opinion on climate change: an empirical assessment of factors influencing concern over climate change in the U.S., 2002-2010. An Interdisciplinary, International Journal Devoted to the Description, Causes and Implications of Climatic Change, 114(2), 169-188. doi:10.1007/s10584-012-0403-y

Bryan, E., Deressa, T. T., Gbetibouo, G. A., \& Ringler, C. (2009). Adaptation to climate change in Ethiopia and South Africa: options and constraints. Environmental Science and Policy, 12(4), 413-426. doi:10.1016/j.envsci.2008.11.002

Bryman, A. (2008). Social research methods / Alan Bryman (3rd ed.. ed.). Oxford, New York: Oxford University Press.

Burnham, M. (2014). The human dimensions of climate change: Smallholder perception and adaptation in the Loess Plateau region of China. In Z. Ma, E. Berry, J. Endter-Wada, R. Kjelgren, \& C. Radel (Eds.): ProQuest Dissertations Publishing.

Cambodia National Committee for Diaster Management. (2014). Analysis Report: Cambodia deaths (1996-2013). Retrieved from

Cambodian Agricultural Research and Development Institute. (2002a, June, 2002). Medium maturity rice (Pka Rumdoul). Farmer Notes, 01, 1-2.

Cambodian Agricultural Research and Development Institute. (2002b). Sen Pidor Rice. Farmer Notes, 01, 1-2.

Cambodian Agricultural Research and Development Institute. (2005, December, 2005). Early Maturity Rice (IR66). Farmer Notes, 4, 1-2.

Center for Climate and Energy Solutions. (2015). Outcomes of the U.N Climate change conference in Paris Retrieved from 2101 Wilson Blvd \#550, Arlington, VA 22201, USA: https://www.c2es.org/docUploads/cop-21paris-summary-02-2016-final.pdf

Chacko, E. (2004). Positionality and Praxis: Fieldwork Experiences in Rural India. Singapore Journal of Tropical Geography, 25(1), 51-63. doi:10.1111/j.01297619.2004.00172.x

Chan, S. (2011). Ten important varieties of rice in Cambodia. Phnom Penh, Cambodia.

Cheang Taung Commune. (2014). Communie Investment Programme. Tramkak, Takeo, Cambodia: Cambodia's local government.

Cheang Taung Commune. (2016). Table 2.2: Prioritised Investment Projects of Cheang Taung Commune. Cheang Taung, Takeo, Cambodia: Cambodeia's local government.

Cheng, C. (2016). Water Dependency and Livelihoods of Rice Farmers in Doung Khpos commune, Cambodia. In W. Murray (Ed.): Victoria University of Wellington.

Cohen, S., Demeritt, D., Robinson, J., \& Rothman, D. (1998). Climate change and sustainable development: towards dialogue. Global Environmental Change, 8(4), 341-371. doi:10.1016/S0959-3780(98)00017-X 
Collins, M. R., Knutti, J., Arblaster, J. L., Dufresne, T., Fichefet, P., Friedlingstein, X., . . . Wehner, M. (2013). Long-term climate change: projections, commitments and irreversibility. In D. Q. T.F. Stocker, G.-K. Plattner, M. Tignor, S.K. Allen, J. Boschung, A. Nauels, Y. Xia, V. Bex, and P. M.Midgley, T.F. Stocker, D. Qin, G.K. Plattner, M. Tignor, S.K. Allen, J. Boschung, A. Nauels, Y. Xia, V. Bex, and P. M.Midgley (Ed.), Climate Change 2013 : The Physical Science Basis. Contribution of Working Group I to the Fifth Assessment Report of the Intergovernmental Panel on Climate Change. United Kingdom and New York, U.S.A: Cambridge Univ. Press (Cambridge, United Kingdom and New York, U.S.A).

Corfee-Morlot, J., Gençsü, I., Rydge, J., Mountford, H., Banaji, F., \& Jaeger, J. (2016). The sustainable infrastructure imeprative: Financing for better growth and development. Retrieved from http://newclimateeconomy.report/2016/wpcontent/uploads/sites/4/2014/08/NCE_2016Report.pdf

Council for the Development of Cambodia. (2012). Cambodia Investment Guidebook. Retrieved from http://www.cambodiainvestment.gov.kh/content/uploads/2011/09/Chap ter1.pdf.

Creswell, J. W. (2009). Research design : qualitative, quantitative, and mixed methods approaches / John W. Creswell (3rd ed.. ed.). Los Angeles : New Delhi: Los Angeles : New Delhi : Sage.

Creswell, J. W. (2014). Research design : qualitative, quantitative, and mixed methods approaches / John W. Creswell (4th ed.. ed.). Thousand Oaks: Thousand Oaks : SAGE Publications.

Diffenbaugh, N. S., Scherer, M., \& Trapp, R. J. (2013). Robust increases in severe thunderstorm environments in response to greenhouse forcing. Proceedings of the National Academy of Sciences of the United States of America, 110(41), 16361. doi:10.1073/pnas.1307758110

Elshemy, M. (2013). Climate Change and Water Resources / edited by Tamim Younos, Caitlin A. Grady. In C. A. Grady \& SpringerLink (Eds.): Place of publication not identified Springer Berlin Heidelberg.

Fankhauser, S., \& Stern, N. (2016). Climate change, development, poverty and economics. Retrieved from http://pubdocs.worldbank.org/en/728181464700790149/Nick-SternPAPER.pdf

Food and Agriculture Organization of the United Nations. (2011a). AQUASTAT Survey-Cambodia. Retrieved from http://www.fao.org/nr/water/aquastat/countries_regions/khm/KHMCP_eng.pdf

Food and Agriculture Organization of the United Nations. (2011b). Cambodia and FAO Achievements and success stories. Retrieved from http://www.fao.org/3/a-at004e.pdf

Food and Agriculture Organization of the United Nations. (2012). Climate change adaptation and mitigation: Challenges and opportunities in the food sector. Retrieved from http://www.fao.org/docrep/016/i2855e/i2855e.pdf

Food and Agriculture Organization of the United Nations. (2014). Country Fact Sheet on Food and Agriculture Policy Trends, Cambodia. Retrieved from http://www.fao.org/docrep/field/009/i3761e/i3761e.pdf 
Fylan, F. (2005). Semi-structured interviewing. In J. Miles \& P. Gilbert (Eds.), $A$ handbook of research methods for clinical and health psychology: Oxford University Press on Demand.

Gill, V. (2014). Climate change 'will make lightning strike more' [Press release]. Retrieved from http://www.bbc.com/news/science-environment30023536

Glesne, C. (2006). Becoming qualitative researchers : an introduction / Corrine Glesne (3rd ed.. ed.). Boston: Boston : Pearson/Allyn \& Bacon.

Global Forest Watch Climate. (2014). Cambodia carbon emissions. Retrieved from http://climate.globalforestwatch.org/countries/KHM

Hagen, B. (2013). Public Perceptions Of Climate Change: Risk, Trust, and Policy. In D. Pijawka, A. Brazel, N. Chhetri, \& S. Guhathakurta (Eds.): ProQuest Dissertations Publishing.

Haines, A., \& Patz, J. A. (2004). Health effects of climate change.(Contempo Updates: Linking Evidence and Experience). JAMA, The Journal of the American Medical Association, 291(1), 99.

Harfenist, E. (2015). Worries on El Niño winds [Press release]. Retrieved from http://www.phnompenhpost.com/national/worries-el-nino-winds

Harmeling, S., Kreft, S., Rai, C. S., \& Vaughan, K. (2010). International action on adaptation and climate change: What roads from Copenhagen to Cancun? . Retrieved from https://germanwatch.org/klima/ad-cph-canc.pdf

Harmer, N., \& Rahman, S. (2014). Climate Change Response at the Farm Level: A Review of Farmers' Awareness and Adaptation Strategies in Developing Countries. Geography Compass, 8(11), 808-822. doi:10.1111/gec3.12180

Harrington, L. J., Frame, D. J., Fischer, E. M., Hawkins, E., Joshi, M., \& Jones, C. D. (2016). Poorest countries experience earlier anthropogenic emergence of daily temperature extremes. Environmental Research Letters, 11(5), 055007. doi:10.1088/1748-9326/11/5/055007

Harry, S., \& Morad, M. (2013). Sustainable development and climate change: Beyond mitigation and adaptation. Local Economy: The Journal of the Local Economy Policy Unit, 28(4), 358-368. doi:10.1177/0269094213476663

Intergovernmental Panel on Climate Change. (2007). IPCC Fourth Assessment Report: Climate Change $2007 \quad$ Retrieved from https://www.ipcc.ch/publications_and_data/ar4/syr/en/spms4.html

Intergovernmental Panel on Climate Change. (2014a). Climate Change 2014: Impacts, Adaptation, and Vulnerability. Part A:

Global and Sectoral Aspects. Contribution of Working Group II to the Fifth Assessment Report of the Intergovernmental Panel on Climate Change. Retrieved from United Kingdom and New York, NY, USA:

Intergovernmental Panel on Climate Change. (2014b) Climate Change 2014: Mitigation of Climate Change. Contribution of Working Group III to the Fifth Assessment

Report of the Intergovernmental Panel on Climate Change United Kingdom and New York, NY, USA.: Cambridge University Press, Cambridge.

Intergovernmental Panel on Climate Change. (2014c). Climate Change 2014: Synthesis Report. Contribution of Working Groups I, II and III to the Fifth 
Assessment Report of the Intergovernmental Panel on Climate Change. Retrieved from IPCC, Geneva, Switzerland:

Jianjun, J., Yiwei, G., Xiaomin, W., \& Nam, P. K. (2015). Farmers' risk preferences and their climate change adaptation strategies in the Yongqiao District, China. Land Use Policy, 47, 365-372. doi:10.1016/j.landusepol.2015.04.028

Johan, R., Will, S., Kevin, N., Åsa, P., Chapin, F. S., Eric, F. L., . . Jonathan, A. F. (2009). A safe operating space for humanity. Nature, 461(7263), 472. doi:10.1038/461472a

Joosu-Palu, T. (2015). Cambodian Agriculture in Transition: Opportunities and Risks. Retrieved from http://www.worldbank.org/en/news/feature/2015/08/19/cambodianagriculture-in-transition-opportunities-and-risks

Khan, M. R., \& Roberts, J. T. (2013). Adaptation and international climate policy (Vol. 4, pp. 171-189). Hoboken, USA.

Khim, L., \& Phearanich, H. (2012). Climate Resilience in Rural Cambodia: Adaptation Mainstreaming, Water Resource Management and Agricultural Practice. Asian Journal of Environment and Disaster Management, 4(4), n/a. doi:10.3850/S1793924012100067

Khmertimes. (2015, 08 September, 2015). Still Waiting for the Rain. KhmerTimes Newspaper. Retrieved from http://www.khmertimeskh.com/news/15484/still-waiting-for-the-rain/

Kreft, S. n., Eckstein, D., Dorsch, L., \& Fischer, L. (2016). GLOBAL CLIMATE RISK INDEX 2016. Retrieved from Berlin, Germany:

Lappé, A. (2011). Diet for a hot planet : the climate crisis at the end of your fork and what you can do about it / Anna Lappé with a foreward by Bill McKibben (Pbk. ed.. ed.). New York: New York : Bloomsbury USA.

Lee, M. B. (2010). Low Carbon, Green Growth. In G. Lean (Ed.), Green Economy.

Leiserowitz, A. (2005). American Risk Perceptions: Is Climate Change Dangerous? Risk Analysis, 25(6), 1433-1442. doi:10.1111/j.1540-6261.2005.00690.x

Leiserowitz, A. (2007). International Public Opinion, Perception, and Understanding of Global Climate Change. IDEAS Working Paper Series from RePEc.

Leng, H. A. (2014). Country Report of Cambodia Diaster Management. Phnom Penh, Cambodia: National Committee for Disaster Management

Lhendup, K. (2008). System of Rice Intensification (SRI): Method of rice cultivation(May, 2008). Retrieved from

Loo, Y. Y., Billa, L., \& Singh, A. (2015). Effect of climate change on seasonal monsoon in Asia and its impact on the variability of monsoon rainfall in Southeast Asia. Geoscience Frontiers, 6(6), 817-823. doi:10.1016/j.gsf.2014.02.009

Louise Barriball, K., \& While, A. (1994). Collecting data using a semi-structured interview: a discussion paper. Journal of Advanced Nursing, 19(2), 328-335. doi:10.1111/j.1365-2648.1994.tb01088.x

Ludwig, F., Scheltinga, C. T. v., Verhagen, J., Kruijt, B., Ierland, E. v., Dellink, R., . . . Kabat, P. (2007). Climate change impacts on Developing Countries - EU Accountability Retrieved from The Netherlands: 
http://www.europarl.europa.eu/RegData/etudes/etudes/join/2007/3935 11/IPOL-ENVI_ET(2007)393511_EN.pdf

Lujala, P., Lein, H., \& Rød, J. K. (2014). Climate change, natural hazards, and risk perception: the role of proximity and personal experience. Local Environment, 1-21. doi:10.1080/13549839.2014.887666

Maher, F., \& Tetreault, M. (1993). Frames of Positionality: Constructing Meaningful Dialogues About Gender and Race. Anthropological Quarterly, 66(3), 118.

Mak, S. (2013). World Geographical Dictionary on Cambodia. Retrieved from http://whrmkamoto.com/assets/files/World\%20geographical\%20dictionary_CAM\%20 30\%20May2013.pdf

Mannke. (2011). Experiences of Climate Change Adaptation in Africa. Berlin, Heidelberg: Springer Berlin Heidelberg, Berlin, Heidelberg.

Mary Robinson Foundation Climate Justice. (2011). The geography of climate justice. Retrieved from http://www.mrfcj.org/pdf/Geography_of_Climate_Justice_Introductory_Res ource.pdf

Matthew, R. (2012). The Green Economy is the Right Solution for our Troubled Times. Retrieved from

Matthews, B. (2010). Research methods : a practical guide for the social sciences / Bob Matthews and Liz Ross (1st ed.. ed.). New York, NY: New York, NY : Pearson Longman.

Measham, T., Preston, B., Smith, T., Brooke, C., Gorddard, R., Withycombe, G., \& Morrison, C. (2011a). Adapting to climate change through local municipal planning: barriers and challenges. Mitigation and Adaptation Strategies for Global Change, 16(8), 889-909. doi:10.1007/s11027-011-9301-2

Measham, T., Preston, B., Smith, T., Brooke, C., Gorddard, R., Withycombe, G., \& Morrison, C. (2011b). Adapting to climate change through local municipal planning: barriers and challenges. An International Journal Devoted to Scientific, Engineering, Socio-Economic and Policy Responses to Environmental Change, 16(8), 889-909. doi:10.1007/s11027-011-9301-2

Men, S. (2007). Rice Production in Cambodia. Phnom Penh, Cambodia: The Cambodia Agricultural Research and Development Institute (CARDI).

Miller, G. (1997). Context and Method in Qualitative Research: Place of publication not identified SAGE Publications Limited.

Ministry for the Environment. (2014). New Zealand's greenhouse gas inventory and net position reort 1990-2012. Retrieved from Wellington, New Zealand https://www.mfe.govt.nz/sites/default/files/media/Climate\%20Change/g hg-inventory-2014-snapshot.pdf

Ministry of Agriculture Forestry and Fishery. (2006). National Biodigester Programme Cambodia Phnom Penh.

Ministry of Agriculture Forestry and Fishery. (2010). National Forest Programme 2010-2029. Phnom Penh.

Ministry of Agriculture Forestry and Fishery. (2016). MAFF annual report for the year 2015-2016 and planning for 2016-2017. Retrieved from http://www.maff.gov.kh/reports/68-annualreport/ 
Ministry of Environment. (2006). Cambodian National Adaptation Programme of Action to Climate Change Retrieved from Phnom Penh, Cambodia:

Ministry of Environment. (2009a). Cambodia Environment Outlook. Phnom Penh: Ministry of Environment, Royal Government of Cambodia.

Ministry of Environment. (2009b). The National Green Growth Roadmap. Phnom Penh: Royal Government of Cambodia.

Ministry of Environment. (2016a). Climate Change Action Plan 2016-2018. Phnom Penh.

Ministry of Environment. (2016b). Climate Change Action Plan (CCAP). Phnom Penh: Ministry of Environment.

Morecroft, M. D., \& Cowan, C. E. (2010). Responding to Climate Change: An Essential Component of Sustainable Development in the 21st Century. Local Economy: The Journal of the Local Economy Policy Unit, 25(3), 170-175. doi:10.1080/02690942.2010.486124

Morn, V., \& Igor, K. (2016). Kingdom's lightning deaths spike in 2015 [Press release]. Retrieved from http://www.phnompenhpost.com/national/kingdoms-lightning-deathsspike-2015

Morton, J. F. (2007). The impact of climate change on smallholder and subsistence agriculture. Proceedings of the National Academy of Sciences of the United States of America, 104(50), 19680.

National Council on Green Growth. (2013). National Strategic Plan on Green Growth. Phnom Penh: Royal Government of Cambodia.

Ockwell, D., Whitmarsh, L., \& O'Neill, S. (2009). Reorienting Climate Change Communication for Effective Mitigation: Forcing People to be Green or Fostering Grass-Roots Engagement? Science Communication, 30(3), 305.

Olivier, J. G. J., Janssens-Maenhout, G., Muntean, M., \& Peters, J. A. H. W. (2015). Trends in global CO2 emissions: 2015 Report. Retrieved from

Open Development Cambodia. (2016). Cambodia's forest cover. Retrieved from https://opendevelopmentcambodia.net/profiles/forest-cover

Palutikof, J. P., Agnew, M. D., \& Hoar, M. R. (2004). Perceptions of unusually warm weather in the UK: impacts, responses and adapations. Climate Research, 26(1), 43-59.

Papworth, A., Maslin, M., \& Randalls, S. (2014). Is climate change the greatest threat to global health? Geographical Journal (2014) (In press).

Pasquali, V. (2015). The world's richest and poorest countries. Retrieved from https://www.gfmag.com/global-data/economic-data/worlds-richest-andpoorest-countries

Perry, A. L., Low, P. J., Ellis, J. R., \& Reynolds, J. D. (2005). Climate Change and Distribution Shifts in Marine Fishes. Science, 308(5730), 1912-1915.

Punch, K. (2014). Introduction to social research : quantitative \& qualitative approaches / Keith F. Punch (3rd ed.. ed.). Los Angeles, California: Los Angeles, California : SAGE.

Reid, H., Alam, M., Berger, R., Cannon, T., Hug, S., \& Miligan, A. (2009). Communitybased adaptation to climate change: an overview The International Institute for Environment and Development (2009): Participatory Learning and Action. Russell Press, Nottingham, UK. 
Renn, O., Burns, W. J., Kasperson, J. X., Kasperson, R. E., \& Slovic, P. (1992). The Social Amplification of Risk: Theoretical Foundations and Empirical Applications. Journal of Social Issues, 48(4), 137-160. doi:10.1111/j.15404560.1992.tb01949.x

Roeser, S., Hillerbrand, R., Sandin, P., \& Peterson, M. (2013). Introduction to Risk Theory Essentials of Risk Theory. Dordrecht: Springer Netherlands, Dordrecht

Ros, B., Nang, P., \& Chhim, C. (2011). Agricultural Development and Climate Change: The Case of Cambodia. Retrieved from Phnom Penh, Camobida:

Royal Government of Cambodia. (2013). Cambodia climate change strategic plan 2014-2013. Phnom Penh: The Royal Government of Cambodia.

Save the Children. (2016). El Niño-induced drought in Cambodia: Rapid Assessment Report. Retrieved from https://www.humanitarianresponse.info/en/system/files/documents/files /may_2016_multi-province_rapid_assessment_save_the_children.pdf

Scott, J. (2000). Rational Choice Theory. In G. Browning, A. Halcli, \& W. F (Eds.), Understanding Contemporary Society: Theories of The Present: age Publications.

Senaratne, A., \& Scarborough, H. (2011). Coping with Climatic Variability by Rainfed Farmers in Dry Zone, Sri Lanka: Towards Understanding Adaptation to Climate Change. IDEAS Working Paper Series from RePEc.

Seng, S. (2013). Climate Change Issues in Cambodian Coastal Area related to Water. Retrieved from

Siegrist, M., Gutscher, H., \& Earle, T. C. (2005). Perception of risk: the influence of general trust, and general confidence. Journal of Risk Research, 8(2), 145156. doi:10.1080/1366987032000105315

Slovic, P. (1987). Perception of risk. Science (New York, N.Y.), 236(4799), 280.

Slovic, P. (2000). The perception of risk. London Sterling, VA: Earthscan Publications.

So, C. (2015). Severe Drought Takes Toll on Women in Cambodia. Radio Free Asia. Sopheak, S. (2017). NASA: Cambodia's forests are gone [Press release]. Retrieved from http://km.rfi.fr/cambodia/nasa-cambodia-forests-are-disappearing11-01-2017

Sørhaug, A. K. (2011). Climate change impacts and adaptations among ethiopian farmers : case studies of Hagere Selam, Tigray, and Kofele, Oromia: University of Agder.

Spence, A., Poortinga, W., Butler, C., \& Pidgeon, N. F. (2011). Perceptions of climate change and willingness to save energy related to flood experience. Nature Climate Change, 1(1), 46. doi:10.1038/nclimate1059

Stake, R. E. (2003). Case studies (2nd ed.. ed.). Thousand Oaks, CA: Thousand Oaks, CA : Sage.

Stern Review. (2006). Stern Review on the Economics of Climate Change. Retrieved from http://webarchive.nationalarchives.gov.uk/20080910140413/http://ww w.hmtreasury.gov.uk/independent_reviews/stern_review_economics_climate_ch ange/stern_review_report.cfm 
Stewart-Withers, R., Banks, G., McGregor, A., \& Meo-Sewabu, L. (2014). Qualitative research. In R. Scheyvens (Ed.), Development fieldwork : a practical guide (2nd edition / edited by Regina Scheyvens.. ed.). London: London SAGE Publications Ltd.

Streeton, R., Cooke, M., \& Campbell, J. (2004). Researching the researchers: using a snowballing technique. Nurse Researcher, 12, 35+.

Sultana, F. (2007). Reflexivity, positionality and participatory ethics: negotiating fieldwork dilemmas in international research. $A C M E, 6(3)$.

Taylor, A. L., Dessai, S., \& Bruine de Bruin, W. (2014). Public perception of climate risk and adaptation in the UK: A review of the literature. Climate Risk Management, 4-5, 1-16. doi:10.1016/j.crm.2014.09.001

Taylor, R. G., Scanlon, B., Doll, P., Rodell, M., van Beek, R., Wada, Y., ... Treidel, H. (2013). Ground water and climate change. Nature Clim. Change, 3(4), 322329.

Thoeun, H. C. (2015). Observed and projected changes in temperature and rainfall in Cambodia. Weather and Climate Extremes, 7, 61-71.

doi:10.1016/j.wace.2015.02.001

Thomas, D., Twyman, C., Osbahr, H., \& Hewitson, B. (2007). Adaptation to climate change and variability: farmer responses to intra-seasonal precipitation trends in South Africa. An Interdisciplinary, International Journal Devoted to the Description, Causes and Implications of Climatic Change, 83(3), 301-322. doi:10.1007/s10584-006-9205-4

Thomas, F., Sabel, C. E., Morton, K., Hiscock, R., \& Depledge, M. H. (2014). Extended impacts of climate change on health and wellbeing. Environmental Science and Policy, 44, 271-278. doi:10.1016/j.envsci.2014.08.011

Thomas, T. S., Ponlok, T., Bansok, R., De Lopez, T., Chiang, C., Phirun, N., \& Chhum, C. (2013). Cambodian agriculture: Adaptation to climate change impact. IDEAS Working Paper Series from RePEc.

Toch, S. (2015). The Accountability of Cambodian NGOs in Climate Change Projects: The impacts on local communities. In J. Overton (Ed.): Victoria University of Wellington.

Truelove, H. B., Carrico, A. R., \& Thabrew, L. (2015). A socio-psychological model for analyzing climate change adaptation: A case study of Sri Lankan paddy farmers. Global Environmental Change, 31, 85-97.

doi:10.1016/j.gloenvcha.2014.12.010

Udmale, P., Ichikawa, Y., Manandhar, S., Ishidaira, H., \& Kiem, A. S. (2014). Farmers' perception of drought impacts, local adaptation and administrative mitigation measures in Maharashtra State, India. International Journal of Disaster Risk Reduction, 10, 250-269. doi:10.1016/j.ijdrr.2014.09.011

United Nations. (1992). United Nations Framework Convention on Climate Change. Retrieved from http://unfccc.int/files/essential_background/background_publications_ht mlpdf/application/pdf/conveng.pdf

United Nations Development Programme. (2012). Cambodia Community Based Adaptation Programme. Retrieved from Phnom Penh, Camboida:

United Nations Development Programme. (2014). Cambodia steps up mainstreaming climate change into local development planning. Retrieved 
from

http://www.kh.undp.org/content/cambodia/en/home/presscenter/article s/2014/08/21/cambodia-steps-up-mainstreaming-climate-change-intolocal-development-planning.html

United Nations Economic and Social Commission for Asia and the Pacific. (2015). El Niño 2015-2016: Impact outlook and policy implications. Retrieved from http://www.unescap.org/sites/default/files/El\%20Nino\%20Advisory\%20 Note\%20Dec\%202015\%20Final.pdf

United Nations Framework Convention on Climate Change. (2013). The Special Climate Change Fund. Retrieved from http://unfccc.int/cooperation_and_support/financial_mechanism/special_c limate_change_fund/items/3657.php

Uphoff, N. (2015). The System of Rice Intensification (SRI): Responses to Frquenctly asked questions. B75 Mann Library, Cornell University, Ithaca, New York 14853, USA: Cornell University.

van Aalst, M. K., Cannon, T., \& Burton, I. (2008). Community level adaptation to climate change: The potential role of participatory community risk assessment. Global Environmental Change, 18(1), 165-179. doi:10.1016/j.gloenvcha.2007.06.002

Vanderstoep, S. W. (2009). Research methods for everyday life : blending qualitative and quantitative approaches / Scott W. VanderStoep, Deirdre D. Johnston (1st ed.. ed.). San Francisco, CA: San Francisco, CA : Jossey-Bass.

Vicuna, S. (2007). Adaptation to climate change impacts on California water resources. In J. A. Dracup (Ed.): ProQuest Dissertations Publishing.

Vida, T. (2015). Gov't Warns Big Dry Spell, Extreme Weather Coming [Press release]. Retrieved from

http://www.khmertimeskh.com/news/19069/gov---t-warns-big-dry-spell-extreme-weather-coming/

Vilain, C., Baran, E., Gallego, G., \& Samadee, S. (2016). Fish and the Nutrition of Rural Cambodians. Asian Journal of Agriculture and Food Sciences (ISSN: 2321 - 1571), 04(01, February 2016), 26-34.

Wachinger, G., Renn, O., Begg, C., \& Kuhlicke, C. (2013). The Risk Perception Paradox-Implications for Governance and Communication of Natural Hazards. Risk Analysis, 33(6), 1049-1065. doi:10.1111/j.15396924.2012.01942.x

Wei, J., Hansen, A., Zhang, Y., Li, H., Liu, Q., Sun, Y., \& Bi, P. (2014). Perception, attitude and behavior in relation to climate change: A survey among CDC health professionals in Shanxi province, China. Environmental Research, 134, 301-308. doi:10.1016/j.envres.2014.08.006

Wheeler, D. (2011). Quantifying Vulnerability to Climate Change: Implications for Adaptation Assistance. Retrieved from http://www.cgdev.org/page/mapping-impacts-climate-change

Wheeler, T., \& von Braun, J. (2013). Climate change impacts on global food security.(Author abstract). Science, 341(6145), 508.

Whitmarsh, L. (2008). Are flood victims more concerned about climate change than other people? the role of direct experience in risk perception and behavioural response. Journal of Risk Research, 11(3), 351-374.

doi:10.1080/13669870701552235 
Wildavsky, A., \& Dake, K. (1990). Theories of Risk Perception: Who Fears What and Why? Daedalus, 119(4), 41-60.

Williams, D. J., \& Noyes, J. M. (2007). How does our perception of risk influence decision-making? Implications for the design of risk information (Vol. 8, pp. 1-35): Taylor \& Francis Group.

World Bank. (2009). Public attitudes toward climate change: findings from a multicountry poll. Retrieved from http://siteresources.worldbank.org/INTWDR2010/Resources/Background -report.pdf

World Bank. (2011). Vulnerability, Risk Reduction, and Adaptation to Climate Change: Cambodia. Retrieved from http://sdwebx.worldbank.org/climateportalb/doc/GFDRRCountryProfiles/ wb_gfdrr_climate_change_country_profile_for_KHM.pdf

World Bank. (2015). Cambodia economic update. Retrieved from http://www.worldbank.org/content/dam/Worldbank/document/EAP/ca mbodia/Cambodia_Economic_Update_April_2015.pdf

World Bank. (2016). World Development Indicators. Retrieved from https://openknowledge.worldbank.org/bitstream/handle/10986/23969/9 781464806834.pdf

World Bank. (n.d). Cambodia's temperature and rainfall from 1900-2012. Retrieved from:

http://sdwebx.worldbank.org/climateportal/index.cfm?page=country_hist orical_climate\&amp;ThisCCode=KHM\#

World Health Organisation. (2016). Cambodia-WHO: Country Cooperation Strategy 2016-2020. Retrieved from http://apps.who.int/iris/bitstream/10665/246102/1/WPRO_2016_DPM_0 04_eng.pdf

Yin, R. K. (2014). Case study research : design and methods / Robert K. Yin (Fifth edition.. ed.): Los Angeles : SAGE.

Yu, H., Wang, B., Zhang, Y.-J., Wang, S., \& Wei, Y.-M. (2013). Public perception of climate change in China: results from the questionnaire survey. Journal of the International Society for the Prevention and Mitigation of Natural Hazards, 69(1), 459-472. doi:10.1007/s11069-013-0711-1

Zaki, T. (2011). Perception of Climate Change Among Egyptians Living in Egypt and Canada. In J. Parkins (Ed.): ProQuest Dissertations Publishing. 



\section{Appendices}

Appendix 1: Ethical approval

TE WHARE WĀNANGA O TE ŪPOKO O TE IKA A MÃUI

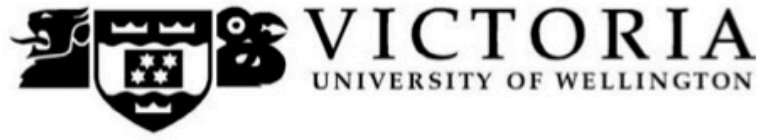

MEMORANDUM

\begin{tabular}{l|l}
\hline TO & Ratanakvisal Chean \\
\hline COPY TO & \\
\hline FROM & \\
\hline
\end{tabular}

\begin{tabular}{l|l}
\hline DATE & 18 May 2016 \\
\hline PAGES & 1 \\
\hline
\end{tabular}

\begin{tabular}{l|l}
\hline SUBJECT & Ethics Approval: 22914 \\
& Perceptions, Attitudes and Behaviors around Climate Change \\
& Risks on Livelihood Activities: A Case Study of Community in \\
& Takeo Province, Cambodia
\end{tabular}

Thank you for your application for ethical approval, which has now been considered by the Standing Committee of the Human Ethics Committee.

Your application has been approved from the above date and this approval continues until 28 March 2017. If your data collection is not completed by this date you should apply to the Human Ethics Committee for an extension to this approval.

Best wishes with the research. 


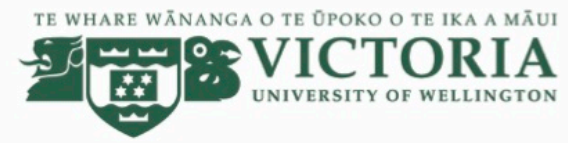

\section{Perceptions, Attitudes and Behaviour around Climate Change Risks on Livelihood Activities: A Case Study of a Community in Takeo Province, Cambodia}

\section{INFORMATION SHEET FOR PARTICIPANTS}

Thank you for your interest in this project. Please read this information before deciding whether or not to take part. If you decide to participate, thank you. If you decide not to take part, thank you for considering my request.

My name is Ratanakvisal Chean and I am a Masters student in Development Studies at Victoria University of Wellington, New Zealand. As part of my degree I am researching the perceptions of the risks posed by climate change on the livelihoods of people in Takeo province, Cambodia and the behavioural changes and adaptation measures being taken by this community. This research project has been approved by the Victoria University of Wellington Human Ethics Committee.

If you agree to take part in my research I will interview you in a public place, such as a rice field or pagoda. I will ask you questions about your experiences of climate change. The interview will take $\mathbf{3 0}$ to 60 minutes. I will record the interview and transcribe it later. You can stop the interview at any time, without giving a reason. You can withdraw from the study up to four weeks after the interview. If you withdraw, the information you provided will be destroyed or returned to you.

This research is confidential. I will not name you in any outputs, and I will not include any information that would identify you. Only my supervisor and I will read the notes or transcripts of the interview. The interview transcripts, summaries and any recordings will be kept securely and destroyed 3 years after this project ends.

The information I collect will primarily be used in my Masters thesis. I may also use the results of my research for conference presentations and academic publications. You will not be identified in any of these outputs.

You do not have to accept this invitation if you don't want to. If you do decide to participate, you have the right to:

- choose not to answer any question

- $\quad$ ask for the recorder to be turned off at any time during the interview; 
- $\quad$ withdraw from the study up until four weeks after your interview;

- ask any questions about the study at any time;

- receive a copy of your interview recording (if it is recorded);

- $\quad$ read over and comment on a transcript of your interview;

- $\quad$ agree on another name for me to use rather than your real name;

If you have any questions, please feel free to contact me. 
Appendix 3: Participant information sheet in Khmer

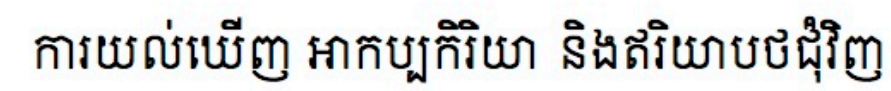

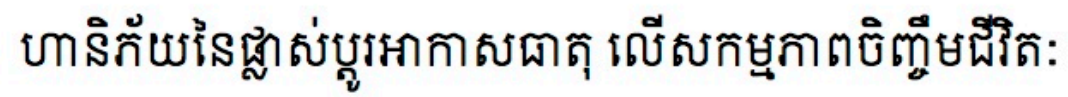

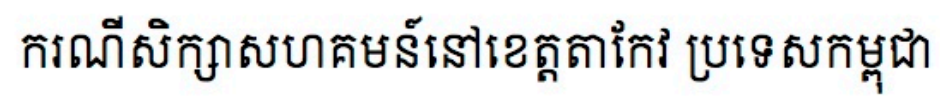

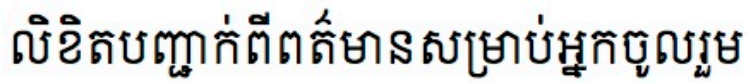

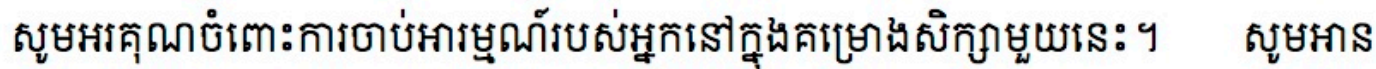

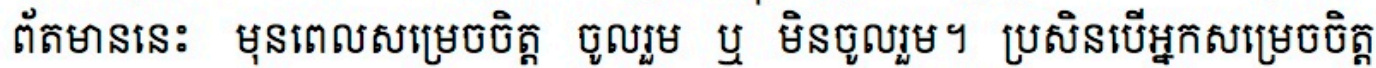

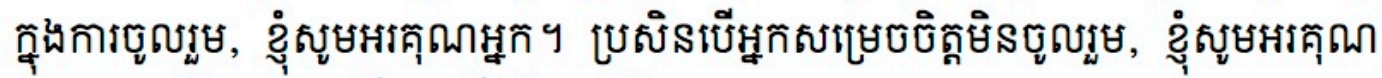

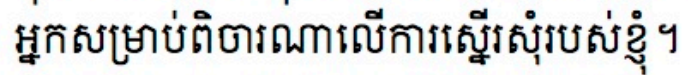

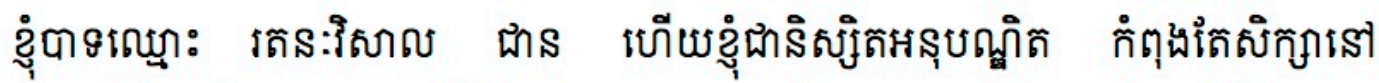

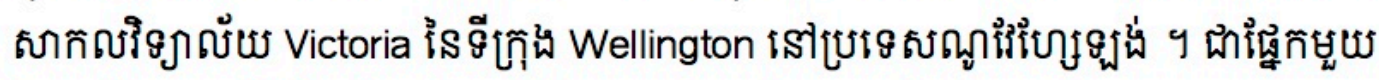

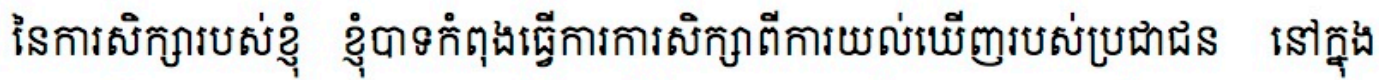

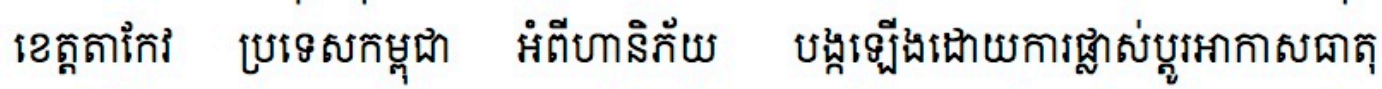

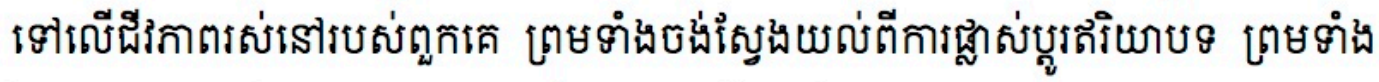

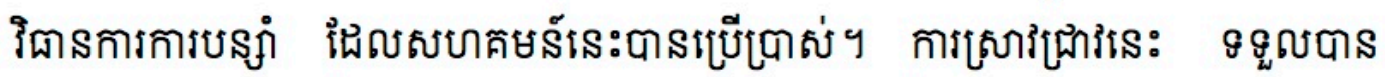

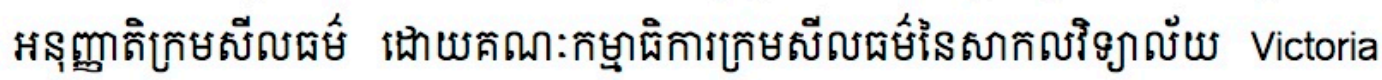

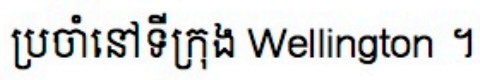

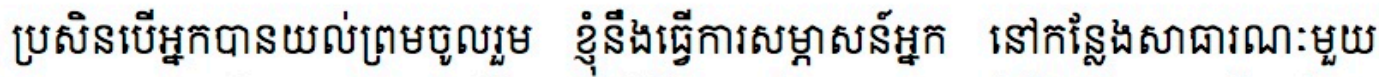

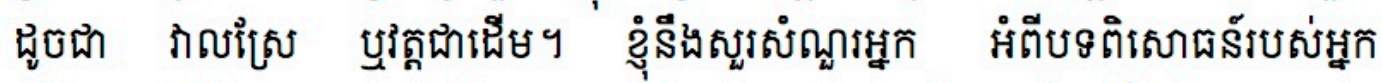

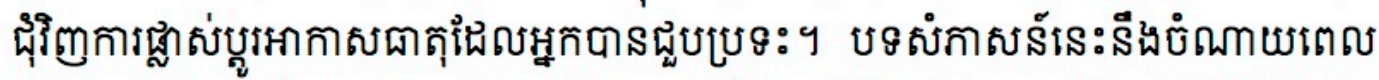

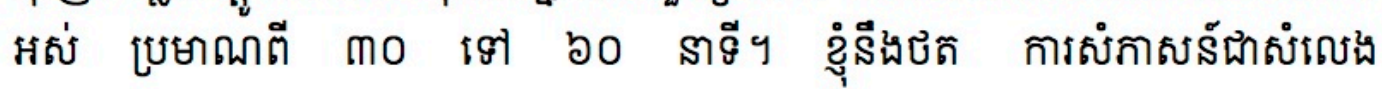




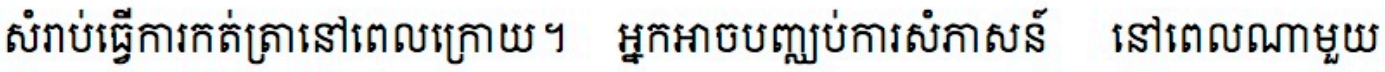

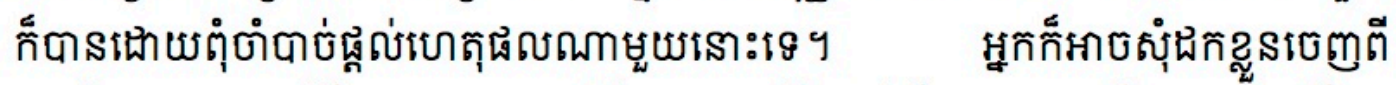

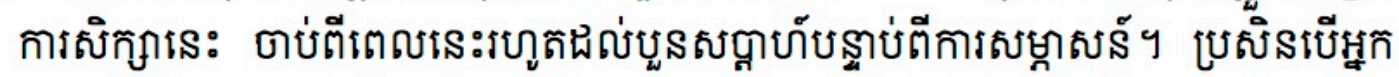

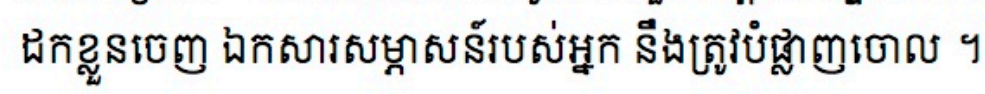

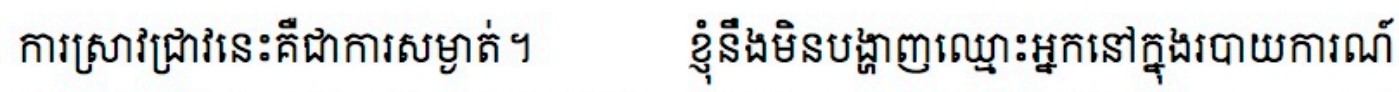

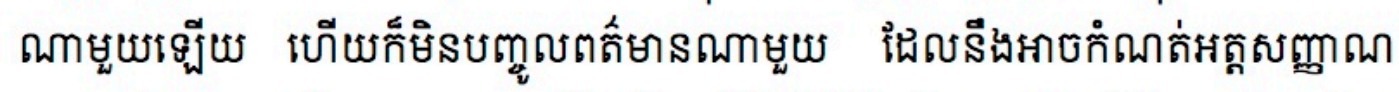
มุกตาง

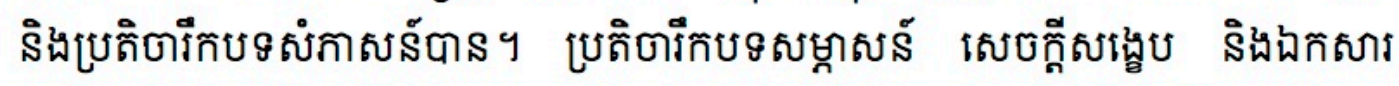

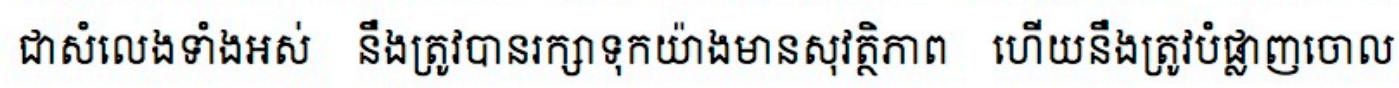

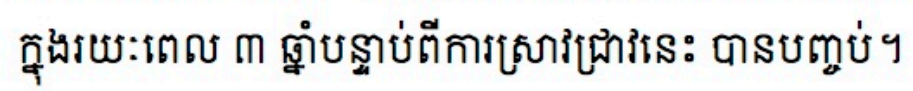

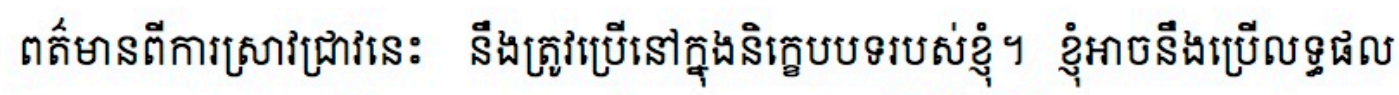

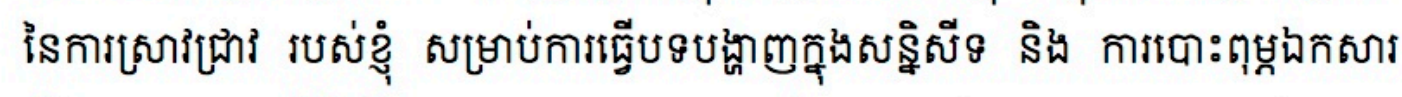

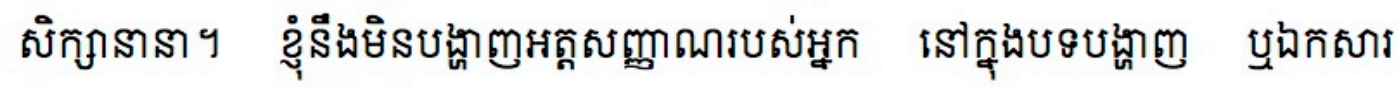

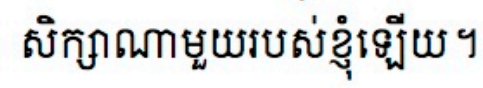

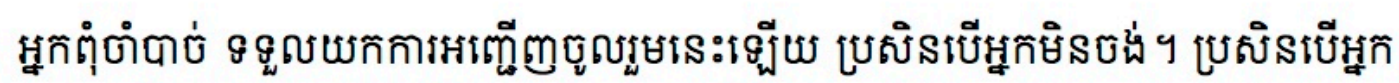

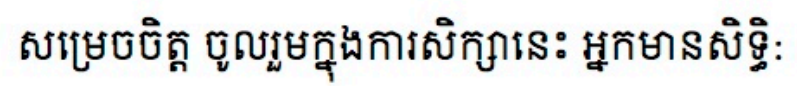

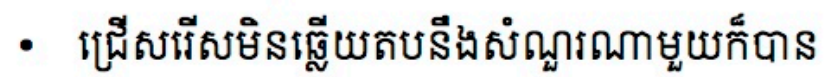

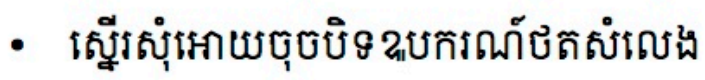

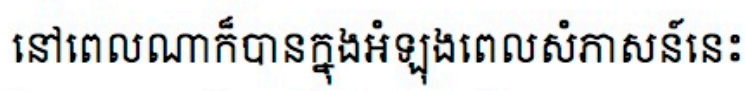

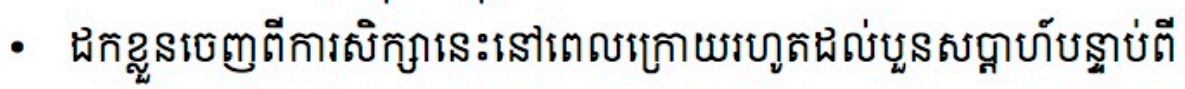

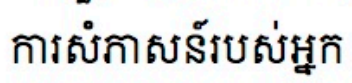

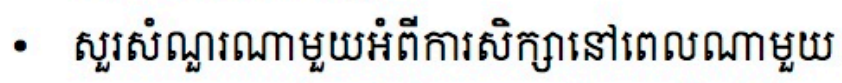

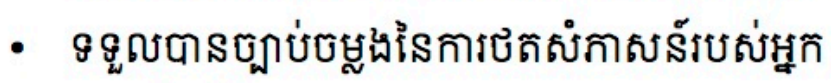

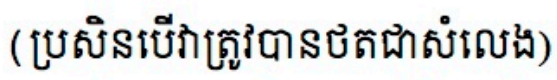

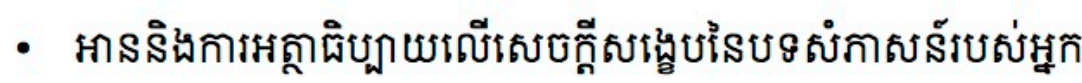




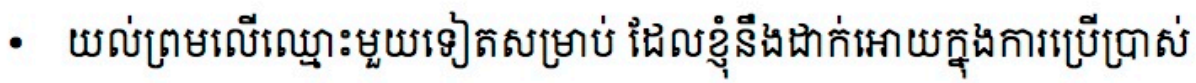

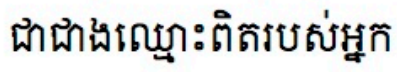

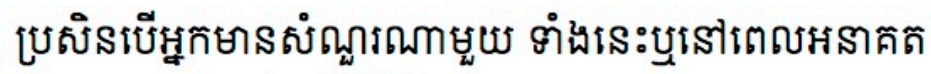

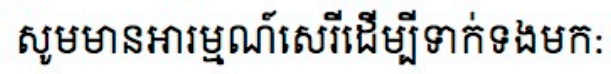




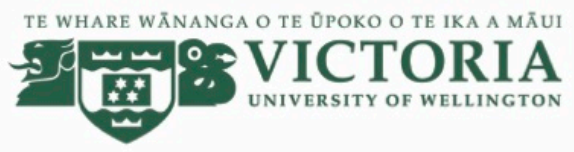

\section{Perceptions, Attitudes and Behaviour around Climate Change Risks on Livelihood Activities: A Case Study of a Community in Takeo Province, Cambodia}

\section{CONSENT TO INTERVIEW}

This consent form will be held for 5 years.

Researcher: Ratanakvisal Chean, School of Geography, Environment and Earth Sciences, Victoria University of Wellington, New Zealand

- I have read the Information Sheet and the project has been explained to me. My questions have been answered to my satisfaction. I understand that I can ask further questions at any time.

- I agree to take part in an audio recorded interview.

I understand that:

- I may withdraw from this study up to four weeks after the interview, and any information that I have provided will be destroyed.

- The information I have provided will be destroyed 3 years after the research is finished.

- $\quad$ Any information I provide will be kept confidential to the researcher and the supervisor. I understand that the results will be used for Ratanakvisal's thesis and a summary of the results may be used in academic reports and/or presented at conferences.

- $\quad$ My name will not be used in thesis, reports, nor will any information that would identify me unless I give consent below.

- I consent to information or opinions which I have given being attributed to me in thesis of this research project:

Yes $\square \quad$ No

- I would like a transcript of my interview:

Yes

No

Signature of participant:

Name of participant:

Date:

Contact details: 
Appendix 5: Participant consent form in Khmer

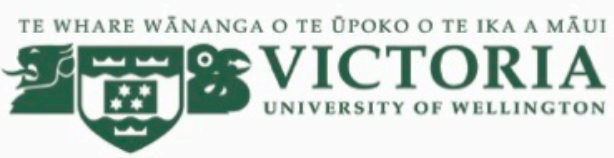

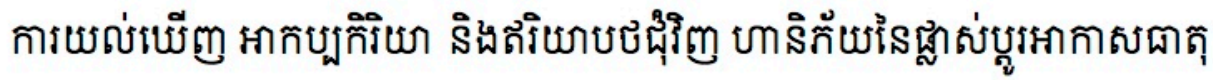

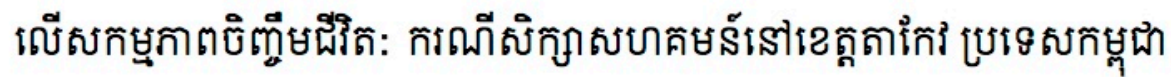

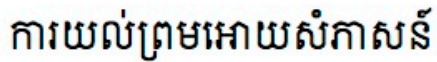

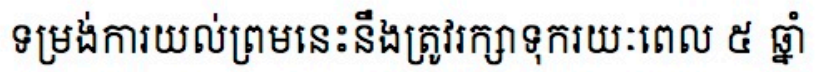

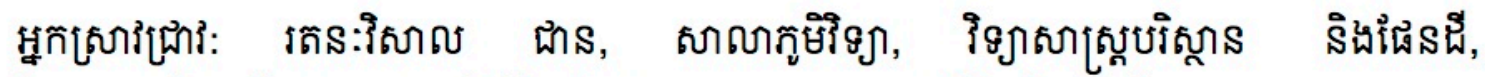

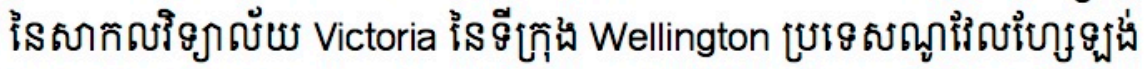

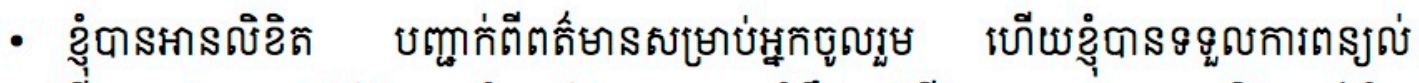

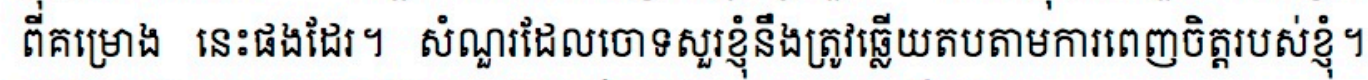

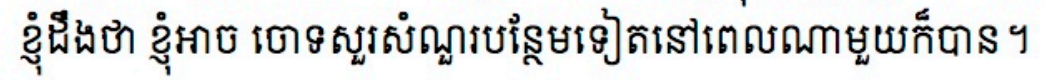

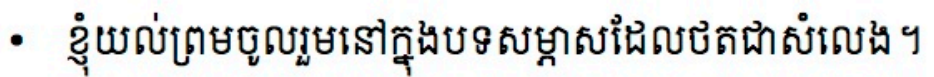

己ุ่แல่ษ์:

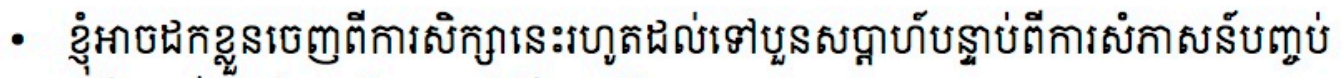

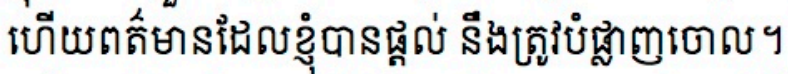

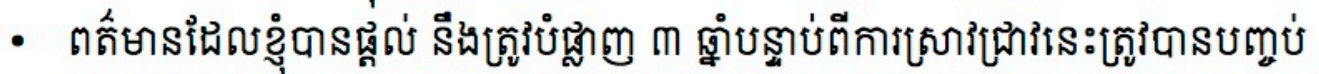

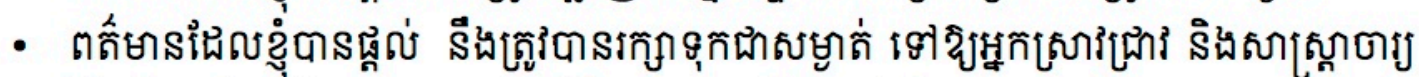

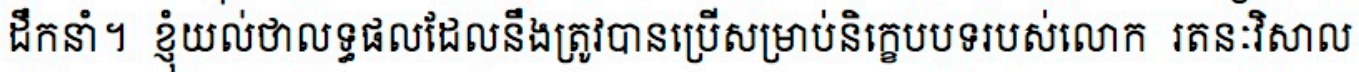

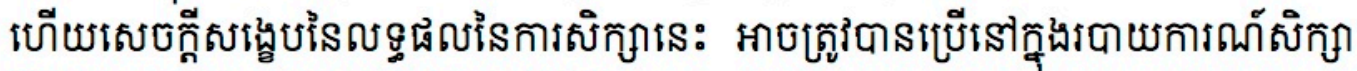

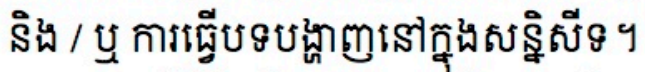

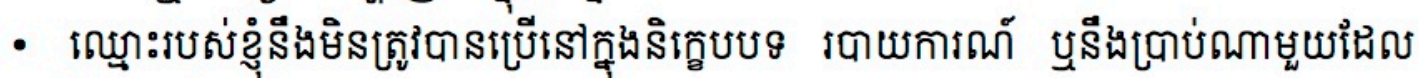

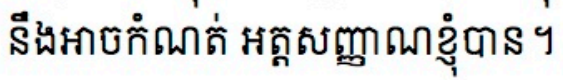




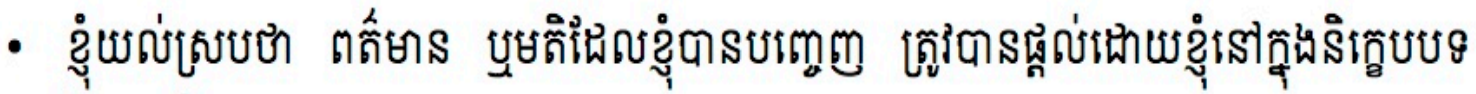
iลกิงปิกิกูก:

\author{
ต९/ติับ ใด
}

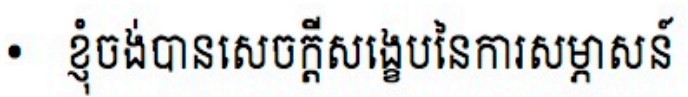

ตาร/ติง บ ใด

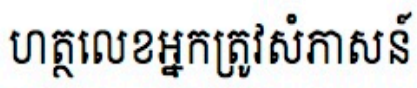

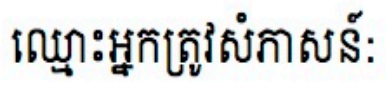

กถงบริบูุด:

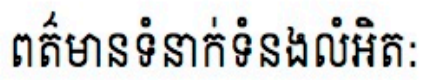


Appendix 6: Question guide for agricultural producers

Question guide for community

Date:

1. Name of respondent:

Gender:

Age:

2. Occupation:

Role in household:

3. What changes in weather pattern have you noticed in your area?

4. For how long have you noticed the changes?

5. Have you heard the change of weather from somewhere?

6. Do you know what cause such changes? Why? Or how do you hear about that?

7. What have been the impacts of climate change on your family lives and livelihood?

8. Do the climate change risks concern you?

9. Which of the risks of climate change you described concerns you the most?

10. Why do you consider that risk as the most concern?

11. Do you think dealing with climate change important, comparing to other problems such as poverty, corruption and robbery for example? Why?

12. What have you done in responding to the risks?

13. What support have you received from the government in mitigation impacts?

14. To what extent have these response strategies mitigate the impacts?

15. What do you think are the changes in the future?

16. Do you think what you will need to do to prepare for the impacts in the future? Why?

17. Do you think dealing with climate change should be priority for your community comparing to other problems such as robbery, poor education system, shortages of electricity? 
Appendix 7: Question guide for local government and community leaders

Question guide for government officers

Date:

1. Name of respondent:

Gender: Age:

2. Occupation:

3. What are climate change risks that have occurred in this region?

4. How long have these risks occurred?

5. How aware of this community about these risks?

6. What have been the impacts of these risks on the community?

7. How did the community respond to these events?

8. What have been the support of government?

9. Does government consider solution to climate change important, comparing to other problems such as poverty, corruption and robbery for example? Why?

10.Does the government have any programme to improve community resilient in the future?

11. Do you think government should give priority to solution of climate change comparing to other problems such as robbery, poor education system, shortages of electricity? 